Right to the City - Right Through the City:

Preemptive strategies to preserve urban public space

By

Shannon A. Martin

A thesis submitted to the Faculty of Graduate and Postdoctoral Affairs in partial fulfillment of the requirements for the degree of

Master of Architecture Professional

Carleton University

Ottawa, Ontario

Copyright @2013 Shannon A. Martin 
Library and Archives

Canada

Published Heritage

Branch

395 Wellington Street

Ottawa ON K1A ON4

Canada
Bibliothèque et

Archives Canada

Direction du

Patrimoine de l'édition

395 , rue Wellington

Ottawa ON K1A ON4

Canada
Your file Votre référence

ISBN: 978-0-494-94327-4

Our file Notre référence

ISBN: $978-0-494-94327-4$
NOTICE:

The author has granted a nonexclusive license allowing Library and Archives Canada to reproduce, publish, archive, preserve, conserve, communicate to the public by telecommunication or on the Internet, loan, distrbute and sell theses worldwide, for commercial or noncommercial purposes, in microform, paper, electronic and/or any other formats.

The author retains copyright ownership and moral rights in this thesis. Neither the thesis nor substantial extracts from it may be printed or otherwise reproduced without the author's permission.
AVIS:

L'auteur a accordé une licence non exclusive permettant à la Bibliothèque et Archives Canada de reproduire, publier, archiver, sauvegarder, conserver, transmettre au public par télécommunication ou par l'Internet, prêter, distribuer et vendre des thèses partout dans le monde, à des fins commerciales ou autres, sur support microforme, papier, électronique et/ou autres formats.

L'auteur conserve la propriété du droit d'auteur et des droits moraux qui protege cette thèse. $\mathrm{Ni}$ la thèse ni des extraits substantiels de celle-ci ne doivent être imprimés ou autrement reproduits sans son autorisation.
In compliance with the Canadian Privacy Act some supporting forms may have been removed from this thesis.

While these forms may be included in the document page count, their removal does not represent any loss of content from the thesis.
Conformément à la loi canadienne sur la protection de la vie privée, quelques formulaires secondaires ont été enlevés de cette thèse.

Bien que ces formulaires aient inclus dans la pagination, il n'y aura aucun contenu manquant. 


\section{Right to the City - Right Through the City preemptive strategies to preserve urban public space}

by

Shannon A. Martin

A thesis submitted to the Faculty of Graduate and Postdoctoral Affairs in partial fulfillment of the requirements for the degree of

\section{Master of Architecture Professional}

Carleton University

Ottawa, Ontario

Copyright

O2013 Shannon A. Martin 


\section{ABSTRACT}

This thesis is an exploration of strategies for the inclusion and protection of the pedestrian realm in urban areas where the survival of such spaces are threatened by future development. Examples of such have been incorporated in some way into most cities for various reasons and with varying results; examples range from the arcades of Paris to indoor and outdoor public plazas in New York City. These spaces are often created for the public as an antidote to excessive urban density. The problem, however, is that the more built-out the urban fabric the more difficult it is to accommodate these spaces. In response I have developed strategies for implementing an urban pedestrian network in advance of development, using the ByWard Market in Ottawa, Canada as a case study. 
ACKNOWLEDGEMENTS

Thank you to my parents, who made this possible and to all those that helped along the way. Thanks to Prof. Benjamin Gianni, for your help with this endeavour. 


\section{CONTENTS}

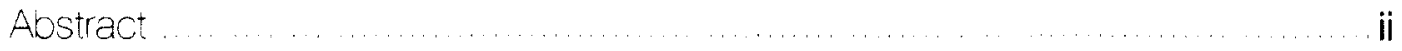

Acknowledgements ............................................................. ii

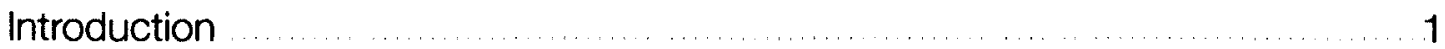

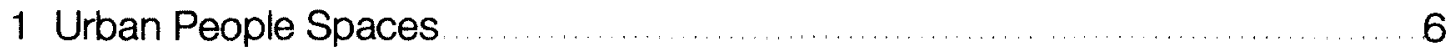

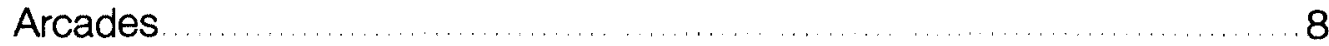

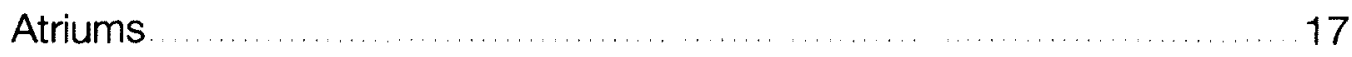

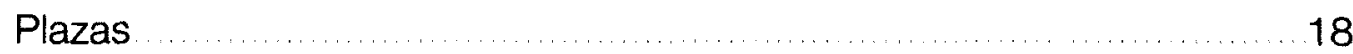

Pedestrian Streets . ........................................................ 19

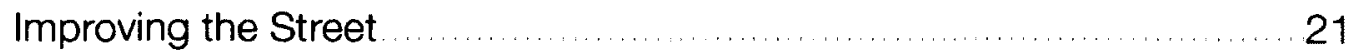

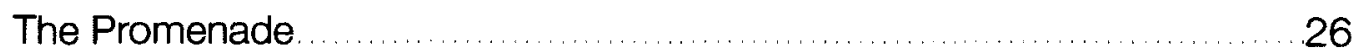

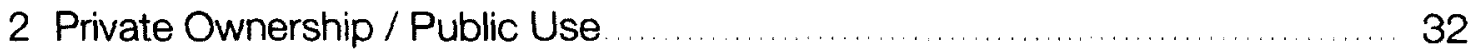

3 Opportunity: vacancy, intemalization and successful spaces ...................... 37

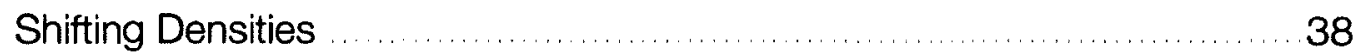

William Whyte and Public Space ........................................ 46

4 Mechanisms for the implementation of publicly accessible space ...................5.50

5 Through the Block: the proposal for a pedestrian network in the ByWard Narket...56 an introduction to the ByWard Market ...................................60 60 the Pedestrian Network ....................................................... 71

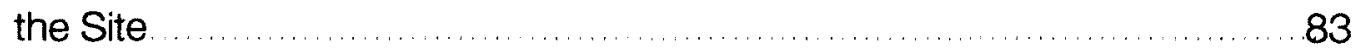

the Process of Implementation ........................................ 90

the Guidelines .............................................................. 102

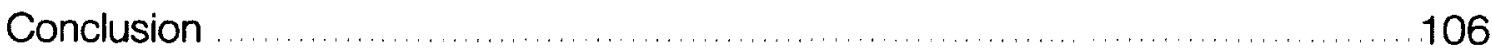

Appendix A Byward Market Analysis Maps ........................................ 108

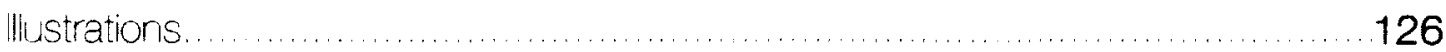

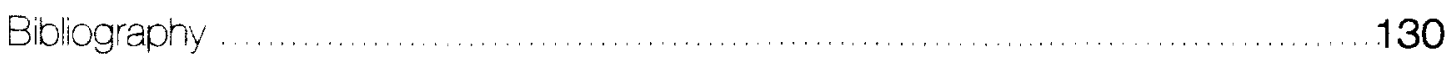




\section{INTRODUCTION}

In response to anti-sprawl sentiment and to changes in housing preferences, North American cities are setting aggressive new intensification targets for established urban neighborhoods. Emerging development standards like LEED-ND call for densities of upwards of 60 units per acre. Achieving this means replacing low-scale and relatively lowdensity residential fabric with mid- to high-rise apartment and condominium buildings. To be sustainable, however, such densification must be accompanied by an expansion of the volume and quality of "people-space." Increases in the number and height of buildings coupled with decreases in the size of dwelling units can result in per-capita shortages of space for those who live and work in the area. Accordingly, the provision of public space is a key component of any program of intensification. This can be achieved through the creation of spaces such as parks, widened sidewalks, and public squares, to name a few, but can also be realized through the provision of publicly accessible private spaces, such as arcades, atriums, plazas, etc. While the design of public spaces and publicly accessible private spaces can share similar principles the mechanisms for implementation are quite different. This thesis explores the relationship between density and public space. In so doing it also blurs the boundaries between public and private space by examining the typologies, principles, implementation mechanisms and methods for producing publicly accessible private spaces. 
Throughout time, cities with physical or geographic constraints grappled with the increases in density that accompanied population growth. Prior to the advent of street rail in the $19^{\text {th }}$ century, more people meant less space per inhabitant, forcing cities to adapt in innovative ways. With the exception of places like Manhattan, however, these challenges are new to North American cities, where population increases were largely accompanied by an expansion of the suburban periphery. As a result, most North American cities are neither familiar with designing for density nor conversant with the categories and qualities of public space necessary to accommodate the density targets that many are now setting. While Modernism attempted to address the potentially inverse relationship between urban density and public space by advocating tall, widely spaced towers, commentators like Jane Jacobs have astutely observed that it is the quality, more than the quantity of publicly accessible space that matters where successful urban environments are concerned.

After examining the provision of "people space" in cities like Bologna, Paris and New York, the study turns to the rapidly intensifying ByWard Market neighbourhood in Ottawa. The Market is used to explore a method for identifying and establishing an expanded network of publicly accessible spaces in advance of development. Drawing on the abundance of vacant lots and capacity for intensification in the Market area, I propose a phased system of incorporating publicly accessible space into the neighborhood. Pathways across privately owned land would need to be designated as publicly accessible through a program of incentives 
and arrangements between the City and private owners. Preemptively designating such spaces for pubic use provides a way to solidify their existence in the urban landscape for the unforeseen future.

The evolution of public space - in particular, privately owned public space - in cities around the world has taken a variety of forms, met with varying levels of success and has involved a number of methods. The thesis both applies lessons from the past and builds on the existing pedestrian routes in the ByWard Market to propose an expanded network of public space.

\section{On Methodology}

I have undertaken a literature review and analyzed several precedents to understand what has been done in the past to address the need for public space in dense urban areas. Looking at both physical and, to a lesser extent, social causes and effects, I found that where physical or geographic restraints limit the availability of truly public land in urban areas, private land has often been utilized for public use. I chose to focus my research on these types interventions and identify elements that might apply to the design and implementation of a network of pedestrian spaces. Focusing my research helped to clarify which elements to include in my proposal for the ByWard market, understanding that not all aspects of these precedents would be directly applicable. A limitation of this strategy might be that, having made the decision not to look at certain kinds of public space (parks, public squares, sidewalks, etc.) I may have inadvertently neglected to identify 
further strategies. The emphasis on mid-block passages, for example, may have been made to the detriment of side walks - which are crucial to the pedestrian movement through the area under investigation (the ByWard Market).

The ByWard market site analysis was done through mapping and making observations from visiting the site.

\section{Structure of the Thesis}

The first chapter identifies several types of urban public space, describing how and where they have been used. The four main forms - arcade, atrium, plaza and pedestrian street - often occur on private property despite being intended for public use. The second chapter discusses public spaces, private spaces and the overlap of the two as a means of supplementing public space in cities.

Chapter 3 describes transformations to urban centres in the $20^{\text {th }}$ century - over the course of which alterations in the scale, density and number of buildings (not to mention the advent of new modes of transportation) changed the way people moved through the city. Ideas on the design of urban spaces is also discussed in this chapter.

Mechanisms for the use of private space for public uses, and how that was dealt with in New York, is discussed in Chapter 4. Zoning incentives have been employed extensively in New York City, where both buildable area and public space are at a premium.

Drawing on these new patterns of movement due to changes in the urban fabric, the final portion of the thesis explores the development of a pedestrian network for Ottawa's 
ByWard Market. The investigation builds on established pedestrian routes to propose a series of paths, spaces and strategies in concert with ongoing residential intensification in the area. Honing in on a specific block, the thesis proposes a phased system of implementation, supplemented with a set of guidelines for the design and operation of the associated spaces. While site specific, the conclusions and recommendations that emerge are intended to be applicable to other neighborhoods and cities that are in a similar situation to the ByWard Market. 


\section{URBAN PEOPLE SPACES}

The desire to meander through the city in public space is ancient. ${ }^{1}$

-Ken Greenburg

Urban public space, privately or publicly owned, has manifested itself in numerous forms throughout history. Although the most inherent examples are streets and sidewalks, such spaces include plazas, arcades, mid-block passageways, atrium lobbies and parks. These spaces are an integral part of the urban experience. Many of these typologies have evolved over time and are clearly discernible today, whether in their original form or a modern interpretation. The following is an investigation of four prominent types of urban Waterloo: Wilfrid Laurier University Press, 2009) 39. 
public space, each of which can be applied to the creation of networks of pedestrian space for growing cities.

As an introduction to these types of spaces, I have looked at four kinds of urban pedestrian space in particular - arcades, artiums, plazas and pedestrian streets- and explored examples of where these forms have been used and how they have come to be. Additionally, I have identified several interventions to street-space that seek to improve the urban pedestrian experience and the concept of the "urban promenade". 
ARCADES - early interventions for public space

Arcades have appeared, evolved and adapted in cities around the world. By definition an arcade is a covered passageway with arches along one or both sides. It is common for arcades to incorporate stores along one or both sides of the walkway. ${ }^{2}$ The arcades of Paris, or the passages couverts, are among the most notable arcades in history. The distinct typology that developed in Paris was copied and adapted in many other cities. The evolution of the form of the arcade was simultaneously urban, architectural and social.

I his book, Arcades, the History of a Building Type, Johann Geist identifies seven major characteristics of arcade:

1. Access to the interior of a block

2. Public space on private property

3. A symmetrical street space

4. A skylight

5. A system of access

6. A form of organizing retail trade

7. A space of transition

In $19^{\text {th }}$-century Paris the concepts of previous eras and other cultures combined with new social situations and technological advancements to create the "Arcade" as a distinct building type. Among the issues at play was a rapid densification of the city's tangled medieval fabric.

Unlike their Roman primogenitors, medieval cities frequently developed narrow and winding streets organized in

2 New Oxford American Dictionary. 3rd edition. (Oxford University Press, 2010) 
organic 'spine and branch' or 'spoke and hub' configurations.

As these cities expanded, there was an increased demand for circulation between various points in the city without having to pass through the centre. In addition to boulevards, which frequently appeared along the footprint of earlier walls, through-block shortcuts were being created. The need for more efficient circulation through the tangle of medieval urban fabric increased as urban growth accelerated in the first half of the $19^{\text {th }}$ century. As was the case in Paris, through-block passages became an increasingly popular and important means of moving through the city in safer, cleaner, more dignified ways.

Historians contend that the arcades of Paris began with the Palais Royal. The clash between the aristocracy and the people that led to the French Revolution in 1789 was the catalyst for the creation of various outlets of public opinion. Numerous clubs, secret societies, and cafes appeared in and around the Palais Royal, which opened to the public around the time of the Revolution. ${ }^{3}$ The scene at the Palais Royal was the origin of the arcade as a public

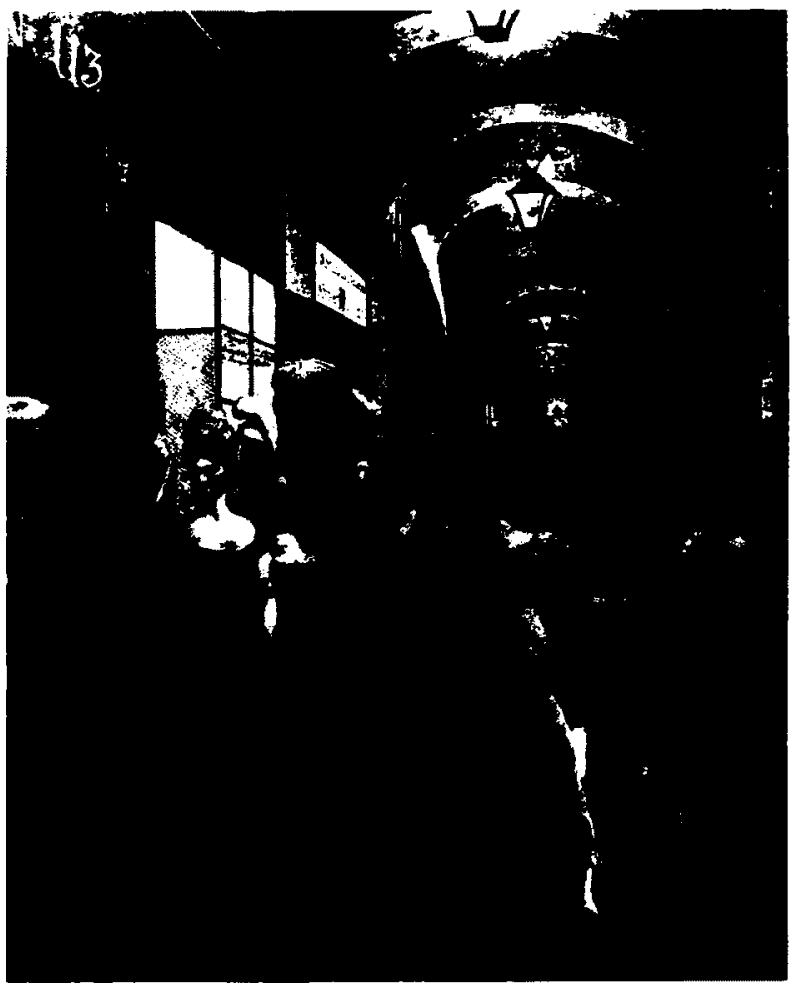

Figure 1.1 - La Sortie du Numero 113, A watercolour of the galleries in the Palais Royal, 1850

3 Geist, Johann Friedrich. Arcades, the History of a Building Type. (Cambridge, Mass: MIT Press, 1983) 59. 


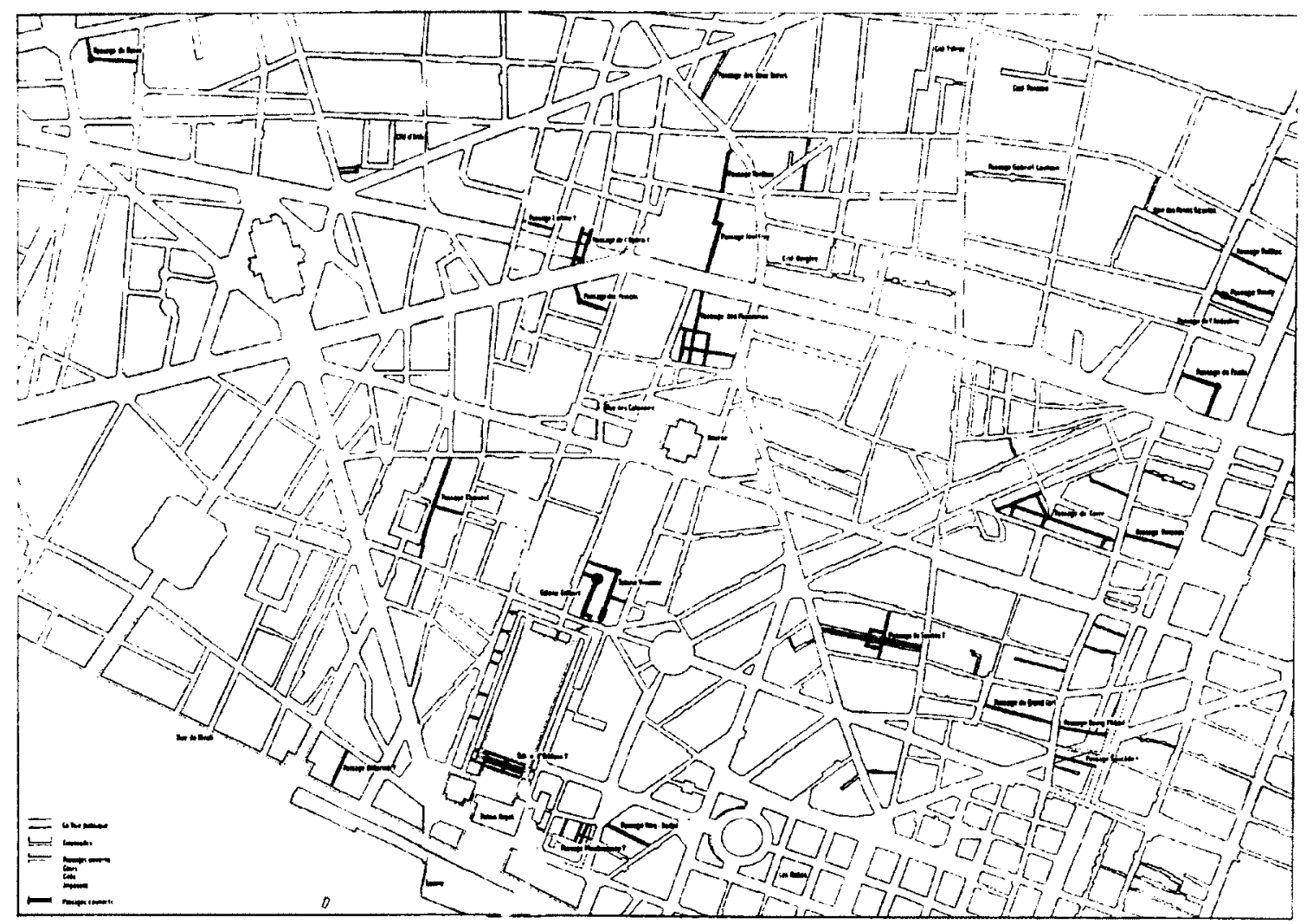

Figure 1.2 - Paris street map of the Right Bank showing arcade locations 


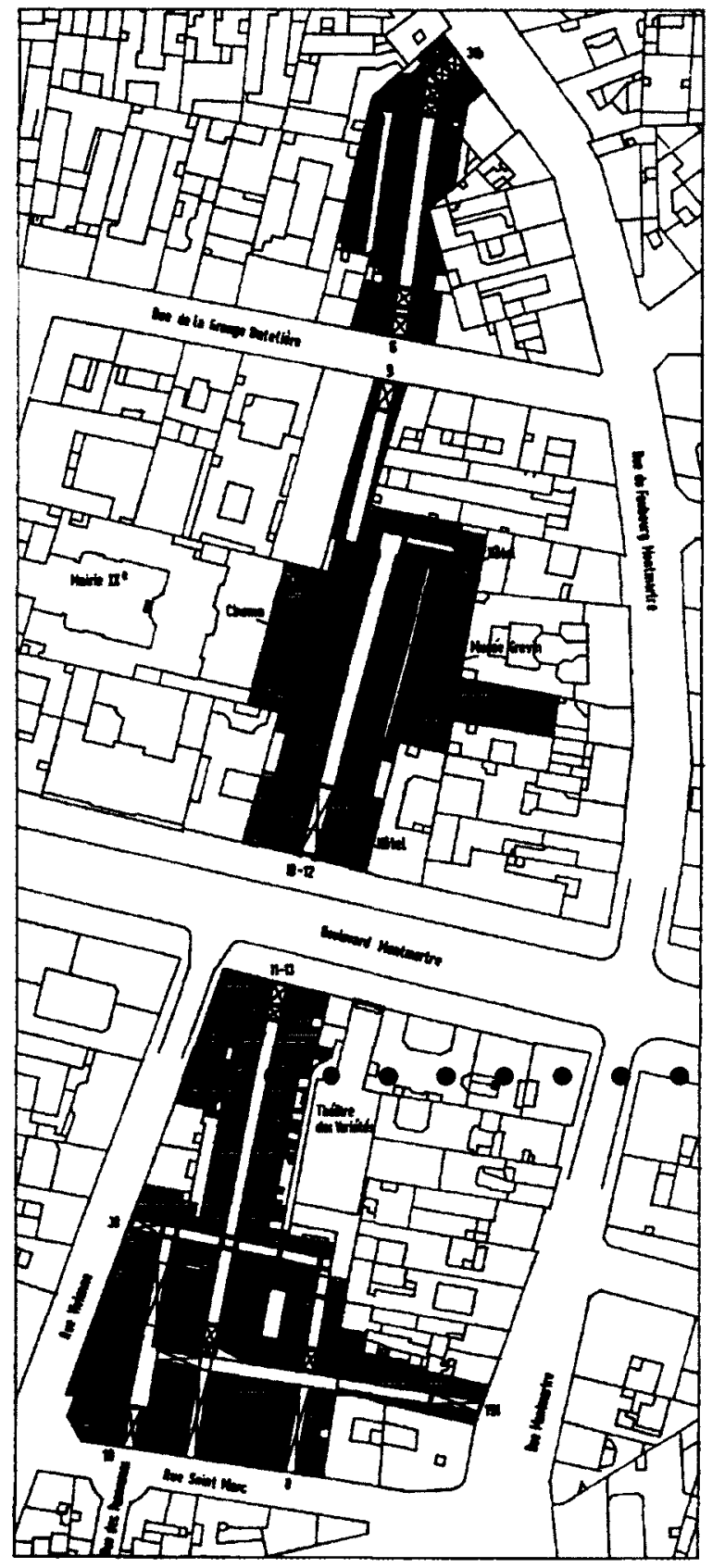

Figure 1.3 - Map of Passage des Panoramas, Passage Jouffroy, and Passage Verdeau, 1950

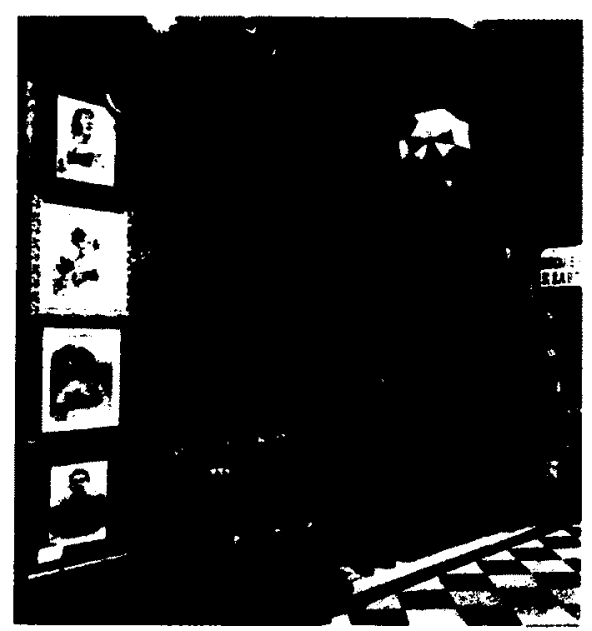

Figure 1.4 - Gallerie Véro-Dorat

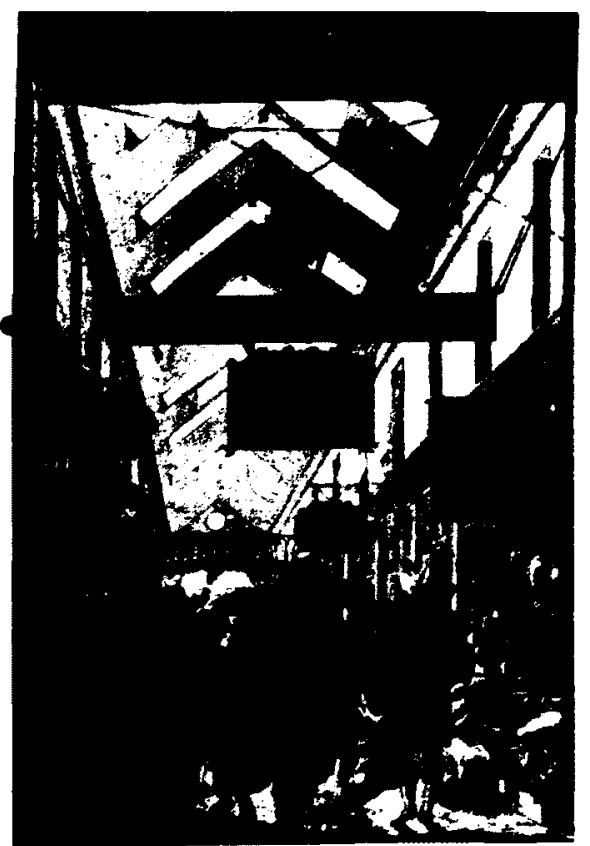

Figure 1.5 - Watercolour of Passage des Panoramas, 1810 
gathering place removed from the street. The Duc d'Orleans lined the large courtyard of the Palais Royal with arcades which were lit from above. ${ }^{4}$ The stores and cafes along these arcades attracted a wide variety of people from all social classes. These arcades paved the way for a new category of urban denizen - the flâneur, who was a wanderer and observer. $^{5}$

The arcades of the Palais Royal show the political influence of the Revolution on the urban form. Social and economic influences are also reflected in the need for undisturbed public space, the developing luxury industry (and the Bourgeoisie), real estate expropriation, the move of real estate into the private sector (the public were able to buy large areas of land), and the lack of sidewalks within the city. The streets of Paris at the beginning of the $19^{\text {th }}$ century were increasingly busy, dirty and dangerous for the emerging middle class because of the lack of designated pedestrian space. These four factors directly influenced the emergence of the arcades. The arcades at the Palais Royal appeared several decades before Napoleon first attempted to create uniform sidewalks along the Rue de Rivoli. They were among the first public places that were accessible exclusively to pedestrians (others being the Pont Neuf and the Tuileries Gardens). ${ }^{6}$

Arcades appeared in other cities during the same

\begin{tabular}{ll}
\hline 4 & Geist 60. \\
5 & Geist 62. \\
6 & Geist $62-64$
\end{tabular}


era and for similar reasons. When it opened in 1819 , London's Burlington Arcade created a covered passage between Piccadilly and Burlington Gardens, very similar in form to the arcades found in Paris. This arcade is 180 metres long and was designed with 21 double shops and 30 single shops lining the walkway. ${ }^{7}$ Another notable arcade is the Galleria Vittorio Emanuele II in Milan, which opened in 1867. This arcade was constructed to connect the Piazza del Duomo, a large area around the main cathedral of Milan, with the Piazza della Scala. The city had long wanted to create a connection from the churches, S. Margherita and S. Fedele, to the Duomo. ${ }^{8}$ The walkways of Galleria form a cross with a central rotunda. "It made the arcade into a central place of public activity independent of the cathedral square and granted it structural autonomy."

By the end of the $19^{\text {th }}$ century the arcades (in what was the current iteration) were becoming a thing of the past for several reasons. Contributing factors in Paris were the prohibition of exposed iron in interior spaces ${ }^{10}$ and the plethora of wide boulevards that were cut through the medieval fabric of central

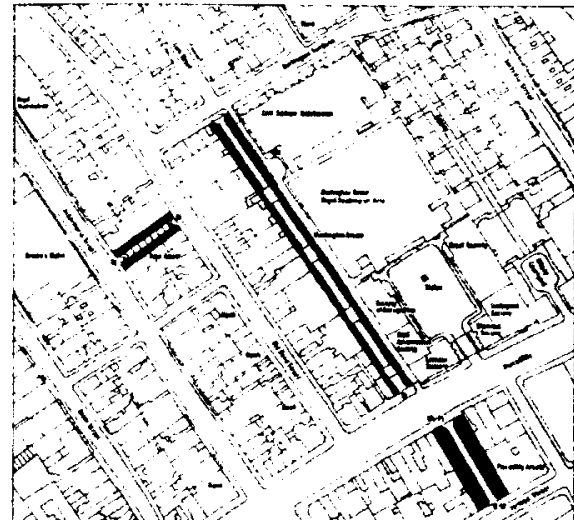
Figure 1.6-Map of the Burlington Arcade, London, 1966

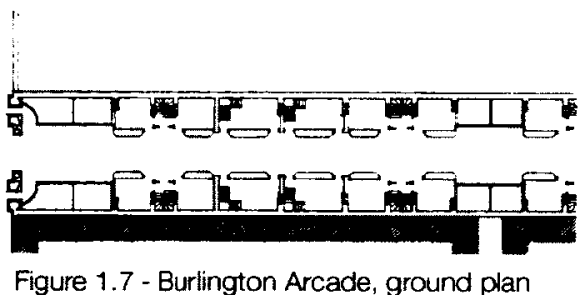
detail
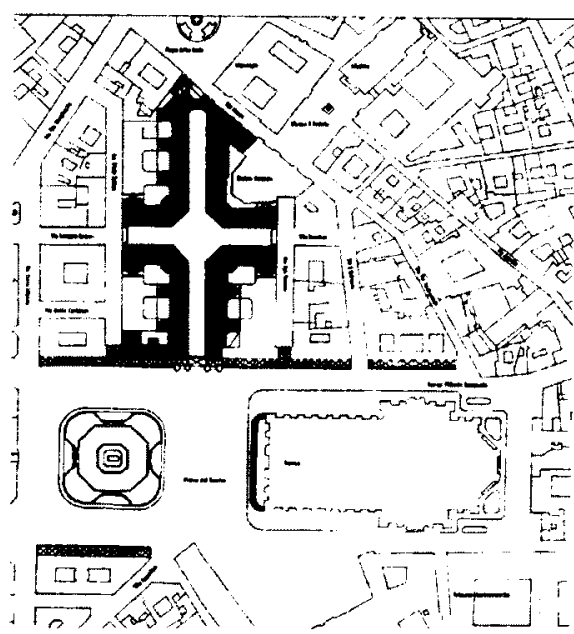
Figure 1.8 - Galleria Vittorio Emanuelle II and Piazza del Duomo, Milan, 1900

\begin{tabular}{ll}
\hline 7 & Geist 324-326. \\
8 & Geist 371. \\
9 & Geist 384. \\
10 & Geist 58.
\end{tabular}


Paris during the Second Empire. The architectural form did not completely die out but it transformed into the grands magasins, such as the Galleries Lafayette and Bon Marché in Paris. These are the direct forerunners to the shopping malls that appeared in North America in the late $20^{\text {th }}$ century.

Although the aforementioned arcades are all two sided, with shops on either side of a central passage, arcades with one open side are also quite common throughout history. The Italian city of Bologna is famous for this type of arcade, or portico as it is referred to there.

Like many Medieval cities Bologna's ability to grow was constrained by the fortifications that surrounded it. Accordingly, the upper floors of buildings were extended out over the street space, forming covered porticoes at grade. There are currently about 38 kilometres of porticoes lining the streets of Bologna. ${ }^{11}$ Having first appeared in the $11^{\text {th }}$ century, these passageways provide a unique zone straddling the public and private realms, which has been inhabited in a variety of ways: as a workspace, for the display of merchandise, and as covered walkways.

Bologna's first porticoes appeared during the Middle Ages. Population growth in medieval Bologna was accelerated by the founding of a university in the $10^{\text {th }}$ century - one of the earliest institutions of its kind. Students flooded to the city from across Europe creating a demand for additional housing. ${ }^{12}$
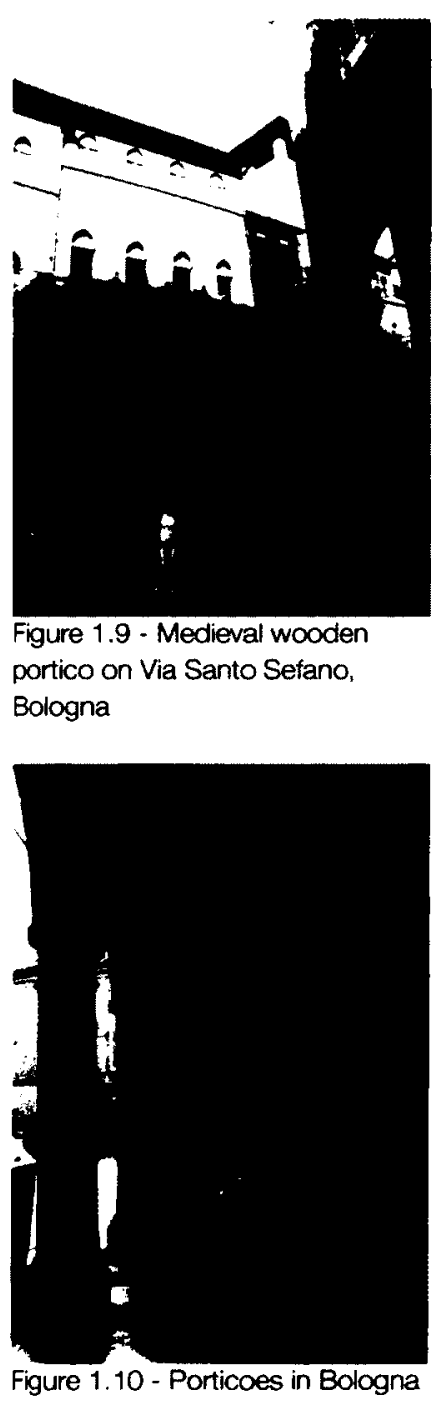

11 "The Porticoes of Bologna". World Heritage Convention. UNESCO. 1 June 2006. 20 Nov 2011. <http://whc.unesco.org/en/tentativelists/5010/>

12 "The Porticoes of Bologna". 
The arcades that resulted were embraced by the city; shop keepers and workshops were able to utilize the covered space under the porticoes adjacent to their storefronts, while the extended façades of the upper floors increased the interior volume of residences. The covered porticoes also protected pedestrians both from the elements and the dirty and crowded streets.

While similar structures were banned in other cities (for their encroachment on public space), porticoes continued to be built in Bologna on private land. In 1288 a law was passed requiring, wherever practical, porticoes to be built on private land and maintained for public use. This law is still in effect. ${ }^{13}$

The significant number of porticoes in Bologna vary in size, colour, style and function. The city's most unusual set of porticoes is probably the series of 666 arches that protect the path out of the city to the Sanctuary of the Madonna di San Luca. The covered path was built in 1674 and most of these porticoes, after separating from Via Saragozza, are enclosed by a wall on one side and are open to the landscape on the other.

Although sidewalks - designated pedestrian space - were common in Roman cities, the concept had largely been lost by the Middle Ages. ${ }^{14}$ Sidewalks, however, were reinterpreted in cities, like Bologna, as porticoes or arcades. The words "portico" and "arcade" both imply a space to be 13 "The Porticoes of Bologna".

14 Loukaitou-Sideris, Anastasia, and Irena Ehrenfeucht. Sidewalks : Conflict and Negotiation Over Public Space. (Cambridge, Mass: MIT Press, 2009) 15. 
moved through ${ }^{15}$ - whether as an entrance way or a passage.

Bologna's porticoes shape a unique space of interaction in the city.

Today many urban buildings in cities around the world incorporate arcades both through blocks and along streets. These are commonly seen in high density downtown areas and through-block passages are often designed in conjunction with atrium spaces in office buildings. This often allows for better pedestrian circulation and supports a mixture of uses at ground level.

15 New Oxford American Dictionary. 3rd edition. (Oxford University Press, 2010) 


\section{ATRIUMS}

High rises became increasingly common in cities over the course of the $20^{\text {th }}$ century. Many high rises have incorporated atriums into their design. An atrium is a central space or court, open through several stories and typically roofed with glass - like a covered courtyard. As mentioned, atriums are often incorporated as a way of introducing a mixture of uses at the ground level and of accommodating connectivity through and within the building. The mix of uses they support serve the building tenants as well as others in the area. They include restaurants, convenience stores, small shops and services. Atriums also act as meeting places, connected to passages through the building. Although the building owners sacrifice some space for public use, atriums can bring in more revenue from those public amenities. Downtown buildings with atriums are popular across North American urban centres. Due to the spatial constraints of Manhattan both public and private space is at a premium, making atriums an attractive option for developers looking to capitalize on the city's zoning incentives.

Figure 1.12 - The atrium designed by

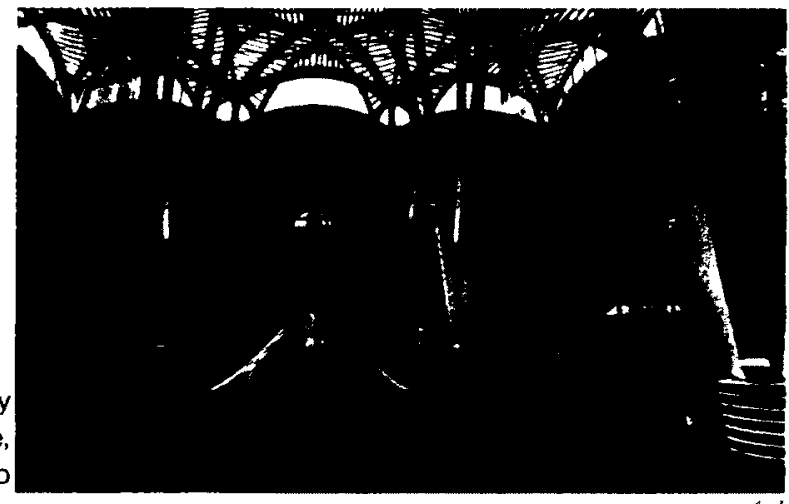




\section{PLAZAS}

Plazas are another common type of urban public space. As open spaces in a built up area, they are often used as public squares and may have buildings against one or two sides (such as a corner location) and sometimes three sides. Like Atriums, plazas are encouraged to offset density by programs such as New York City's zoning incentive. They often include at least one type of seating and may include features like sculptures, fountains and planters. The large plaza in front of the Seagram Building, built in 1958, had a significant impact on the city. Its popularity as a place for people to sit encouraged the building of other, similar plazas within the city. Plazas that are located at the base of office towers allow people to enjoy the street without being directly on it.

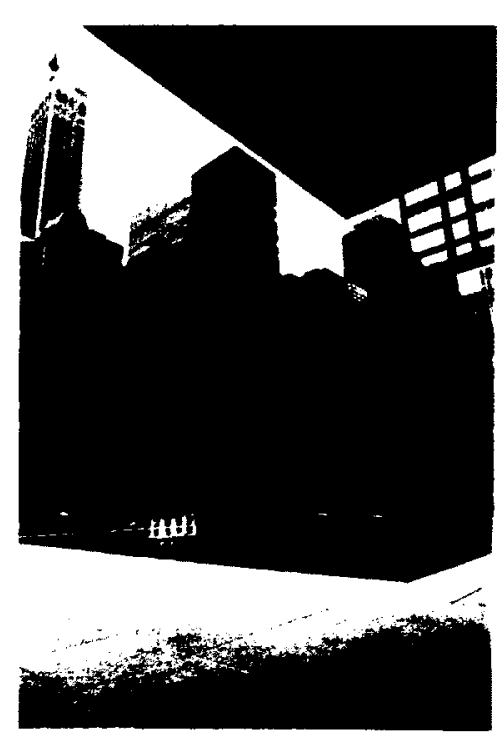

Figure 1.13 Seagram Plaza, New York

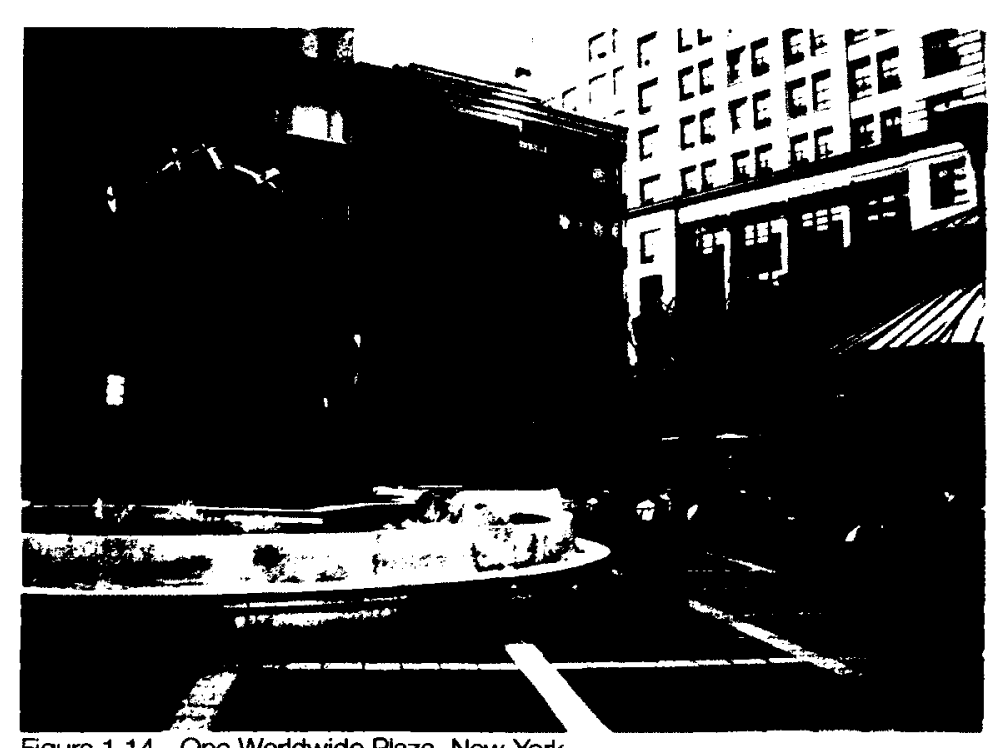

Figure 1.14 - One Worldwide Plaza, New York 


\section{PEDESTRIAN STREETS}

Whether a former street that has been closed to automotive traffic or one specifically designed for people, pedestrian streets are often used to encourage the public to walk through urban areas and discourage the use of vehicles. Pedestrian streets are either entirely closed to automotive traffic or open only to service vehicles. As with other pedestrian spaces, these streets are frequently lined with shops, restaurants and cultural attractions for people to enjoy.

In Copenhagen, a large stretch of street was converted to a pedestrian mall in 1962 . The area, known as Strøget, is located in the old part of the city where the narrow medieval streets were ill-suited to the increase in the number of cars and pedestrians that the expanding shopping district was attracting. The city decided to close a large section of the street to automobiles, specifically a key stretch between two main squares (along with a few branching streets). Stroget is

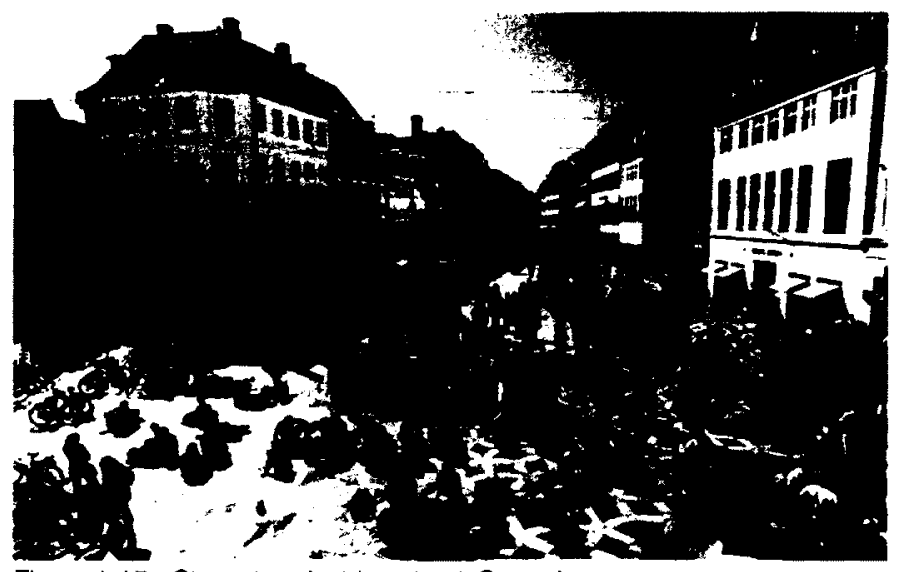

Figure 1.15 - Strøget pedestrian street, Copenhagen

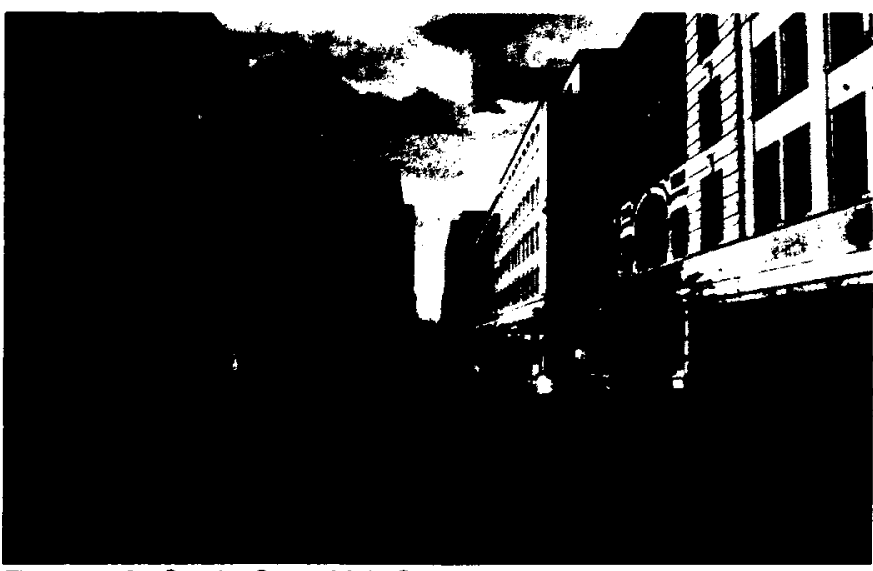

Figure 1.16 - Sparks Street Mall, Ottawa 
adjacent to several popular attractions and the street is lined with restaurants, shops, galleries and entertainment venues, enabling it to maintain its vitality throughout the day and into the evening. The total length of the pedestrian portion is about 3.2 kilometres, making it the longest pedestrian street in the world. ${ }^{16}$

Ottawa's Sparks Street Mall has not been as successful as Stroget. It currently lacks the variety of uses needed to attract sufficient numbers of people, especially after 5:00 pm. There is also a noticeable lack of activity during Ottawa's winter months when the slushy walkway is largely abandoned. While Sparks Street does not offer protection from rain, snow or cold winds, some other pedestrian streets, like those of Clarke Quay in Singapore, address the issue of harsh climate by providing protective canopies and a controlled microclimate, ${ }^{17}$ not unlike the appeal of the Parisian arcades. The canopies enable shoppers and restaurant patrons to stay cool during hot humid summers and dry in the rainy season.

16 "The Wortd's longest Pedestrian Street - Stroget". Copenhagen-Portal. Web. 3 Feb. 2012 <http://www.copenhagenet.dk/cph-map/CPH-Pedestrian.asp>

17 Alsop, William. "Clarke Quay Redevelopment." Europaconcorsi. 13 Oct. 2006. Web. 27 Dec 2012. <http://europaconcorsi.com/projects/16777-Clarke-Quay-Redevelopment> 


\section{IMPROVING THE STREET}

While this thesis focuses on spaces that are connected to - but separate from - the street, there have been numerous interventions (both sanctioned and unsanctioned) to improve public spaces along streets in recent years. Many of the ideas are also applicable to off-street pedestrian spaces. The New York City Department of Transportation (DOT) has undertaken a number of high-profile projects, while acts of "guerilla urbanism" have also improved the public realm, often using parking spaces to create temporary parkettes.

Amongst the recent changes to Broadway in New York City are the Green Light for Midtown and reNEWable Times Square projects, spearheaded by the New York City DOT. As a part of reNEWable Times Square, Broadway was closed to traffic between $42^{\text {nd }}$ and $47^{\text {th }}$ Streets, creating a large pedestrian plaza. Artist Molly Dilworth was commissioned to make a visual impact on the space. She transformed the pavement into a work of art entitled "Cool Water, Hot Island" by applying a durable surface treatment to the road depicting the original contours of the land. Green Light for Midtown redesigned large sections of Broadway between Columbus Circle and Madison Square to improve pedestrian space, create clearer, more defined bike lanes and improve traffic flow. ${ }^{18}$ As with Times Square, Broadway has also been closed

18 New York City Department of Transportation. The City of New York. 2012. Web. 10 Nov. 2011. <http://uww.nyc.gov/html/dot/htm/home/home.shtml > 


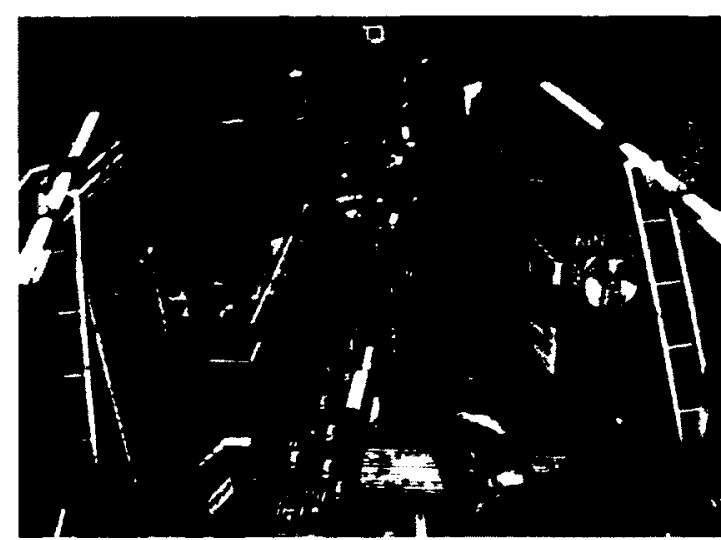

Figure 1.17 - Looking south across Times Square (reNewable Times Square)

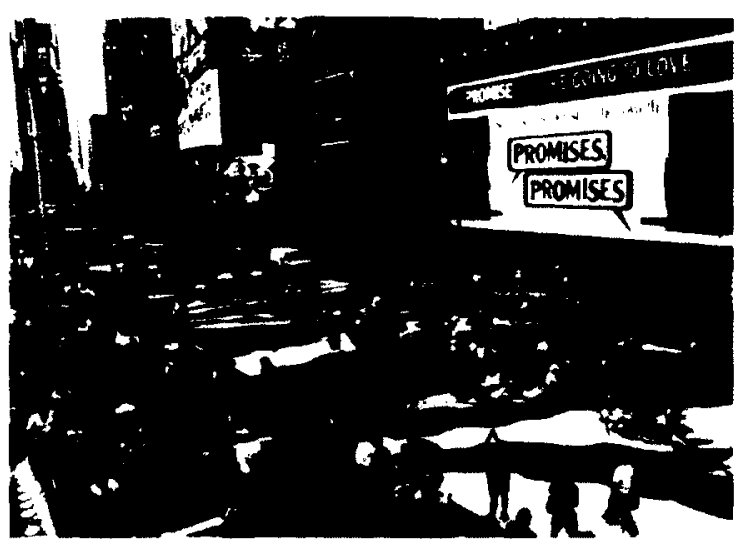

Figure 1.18 - The new public space on Broadway at Times Square

to vehicular traffic at Harold Square, between $33^{\text {rd }}$ and $35^{\text {th }}$

Streets. These two squares occur where Broadway intersects north-south avenues $\left(6^{\text {th }}\right.$ and $\left.7^{\text {th }}\right)$ at an acute angle, making the resulting intersections difficult to navigate for both cars and pedestrians. By closing these sections of Broadway to automobiles, traffic was streamlined. Streamlining these complex intersections improved north-south traffic flow, reducing commute times while making these crowded areas easier to navigate on foot. ${ }^{19}$ The streetscape along Broadway now includes public seating, planters, safer crosswalks, wider sidewalks and separated bike lanes. While initially conceived as temporary studies, it soon became clear that these projects greatly improved the street for all concerned. Due to the success, both have since become permanent. The New York City DOT has also been improving public spaces through several other programs, including upgrades to pedestrian plazas throughout the city and incorporating more public art into the urban environment.

$19 \quad$ Ibid. 


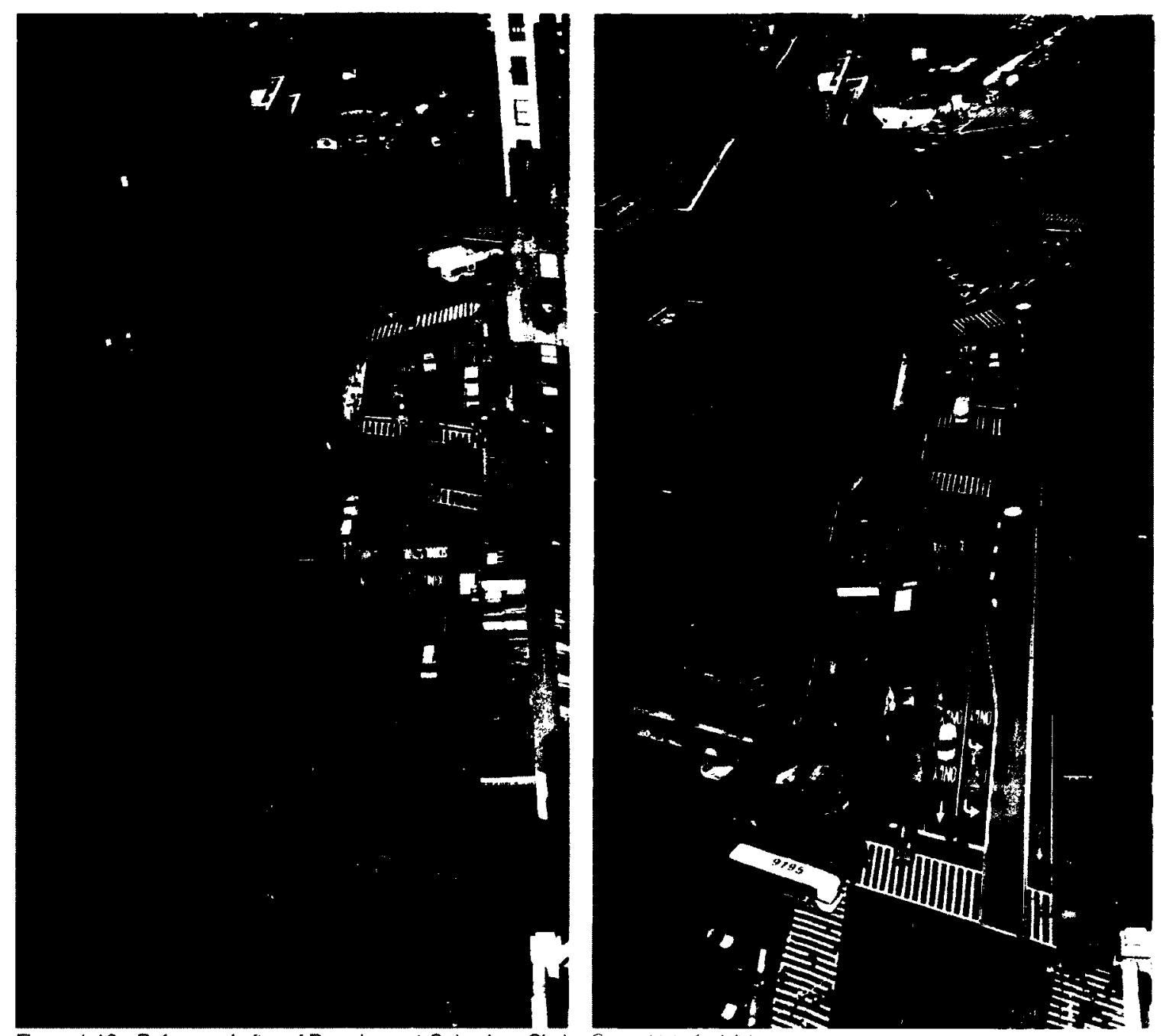

Figure 1.19 - Before and after of Broadway at Columbus Circle, Groen Light for Moftown:
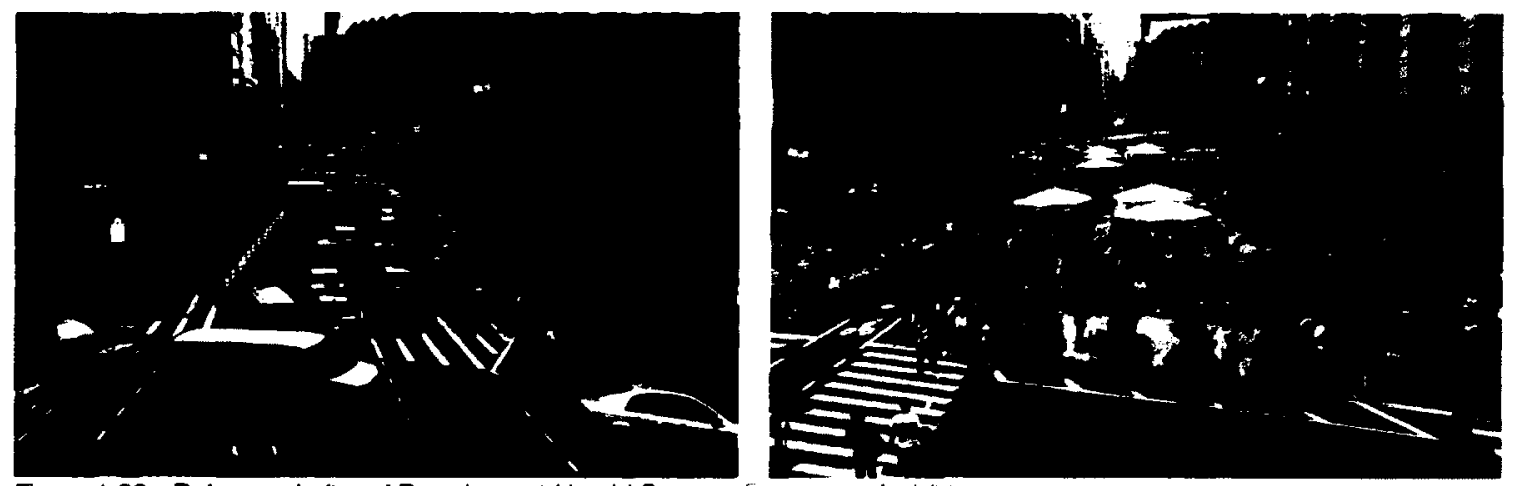

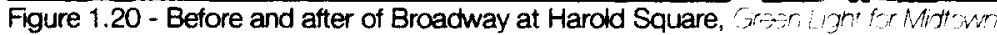


Increasingly, efforts to improve streets for pedestrians are being undertaken by individuals, organizations and private companies. PARK(ing) Day has become an annual event in over 100 cities around the world. Starting in San Francisco in 2005, a metered parking space was converted into a mini-park with sod, a tree and a bench by design studio, Rebar. They are now encouraging people to participate around the world and once a year meters are being fed to provide a temporary public park in just under 1000 parking spaces worldwide. ${ }^{20}$ Apart from PARK(ing) Day, many other projects utilize parking spaces to expand public spaces. Some, like the Andersonville Parklet in Chicago, are semipermanent installations. The Andersonville Parklet is comprised of two parking spaces which are converted into a parkette during the warmer months of the year.

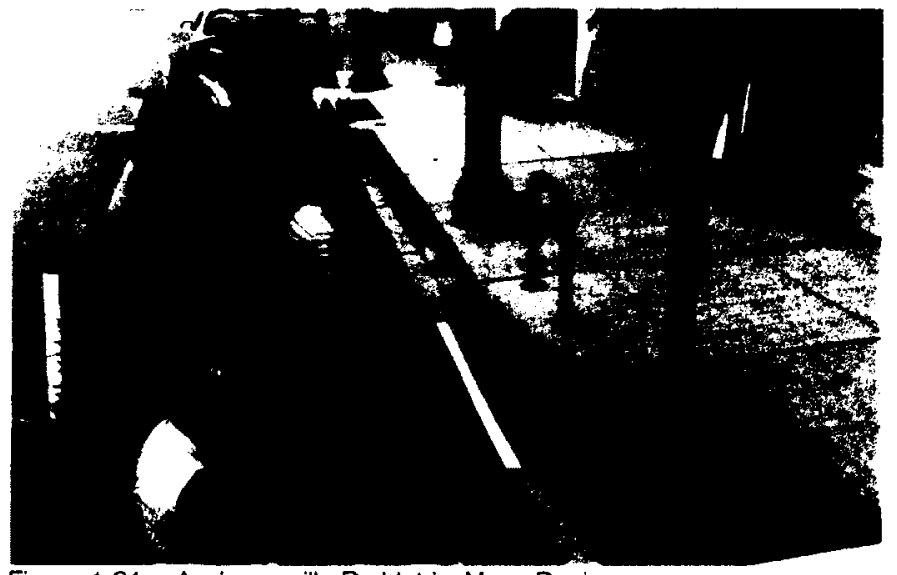

Figure 1.21 - Andersonville Parklet by Moss Design

The Centotrecento Project in Bologna also carves spaces for the community out of parking spaces to act as an extension of the porticoes. These piazzette are defined with a coloured ground covering and a few simple elements such as chairs and a table to which occupants can add. These spaces are meant to function as social gathering spaces for local residents.

The basic message of these projects is that our cities

20 parking day web 
are lacking quality public space for their inhabitants, while devoting a lot of space to cars. The lack of public space will only increase with urban density if not addressed in the design of urban areas. 


\section{THE PROMENADE}

In many ways, the idea of the promenade has been lost in contemporary society, or at lest the idea of promenading. In the $19^{\text {th }}$ century the promenade was an important part of life and the enjoyment of urban spaces in public. The world today is much more concerned with getting from Point- $A$ to Point- $\mathrm{B}$, using walking as a means of transportation, rather than as an opportunity for an experience. Promenading is about being in public, wandering, and experiencing a place. The most common places for people to walk in cities are of course sidewalks, which are generally not conducive to those who wish to slow down and take in their surroundings. One must move at a swift pace so that everyone else can get to where they are going.

Promenading in the $19^{\text {th }}$ century became a way of life for some and a weekly ritual for many. The phenomenon was especially popular with the bourgeoisie in Paris where the arcades were considered ideal places to see and be seen. A new persona emerged as a result of the arcades, the flâneur - a wanderer, an observer. The flâneur was typically a person of means, who inhabited and promenaded through the arcades, making it a way of life. The flâneur would often not only want to observe but also to be seen while observing and would be dressed up in their finest clothes

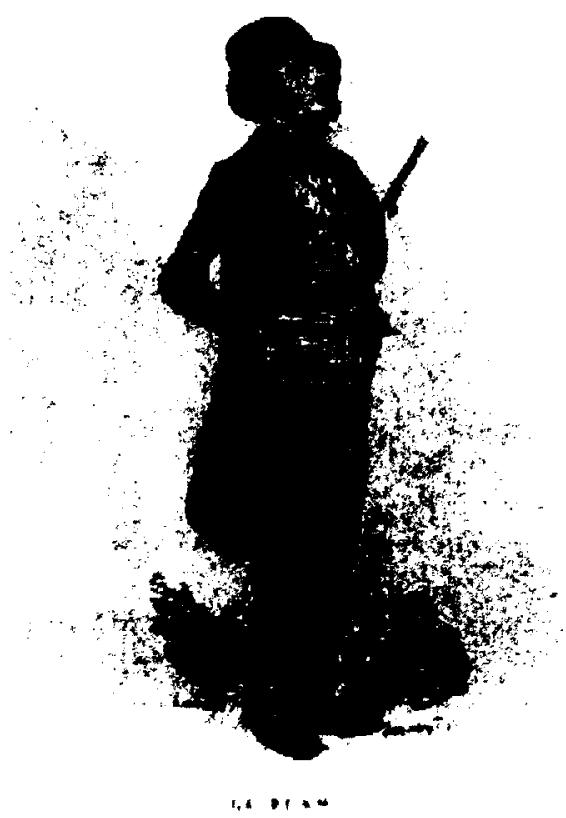

Figure 1.22 - Le Flaneur, by Paul Gavarni, 1842 
and accessories. "In 1839 it was considered elegant to take a tortoise out walking. This gives us an idea of the tempo of flânerie in the arcades." 21

In Paris, the theme of viewing the city as a phantasmagoria - like a series of images - became popular amongst flâneurs. The visual stimulation to which one was subjected while wandering the arcades translated to a dreamlike state of mind, in which the mind wandered with the body. Walter Benjamin writes of two aspects of the flâneur: that they let their imaginations drift, thinking of another place and being in another time, but also living in the moment and observing everything around them. The imagination of the flâneur was triggered by what one saw in the landscape (cityscape); he viewed the city and its inhabitants as a phantasmagoria against the dream-like spaces of the arcades.

The crowd is the veil through which the familiar city beckons to the flâneur as phantasmagoria - now a landscape, now a room. Both become elements of the department store, which make use of flânerie itself to sell goods. The department store is the last promenade for the flâneur. ${ }^{22}$

Prior to this, of course, flânerie moved onto the grand boulevards that appeared in the Second Empire.

Although more ritual and less phantasmagorical, residents of Aberdeen, Scotland also had a long-standing tradition of promenading along Union Street up until the 1970s. Opened at the beginning of the $19^{\text {th }}$ century, Union

$21 \quad$ Benjamin 422.

22 Benjamin 10. 


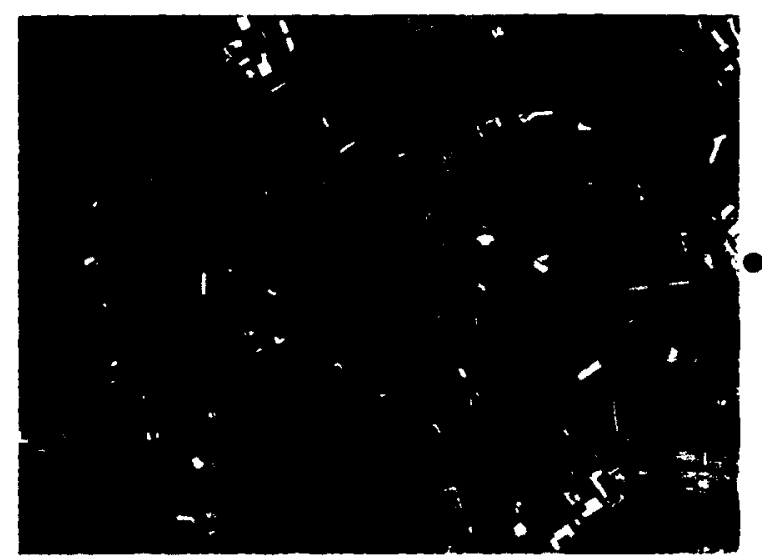

Figure 1.23 - Union Street, Aberdeen

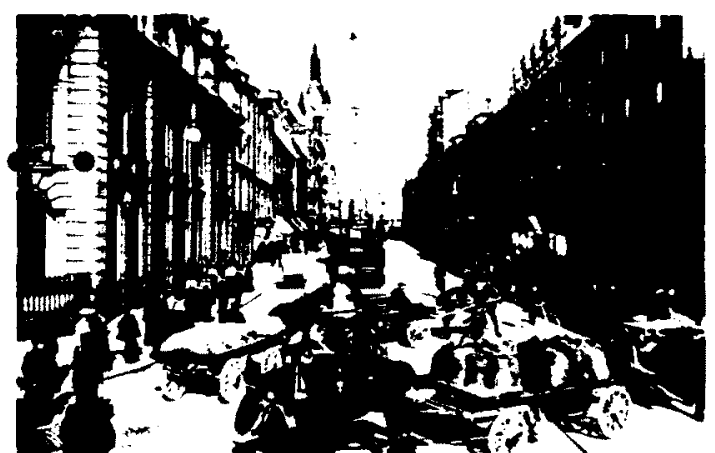

Figure 1.24 - A view of Union Street, looking north-east, C. 1900

Street was designed in response to proposals commissioned

in 1794 , to address population growth and the need for better road connections through the town. ${ }^{23}$ This street transformed Aberdeen physically and socially. Sociologist Jo Vergunst writes that Union St. imparted "a social class hierarchy, in which the new straight street embodied taste, elegance, and improvement", ${ }^{24}$ in strong contrast to the old winding streets. While originally built without sidewalks, Union Street quickly became the most popular public space in town; as soon as sidewalks were added they were filled with pedestrians. By 1829 bans were put in place on activities that would disturb or obstruct the use of sidewalks in order to "prevent the breakdown of order on the street". ${ }^{25}$ It was a long running tradition in Aberdeen to promenade up and down Union St. every Sunday afternoon. Known as "walking the mat", this tradition dates to the time that promenading became popular in Paris. Walking the mat was usually done by groups of

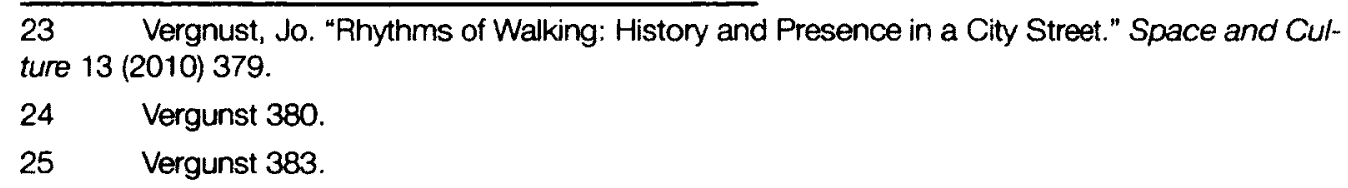


young people who would meet up with others along the way. The tradition imparted a sense of community. ${ }^{26}$ The tradition dissipated in the 1970s due in part to the large number of people that moved to Aberdeen from other places with the oil industry. Other contributing factors include higher incomes, an increase in car traffic and the advent of the television. ${ }^{27}$ With so many outsiders moving in, the community was no longer as close-knit and people kept to themselves more, finding other things to do.

Named for the activity it supports, a promenade is a public space, generally consisting of a long or connected series of pedestrian pathways with a variety of things to see and places to stop along them. The promenade should be uninterrupted, allowing one to wander freely in an open and safe environment.

As a type of public space, the urban promenade allows people to experience and enjoy the city rather than being herded along crowded sidewalks. Encouraging people to be out walking in the city is also beneficial to the businesses located along their path, such as retail shops, restaurants and services catering to the public. The concept of a promenade can be conducive to residents and visitors alike, as a way to navigate and explore a city.

$26 \quad$ Vergunst 383.

27 Vergunst 384. 
Through the investigation of these precedents I have been able to find elements and principles that can be applicable to the spaces of the pedestrian network that I am proposing.

Firstly, it is apparent that the typology of spaces for the network should not be limited. Many different forms of public space can be successful and should be used in conjunction with each other. Although I do not propose to follow the Parisian arcade model, through-block passages (exterior or interior) are an excellent way to increase pedestrian circulation and maximize use of block interiors while providing space for the public. Through-block passages are also beneficial because they divide city blocks, creating shortcuts through the city. By having a variety of public-oriented businesses along pedestrian routes more people will be attracted to the area throughout various times of the day and evening (and possibly into the night).

Although my focus is on pedestrian spaces that are removed from the street, many of the interventions for improving pedestrian space along the street can be translated to through-block spaces, particularly the application of a surface treatment to denote plaza/passageways and the introduction of seating and greenery.

The social aspects of a promenade cannot be forced on people but spaces can be provided that allow 
for promenading. Among other things, pedestrian networks should include opportunities for promenading by incorporating extended stretches of pathways. 


\section{PRIVATE OWNERSHIP / PUBLIC USE}

Urban private and public realms have overlapped for centuries; making private property available for public use is a relatively common solution to the need for more people-space in urban areas. Examples include the porticoes of Bologna, the arcades in Paris (and many other cities) and the spaces produced under the zoning incentives adopted by New York City in 1961. Although these spaces remain under private ownership, they were built with the intent of public use. Private ownership of publicly accessible space may also afford a level of security and regulation that might not be present in public areas. The owners of these spaces not only want to keep their property in good condition because it is theirs but may 
be motivated to do so because a clean, safe environment has the potential to attract more people and in turn potentially produce more profit. This is particularly true where stores or other public-oriented services are involved.

Public space is generally defined as space that is accessible to the public at large - open at all times to all - and is made available under the aegis of a government body rather than an individual or company (as is the case with privately owned space). Urbanist A. Mandanipour defines public space as 1) multi-functional and used in a variety of ways 2) outside of individual or group control 3) space that mediates between various private spaces. ${ }^{1}$ The over specification of spaces might limit the public's use or access of the space. Private space is defined as "for or belonging to a particular person or group only."2 Among the most common forms of private space are housing and offices for individuals or privates companies.

As discussed in Chapter 1, however, there are many examples of the mixing of public and private uses, most often where land is privately owned. In retail environments, for example, the public is invited onto the property for a particular use (i.e. shopping), subject to the rules and conditions set forth by the owner. A further elaboration of the overlap between public and private uses is the making available of private land for public use. This is often done through agreements between cities and property owners, such as those implemented in New York City's 1961 zoning ordinance.

1 Madanipour, A. "Why are the design and development of public spaces significant for cities?" Environment and Planning B: Planning and Design, 26(1999), 881.

2 New Oxford American Dictionary. 3rd edition. (Oxford University Press, 2010) 
The provision of public space and particularly "privately owed public space" raises the question of democratic access. Implicit in the idea of public space is that it will be accessible and usable to all - regardless of class or social standing - in what sociologist Henri Lefebvre denotes as the right to the city. Lefebvre's main concern was the relationship between everyday life and urbanism, of which the bureaucratic planning limited the vitality and spontaneity of its inhabitants. ${ }^{3}$

Ownership of designated publicly accessible space has the ability to give the public both greater freedom and less freedom. The arcades in Paris for example allowed greater freedom of opinion and access to all classes but such spaces under private ownership might impose rules with the ability to hinder access and/or use of space. Accordingly, guidelines that do not allow the owner to restrict these aspects may be necessary to maintain the public integrity of the space.

Both porticoes and arcades are great examples of how private property has been maintained for public use in the past. The porticoes in Bologna were (and continue to be) maintained and kept clean by the owners of the shops that front onto them. Some owners also utilise the space to display goods or to set out cafe tables and chairs to attract customers. Arcades, such as those built in $19^{\text {th }}$-century Paris, were privately owned. The owners of these arcades had full control over the passages, which were marketed as a safe and clean environment in which people, especially women, could shop and move about the city.

3 Ockman, Joan. Architecture Culture 1943-1968: A Documentary Anthology. (New York: Rizzoli, 1993) 427. 
Before it became standard practice for vendors to sell goods from shops, goods were spread out on the ground in a public markets. The evolution of selling methods produced numerous variations of public and private ownership and use, including the cart, covered stands, and moveable stands. "The predecessor of the shop is the booth with two large wooden chests and two flaps which open"4 like the bookanists along the banks of the Seine in Paris. Booths like these were set up on leased land that, over the generations, became owned. Ownership, in turn, led to the construction of permanent structures. ${ }^{5}$ These booths tended to be set up along well-travelled routes through medieval cities, especially along bridges where foot and cart traffic were most concentrated. The phenomenon can still be seen, among other locations, at the Ponte Vecchio in Florence.

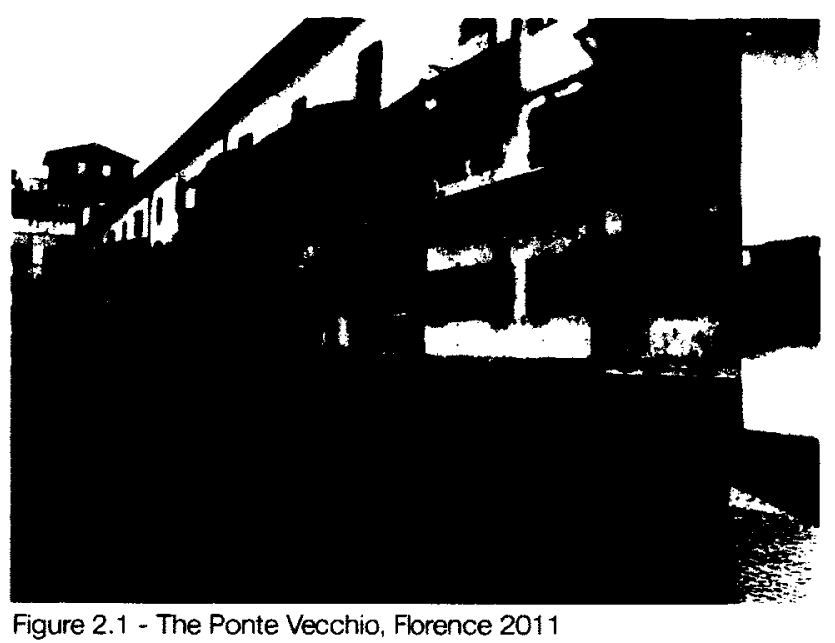

Figure 2.1 - The Ponte Vecchio, Florence 2011

Where sales and merchandising are concerned, the lines between public and private spaces have long been blurred. Privately owned spaces were frequently designed to encourage public occupation. In the past private ownership gave patrons of the spaces certain freedoms that might not be possible in public spaces. They were safe spaces where one was able to express opinion, women could shop in a

4 Geist, Johann Friedrich. Arcades, the History of a Building Type. (Cambridge, Mass: MIT Press, 1983) 35.

$5 \quad$ Geist. 36. 
protected environment, and where people of various social class could wander about at will.

It is still quite common for private property to be opened to the public in order to generate revenue while introducing more space for the public in dense urban areas. This is of course officially sanctioned in New York City through zoning incentives (discussed in more detail in chapter 4). Like medieval Bologna and $19^{\text {th }}$-century Paris, Manhattan has a limited amount of land available. Accordingly, the integration of public space and private property allows for both density and people space. With the increasing desire for urban density across North American cities (to quell horizontal growth) the incorporation of privately owned, publicly accessible spaces is a viable option to accommodate the resulting need for more public spaces as the urban population grows.

For the ByWard Market, the use of private property for the proposed pedestrian network will allow for throughblock spaces to be used by the public. This will help ensure an appropriate supply of public space in the Market as it continues to densify. The terms of the provision of these spaces through agreements between owners and the City of Ottawa would ensure that the public aspect is maintained. 


\section{OPPORTUNITY: \\ vacancy, internalization, and successful spaces}

The deterioration of smaller-scaled urban fabric with the emergence of new building types and new modes of transportation in the $20^{\text {th }}$ century has forced us to look at pedestrian movement differently. Street and block sizes optimized for automobile movement might not be at the appropriate scale for other uses. Accordingly it may be desirable to adapt the grid to encourage pedestrian flow and circulation throughout an area. William $\mathrm{H}$. Whyte's study of public spaces in New York City may help us to understand what factors contribute to and detract from the success of public space. Whyte's findings will be discussed later in this chapter. 


\section{SHIFTING DENSITIES}

Changes to urban fabric are continuous and frequently unpredictable. In the second half of the $20^{\text {th }}$ century, city centres lost many smaller-scaled buildings. In many areas, up-zoning and changes in the grain of the fabric created vast tracks of open land in the core. By the 1970s Central Business Districts in many North American cities were a patchwork of vacant lots, freestanding office towers and mega-structures. Tall, large-floor-plated towers had the tendency to draw tenants out of block after block of lower-scaled buildings, many of which were subsequently demolished, leaving vacant lots among the larger scaled buildings.

A positive effect of these changes was that blankness enabled new patterns of movement through the urban grid; notably diagonal shortcuts across empty blocks and throughblock detours where buildings were missing. With buildings out of the way, pedestrians could devise their own paths to get to their destinations in the shortest way possible. Human beings are not inclined to walk orthogonally if it is not the quickest way to get somewhere. The predilection for shortcuts, coupled with a surfeit of open space in cities, allowed pedestrians to define rights of way across vacant, privately owned properties. Even if privately held, paths across vacant land can constitute easements based on long-term common usage. As easements, these pedestrian shortcuts have the potential to become permanent, overlaying the grid with more organic and natural patterns of movement. The change in status from 
informal paths to recognized easements would grant a degree of permanence to secondary circulation networks, enabling future development to capitalize on established pedestrian routes.

Grids are generic and flexible. This is their advantage over, for example, the more accretive and irregular fabric associated with medieval cities. Grids and even zoned uses (as re-zoning could occur) can't anticipate where nodes of activity might occur and/or shift over time - whether over the course of a day or several decades. Given the number of single-use districts in cities, areas that may be hives of activity during the day can sit all-but-vacant in the evening. In contrast, cultural districts may be more active in the evenings and on weekends than during the day. In this regard, the uniformity and neutrality of grids often belie the intensity and changing hierarchies of the uses they support. This reinforces the importance of mixing uses - even if it means adjusting the grid to do so. Manhattan's long east-west blocks, for example, were designed to shield residents from commercial activity on the north-south avenues. When called upon to adapt to a mix of uses, however, the length of these blocks proved problematic. Even in strictly residential areas, critics contend that these long blocks isolate residential streets from each other and inhibit the formation of neighborhoods. ${ }^{1}$

In The Death and Life of Great American Cities Jane Jacobs observes that smaller blocks are a key factor in 
creating lively, prosperous cities. This effect can be seen in Midtown and at Rockefeller Center where additional streets were introduced. These smaller blocks are more conducive to incorporating a mixture of uses into an area - another important factor according to Jacobs - because the shorter blocks allow for more people to navigate the streets in a variety of paths. ${ }^{2}$ In Midtown, commercial uses have spread along east-west streets, capitalizing on the area's shorter blocks. Such changes of use pose challenges where sunlight is concerned, as commercial buildings are frequently taller and denser then the brownstones for which New York's east-west blocks were planned. Accordingly, many of these large buildings have been designed to include areas of public space.
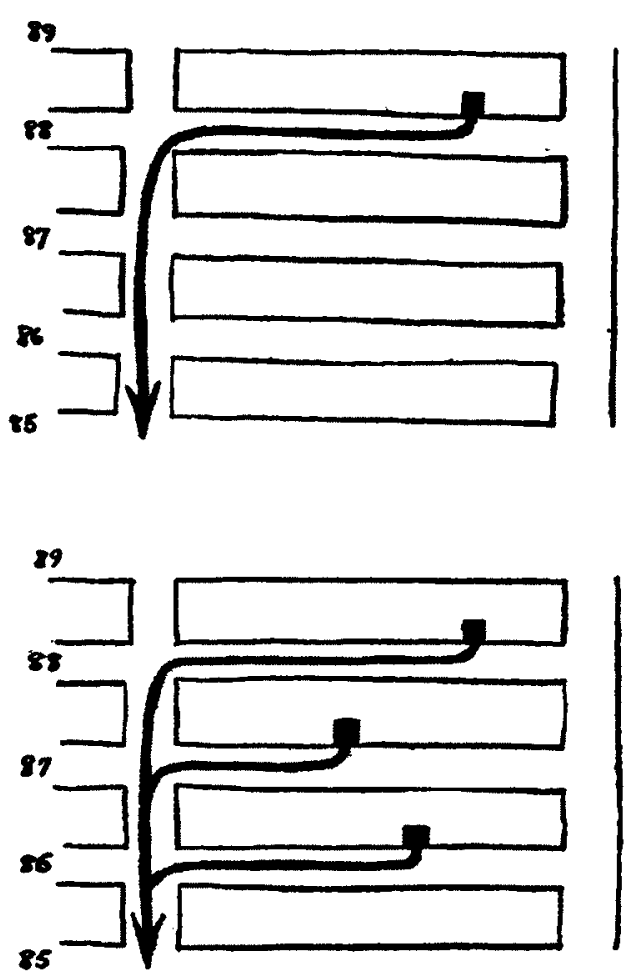

Long blocks thwart the principle that if city mixtures of use are able to be more than a fiction on maps, they must result in different people, bent on different purposes, appearing at different times, but using the same streets ${ }^{3}$

The need to adapt the grid to changing uses is one of the considerations behind New York's zoning incentive for public space, described in Chapter 4. Indeed, the advantages of shorter

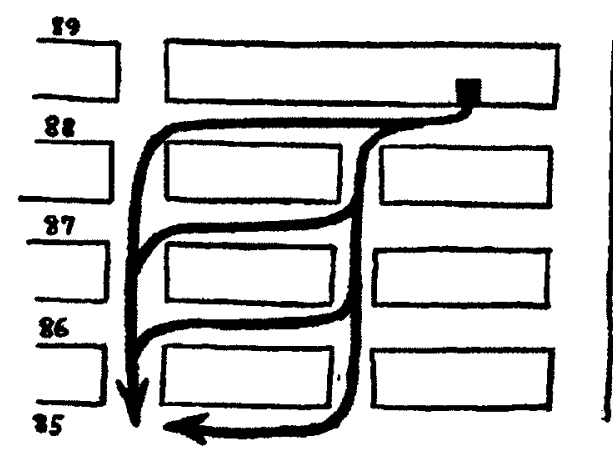

Figure 3.1 Jane Jacobs' sketches showing circulation around long vs. short blocks blocks helps explains why office uses migrated 2 Jacobs, Jane. The Death and Life of Great American Cities. (New York: Random House, 1961) 180.

2 Jacobs, 183. 
to midtown Manhattan after World War II. Madison and Lexington Avenues divide what were originally $920 \mathrm{ft}$. eastwest blocks between $5^{\text {th }}$, Park and $3^{\text {rd }}$ Avenues to create a finer, more flexible grid.

\section{From Too Big to Even Bigger}

Notorious among $20^{\text {th }}$-century adaptations of the urban gird is the superblock. The appearance of superblocks and mega-structures after World War II led to the isolation and internalization of city districts and tower complexes. Large developments frequently turn away from the city, presenting large blank walls to the street and cutting off through-roads.

Particularly poignant examples of this are the shopping malls and concourses that appeared in cities in the 1960s. Although these spaces are the descendants of the $19^{\text {th }}$ century arcade, their character and aspirations are significantly different. Isolating themselves from their surroundings, shopping concourses tend to compete with, rather than complement, life on city streets. Several forms of shopping venues appear in urban areas. The three main types are; the regional shopping mall, shopping concourses associated with major office complexes, and underground concourses that connect key destinations in the city to subways and other regional transit.

The shopping mall - examples of which include Toronto's Eaton Centre and the Rideau Centre in Ottawa is effectively a suburban type, grafted into the city to enable 
the Central Business District to compete more effectively with regional shopping venues. These facilities are designed to be both familiar to and comfortable for shoppers who might not ordinarily make the trip downtown to shop. They are comprised primarily of national retailers requiring large amounts of square footage. Like suburban malls, they frequently include one or more department store anchors. Designed to appeal to consumers who might not be comfortable with cities, they frequently turn their back on the street in favor of an internalized, faux urbanity.

Toronto's Eaton Centre is located along Yonge Street between Queen and Dundas Streets. Rather than running perpendicular to a main shopping street as arcades did (i.e., through the middle of blocks), the Eaton Centre runs parallel to Yonge St., against which it competes directly for commercial activity. The Centre's Yonge St. façade is almost entirely blank, with

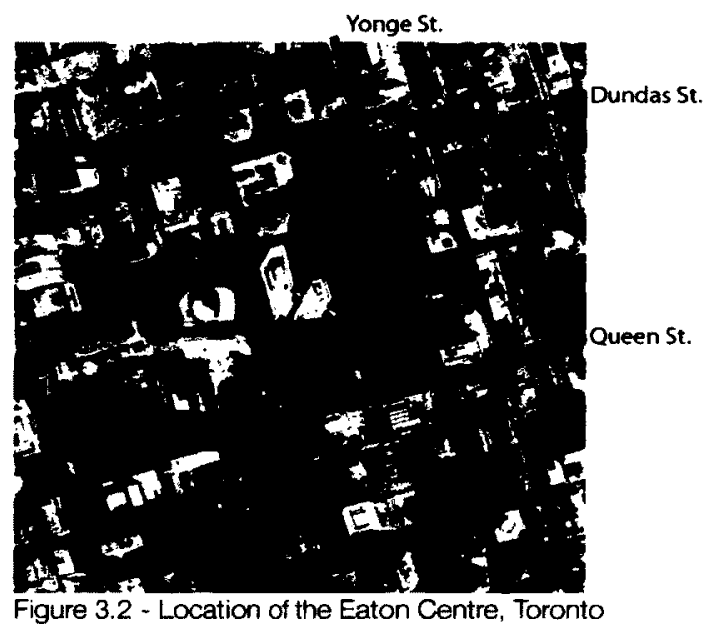
only a few display windows and entrances. Internalization is consistent with current retailing practices according to which entrances are best hidden from the interior spaces (i.e., placed around corners and out of direct view from the main shopping arteries) in order to not disrupt or detract from the flow throughout the retail environment. The Rideau Centre in Ottawa arguably detracts less from the street than the Eaton Centre, as its main axes run perpendicular to the 
main shopping street (Rideau St.) and it accommodates pedestrian access between a major transit stop at the south side to Rideau St. and the ByWard Market on the north side. Like the Eaton Centre, however, the Rideau Centre presents blank walls to most of the surrounding streets, isolating the complex.

As noted in previous chapters, many office towers provide space for commercial uses at their ground floor and concourse levels. An array of stores, services, restaurants and food courts are incorporated as a convenience to the occupants of the building, obviating the need to leave the building during the day. Internalization is especially pronounced when these office complexes connect directly, via underground passageways, to parking garages or regional transit. As with shopping malls, commercial usages in office plinths are frequently organized around an interior atrium or series of concourses that operate largely independently of surrounding streets. These spaces are quite common in financial or business districts where office towers are prominent. Ottawa's World Exchange Plaza and Toronto's TD Centre and Brookfield Place provide internalized public amenities at the ground or concourse levels of the office towers.

\section{UNDERGROUND}

Numerous cities have developed vast subterranean networks of commercial development: pedestrian concourses 
connecting office towers, shopping, parking garages and subway systems. Montreal's Underground City (La Ville Souterraine, RÉSO) comprises thirty-two kilometers of tunnels beneath the downtown area, connecting eighty percent of office space and thirty-five percent of all commercial space in downtown. With the implementation of the Underground City in 1964, Montreal's street level retail development virtually ground to a halt. ${ }^{4}$

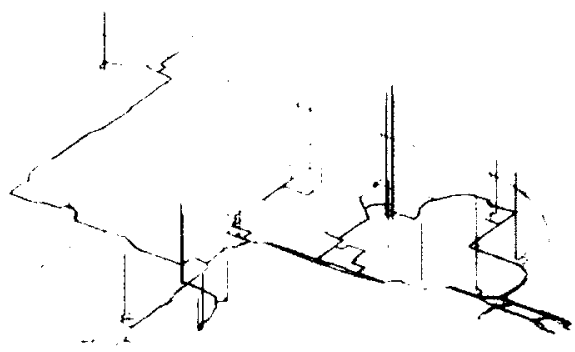
Similarly, Toronto's PATH system consists of twenty-eight kilometers of walkways along which are located some 1200 shops Figure 3.3 - Tracking commuter routes through the PATH network and into office towers

and services. PATH connects more than fifty buildings/office towers in downtown Toronto ${ }^{5}$ - both to each other and to Union Station, the main transit stop for
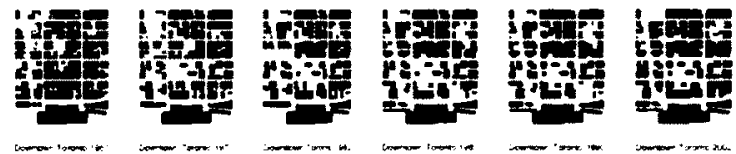
commuters entering the city. One of the major appeals of PATH and RÉSO is that users are protected from the elements, especially during harsh winter months.

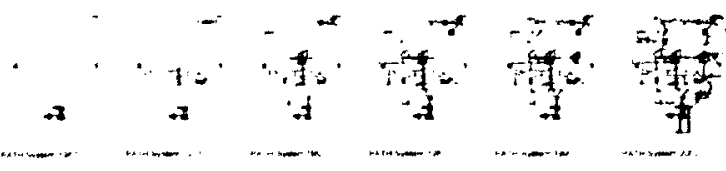

Figure 3.4 - The changing fabric of downtown Toronto in comparison to the growth of the PATH system

Because these networks are so connected

with various buildings, it is often more convenient to move about the city through the tunnel systems than along streets.

Montreal and Toronto's underground networks are among the

\footnotetext{
4 "Underground City: La Ville Souterraine (RÉSO)" A view on cities. 2012. Web. 20 Feb. 2012. <http://wnw.aviewoncities.com/montreal/reso.htm>

5 "PATH facts" Toronto. City of Toronto. 2012. Web. 20 Feb. 2012. <http://unw.toronto.ca/ path/ $>$
} 
most extensive in the world. The creation of grade-separated networks either above or below street level has the potential to draw large numbers of people off of the street, leaving the fabric of the city to atrophy and the street unable to support a healthy mix of uses. 


\section{WILLIAM WHYTE AND PUBLIC SPACE}

What makes public space successful? For three years

in the 1970 s William H. Whyte's Street Life Project conducted

extensive research and surveys of urban public spaces in New

York City. Whyte found there are no simple answers when it

comes to the design of public space. Not only is a combination

of different elements at play, but the factors

one might expect to be the most important

are often not. The size and shape of public

plazas in New York, for instance, did not

correlate directly with the amount of use

they received - smaller is often better.

Among the elements Whyte found to enhance public plazas were the availability of "sitting space," the amount of sunlight, protection from wind, availability of food, connection to the street and the inclusion of natural elements like trees and water. Whyte noted that sitting space should not be limited to "park bench" style seating, but should include ledges, steps and movable chairs. While Mies van der Rohe

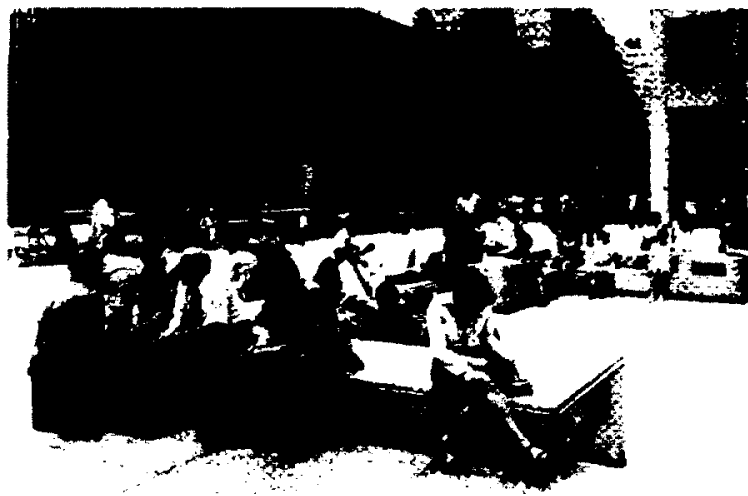

Figure 3.5 - There are a variety of well used seating options at 345 Park Avenue

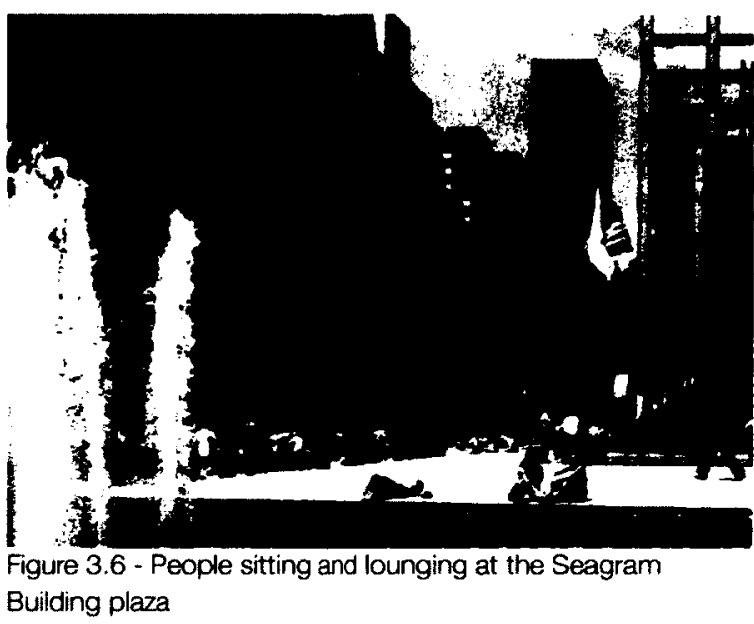

never intended the ledges and steps in the Seagram Building plaza to be used as seating, their simplicity and location made them popular places to sit. ${ }^{6}$ Whyte observed that people

$6 \quad$ Whyte, William Hollingsworth. The Social Life of Small Urban Spaces. Washington, D.C: Conservation Foundation, 1980) 29. 
attract people, people tended to sit close to pedestrian flow, and pedestrians walking through public spaces didn't mind navigating around people sitting in the plaza. Pedestrian circulation and sitting space are complementary and shouldn't be separated. Even when plazas were crowded, most people preferred to walk through them rather than use sidewalks to get around them. ${ }^{?}$

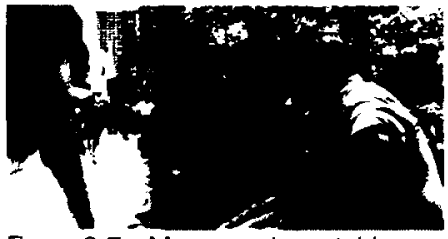

Figure 3.7 - Men people watching along a New York sidewalk

Indoor public spaces can take a variety of forms including the indoor plaza. Many of the same elements that make exterior plazas successful contribute to the success of interior public spaces. Again, seating is important and Whyte found that successful interior public spaces often met or exceeded the requirement that public plazas should incorporate one linear $\mathrm{ft}$. of seating per 30 sq. ft. of open space. ${ }^{8}$ Successful spaces also provide food service (e.g., snack bars or cafes) and retail outlets, which contribute to their liveliness and attract additional pedestrian flow-through. While through-block passages enhance pedestrian circulation, it is important that they not be designed solely

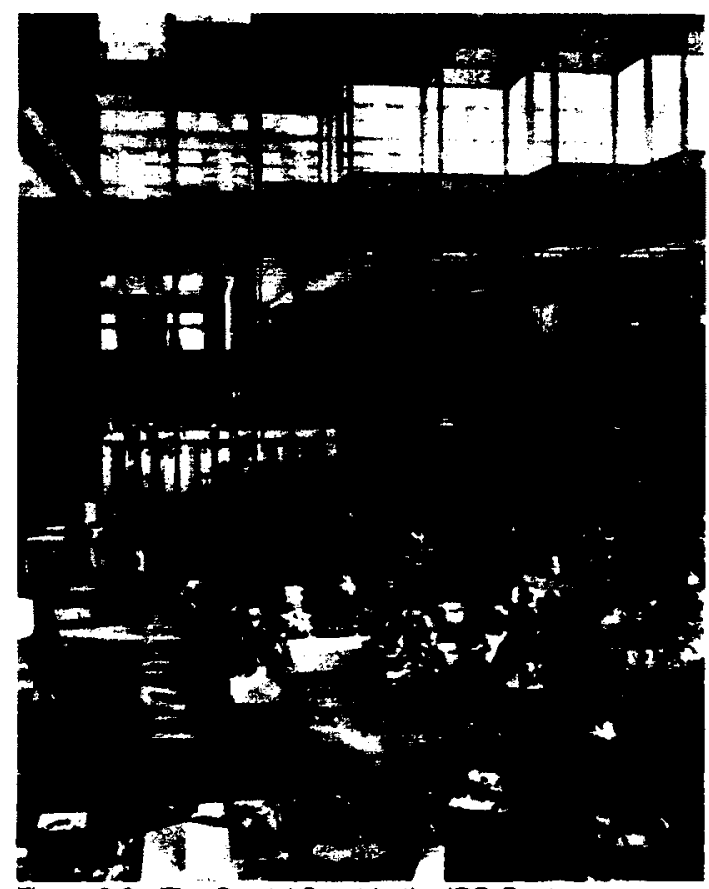
Figure 3.8 - The Crystal Court in the IDS Center, Minneapolis, creates an indoor public plaza for walking. As people want to be around other people, through-block passages should include sitting spaces and activities that support and depend on each other. 
The relationship between interior space and the street is very important. The public should feel invited into the space and the interior should be visible from the street (and vice versa). To mitigate the risk that a successful interior space might compete with the street, it is important not to wall off or otherwise internalize the space. ${ }^{9}$ Interior and exterior public spaces must work together.

The boundary between public and private is often blurred - especially in the case of spaces created through zoning incentives. While intended for use by the public, such spaces are privately owned and often carefully monitored for reasons of liability. For better or worse, public use of these spaces is more narrowly defined than in city streets. Ideally such spaces can be "policed" by their regular users. Indeed the more people making regular use of a space, the less likely problems and conflicts will occur. Good design can help minimize these types of problems.

Well-designed spaces that work in conjunction with pedestrian routes through the city can greatly enhance our experience and appreciation for the urban environment. The aforementioned factors can be used to aide in the enhancement of and promote the successful design of public spaces and publicly accessible private spaces. Understanding what has worked and what has not for public spaces in the past can provide insight into the needs of people in the city. Vacancy, 
endemic to the ongoing transformation of cities, represents both capacity and opportunity for future public space.

A number of the design principles discussed in this chapter will be applied to my proposal for the ByWard Market. The current state of the urban fabric in the area is fragmented due to many open lots being used for parking. The goal is to capitalize on this fragmentation as an opportunity to create shorter blocks that promote pedestrian movement and better support a mixture of uses. Examining pedestrian patterns and leveraging opportunities presented by vacancies can enable us to expand the network and incorporate latent possibilities for public space. Such a network would privilege connectivity (between streets and spaces as well as between different spaces) rather than encourage the genre of isolated spaces associated with shopping malls and concourses.

The primary factors for the design of such spaces include: the presence of natural elements (trees and plant, water, sunlight), availability and variety of seating, proximity of additional amenities (street vendors, stores, restaurants, etc.). These can be applied to the design of spaces for the ByWard Market, whether indoor or outdoor. 


\section{MECHANISMS \\ for the implementation of publicly accessible space}

The creation of publicly accessible private space requires the use of implementation mechanisms, ways for the City to impose the provision of publicly accessible space on private property. An agreement between the owner and the City, or public-private partnership, would see benefits for the owner in exchange for providing public space. A zoning incentive or density bonusing, is a mechanism whereby developers provide publicly accessible space in exchange for permission to build additional square-footage ( generally through additional height). Through density bonusing, additional people space is introduced into increasingly densifying downtowns, creating balance and integration 
of the public and private realms. One of the best examples of the use of zoning incentives is in New York City, where the amount of developable land is severely restricted.

After World War II, New York experienced an increased demand for office space in the form of tall buildings with large floor plates. As this form of building was at odds with the city's sky-plane setback ordinances, developers sought relief from and alternatives to existing zoning laws. With this came concerns about an increasing lack of public spaces at ground level. Larger, taller buildings attracted more people into the city and reduced the amount of open space available. In order to maintain pedestrian access and public space, New York implemented a zoning incentive program (now known as Publicly Owned Private Spaces or POPS) with its 1961 zoning ordinance that permitted developers to build higher in certain districts in exchange for providing publicly accessible "amenity" space at grade. ${ }^{\top}$ Designed and built before the New York incentive, the public spaces of Rockefeller Center and the public plaza in front of the

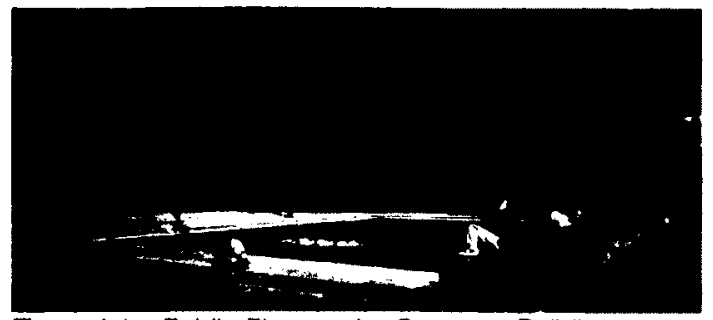

Figure 4.1 - Public Plaza at the Seagram Building, New York
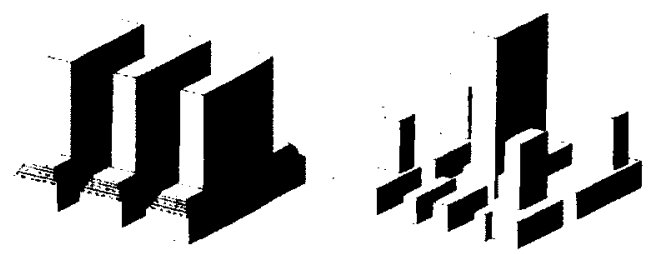

Mecoing of the cite madribing

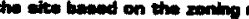
ond

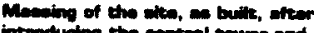
plowe

Figure 4.2 - Rockefeller Center massing

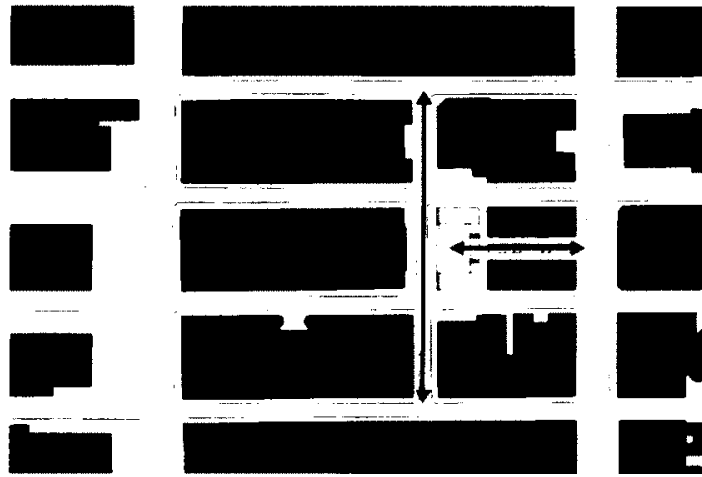

Figure 4.3 - Rockefeller Center, pedestrian movement at street level
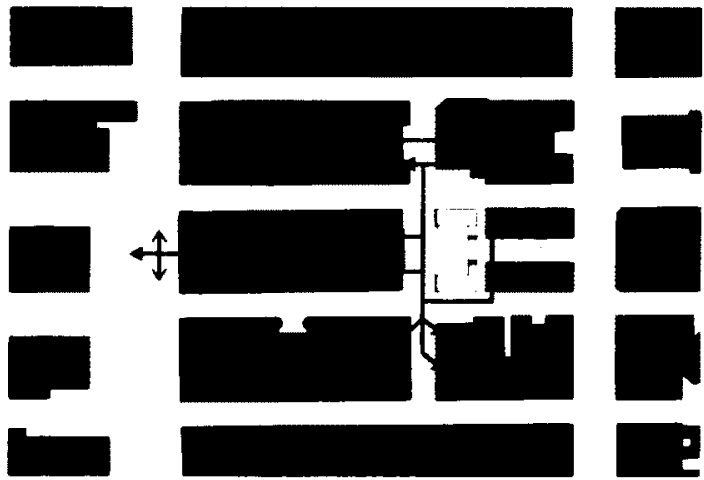

Figure 4.4 - Pedestrian movement below grade at the concourse level

1 Kayden, Jerold S., New York. Dept. of City Planning, and Municipal Art Society of New York. Privately Owned Public Space: The New York City Experience. (New York: John Wiley, 2000$) 11$. 


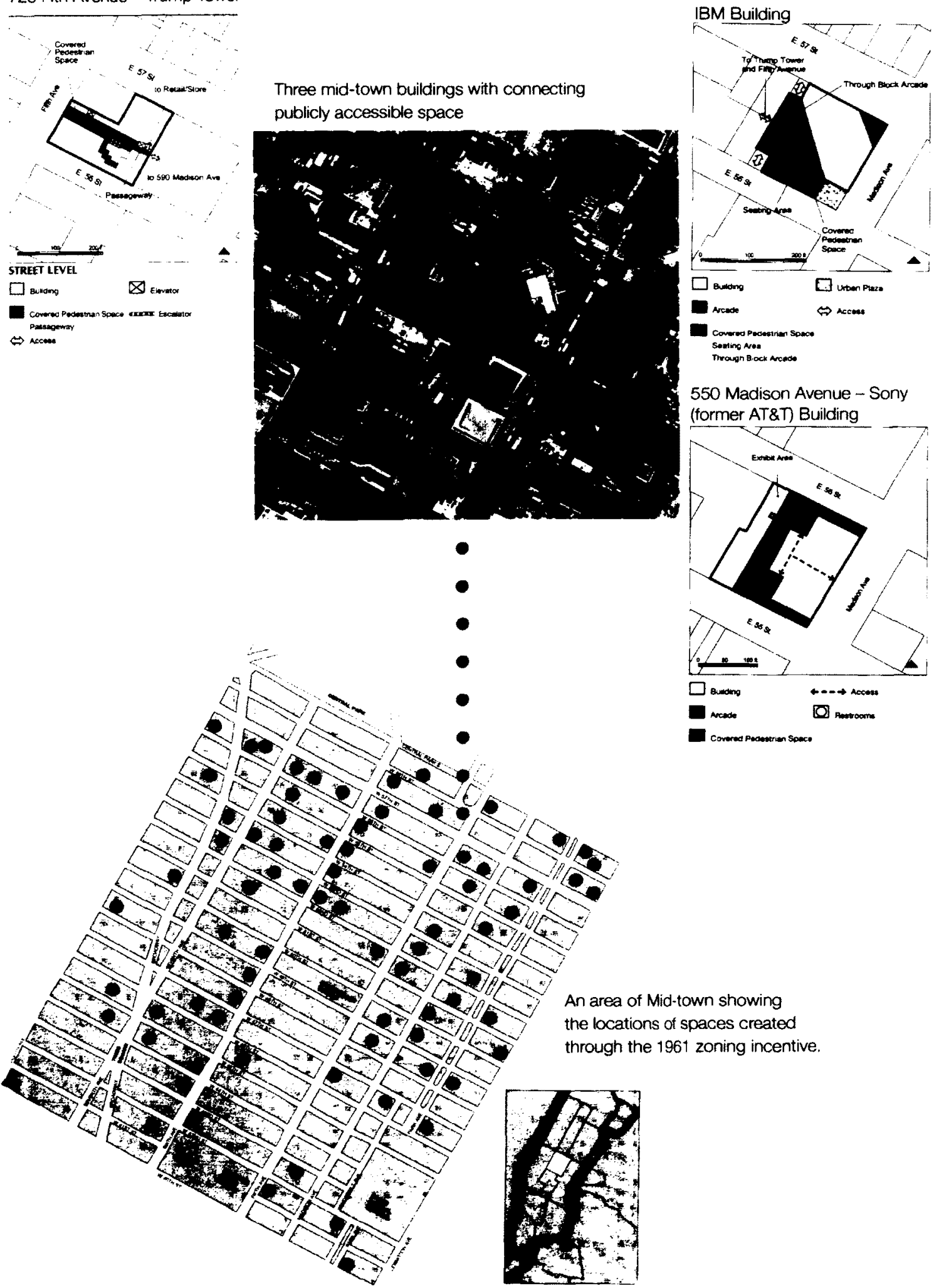

Figure 4.5 - Detail of three publicly accessible through-block passages in Mid-town Manhattan 
Seagram Building were two of the first in this new generation of public space in New York City - spaces both built and managed by private companies for public enjoyment. Indeed, the pedestrian spaces incorporated into Rockefeller Center and the Seagram Building greatly influenced the creation of the incentive program, parting the way for what now amounts to some 503 different spaces in 320 buildings. These Privately Owned Public Spaces were the subject of a recent study by Jerold S. Kayden, in conjunction with the Department of City Planning and the Municipal Art Society. Kayden categorized spaces by type and by used (Destination, Neighborhood, Marginal, Circulation, Hiatus). While many of the spaces created through zoning incentives have not been successful, many have, and several are extremely popular. Among those deemed to have been the most successful are two adjacent spaces in Midtown between Fifth and Madison Avenues. The Sony Building (former AT\&T) (550 Madison Ave.), designed by Philip Johnson, incorporated a pedestrian through-block passage along the west side of the base of the tower and access through the building to/from Madison Avenue. The former

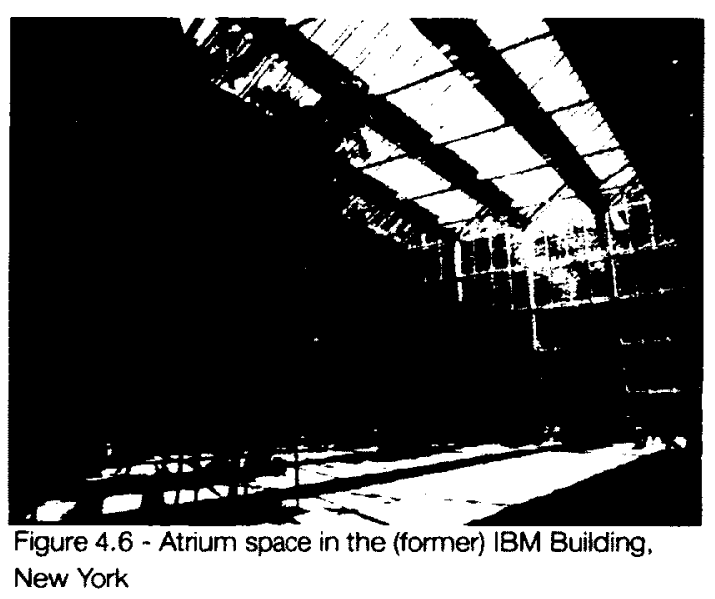
IBM building (590 Madison Ave.), immediately to the north, also incorporated a through-block passage aligning with the Sony passage and also connecting to a passage through the Trump Tower (725 Fifth Ave.) to Fifth Avenue. The IBM block incorporates an atrium space with seating at the $56^{\text {th }}$ Street 
entrance. Both of these spaces benefit from an abundance of natural light, public seating, and provide access to various buildings. They create shortcuts through blocks as well as places to stop en route. They are examples of the wide variety of spaces that can be incorporated into a building and coordinated with other, similar spaces to create alternate routes through the city.

The New York City Department of Planning maintains a set of guidelines for spaces created under its zoning incentive program. This is done to ensure a standard of quality, safety and accessibility for the spaces and includes a requirement for signage indicating that it is a Privately Owned Public Space, with information about the space. Although other cities have similar zoning incentives, they often do not follow through with guidelines, monitor upkeep, or require owners to make it apparent that spaces are open to the public. Such is the case in Toronto, where condo developments often provide space for public use without giving any indications (such as signage or visual cues) to the public or even notification to the residents that the space is available for public use. ${ }^{2}$ This shows the importance of designing a welcoming and accessible space in such a way as to add to the community without making building occupants uneasy about the use of the space. The signage used in New York must not only indicate that the

2 Topper, Josh. "Density Toronto: Could that condo's courtyard be a public park" Toronto Star. 23 Nov, 2012. 24 Nov, 2012. <http://www.thestar.com/ news/gta/article/1292209--density-torontocould-that-condo-s-courtyard-be-a-public-park> 
public is welcome, but also show what hours the space is required to be open, making it apparent if the owner is not fulfilling his obligation. Whether or not a privately owned public space is created though some sort of incentive, it is important to indicate in some way the intent of use as public space.

Although "density bonusing" is commonly used as an incentive, other mechanisms could be employed to achieve the same goal of publicly accessible space. Portions of the ByWard Market Area of Ottawa is under a blanket heritage overlay that imposes strict height regulations over much of the area. This means that in most cases zoning incentives that allow extra height would not be allowed. Other arrangements might include: 1) lower property taxes - in exchange for making portions of the land publicly accessible, 2) grants to aid the cost of creating quality public space, 3) changes to zoning - to impose new, legally recognized, rights of way across private property, and 4) Density transfers. Under the latter, developers would be permitted to add density to another project/site (i.e., elsewhere in the city) in exchange for opening up a portion of this property for public use. Each of these methods could be used on its own or in conjunction with one another to expand the supply of publicly accessible space. As with density bonusing, it is important that spaces provided for public use be subject to guidelines (built into the terms of the incentive) to ensure quality, safety and access for the public benefit. 


\section{THROUGH THE BLOCK \\ the proposal for a pedestrian network in the ByWard Market}

I am proposing the design of a pedestrian network and a phased system of implementation for the ByWard Market area of Ottawa, Canada. Beginning with the idea of the "right of way" through private property, an extended network of pathways has been identified, providing an alternative but complementary pattern of movement through the gridded network of streets and sidewalks. The incorporation of existing pathways and shortcuts, supplemented by additional routes that will become available as redevelopment occurs, can form the basis for a lasting, integrated network of through-block pedestrian pathways and spaces.

To test this idea, I have developed strategies for the 
implementation of the pedestrian network and guidelines for the design of the network spaces for Ottawa's ByWard Market. The ByWard Market was selected because of the development pressure it is facing and in light of its predominantly pedestrian character. Within the constraints of the area's rather restrictive zoning, empty lots in the area represent significant development capacity, with numerous new condos having been built around the edges of the Market in recent years. Although specific to this case study, the strategies identified are intended to be flexible enough to be applied to other cities and districts facing similar development challenges.

The previous chapters identified numerous examples of factors that contribute to and detract from successful public space. That said, there is no concrete formula for "good" spaces. A range of factors should be considered in the planning of public space - in this case through-block passages and mid-block spaces. Learning from precedents, I have determined the following to be applicable to the design of a pedestrian network for the ByWard Market:

- Private land should be made available for public use through incentives, such as tax breaks or density transfers (density bonusing is less likely for the ByWard market due to heritage restrictions).

- Regulations must be imposed as a part of any incentive agreement (to maintain the quality, safety and accessibility of the spaces in question).

- To act as true public space, when provided on private property there needs to be freedom of access and use (within the law). Such access could be enforced through an incentive agreement. 
- A variety of types of space will encourage a variety of uses. Similarly, different kinds of spaces may be combined (e.g., passages, plazas and atriums).

- Aligning through block spaces of adjacent blocks will aid pedestrian flow and encourage the "urban promenade".

- Entrances to pathways should be apparent and unobstructed from the street and ways through the site should also be clear.

- Visual indication of pedestrian spaces through surface treatment is useful for marking newly designated spaces.

- Availability of seating is very important; at least two types of seating should be made available in each space.

- Spaces should be well lit, with as much sunlight as possible (applies to both indoor and outdoor spaces).

- Other elements of nature, such as trees and plants, make a space more appealing to people.

- Amenities that are adjacent to or within a public space help to draw people to/through the site (shops, restaurants, vendors).

Despite the crucial role they play in dynamic urban environments, pedestrian networks are often an afterthought rather than a primary component of design. Bologna's porticoes, as noted, were created inadvertently, as a byproduct of efforts to increase the amount of residential space. Parisian arcades appeared after the city's streets became too dense, dirty and confusing to navigate on foot, and in New York City zoning incentives were established out of concern that the city was losing public space to densification.

So, why not make sure that these valuable public 
spaces are defined and protected in areas where densification will inevitably occur? The use of an implementation mechanisms by the government to designate spaces for public use through private property can ensure the integration of people spaces throughout densification. Block-by-block sections of the network will be incorporated through a phased system that sees 1) the visual indication of pathways, 2) the occupation of the site with seating, planters and pop-up shops, and 3) the building of more permanent features and infill around the pedestrian pathways. The goal of this is to allow for integration of the use of pathways into the everyday life of people who traverse the ByWard market and allow the design and implementation on various sites to occur congruently or consecutively as sites become ready/available. Having applied strategies employed in other cities to the formulation of a pedestrian network for Ottawa's ByWard Market, it is my hope that the proposed guidelines and mechanisms will be applicable to other neighborhoods and cities. In this regard I have attempted to walk the line between the sitespecific and the generic. The strategies could be applicable to other districts or cities while the specific requirements of the guidelines would be able to be adjusted on a per-case basis. 


\section{AN INTRODUCTION TO THE BYWARD MARKET}

The ByWard market was established in 1826 by

Lieutenant-Colonel John By, in what was then known as

Bytown. He commissioned York and George Streets to be

extra-wide - a feature that can still be seen - to accommodate

the horse-drawn carriages bringing

fresh produce to the market. The

market still operates on its original

site and although the current

building is smaller and the market

no longer extends into the block to

the north. It is one of the largest

and oldest markets in Canada.

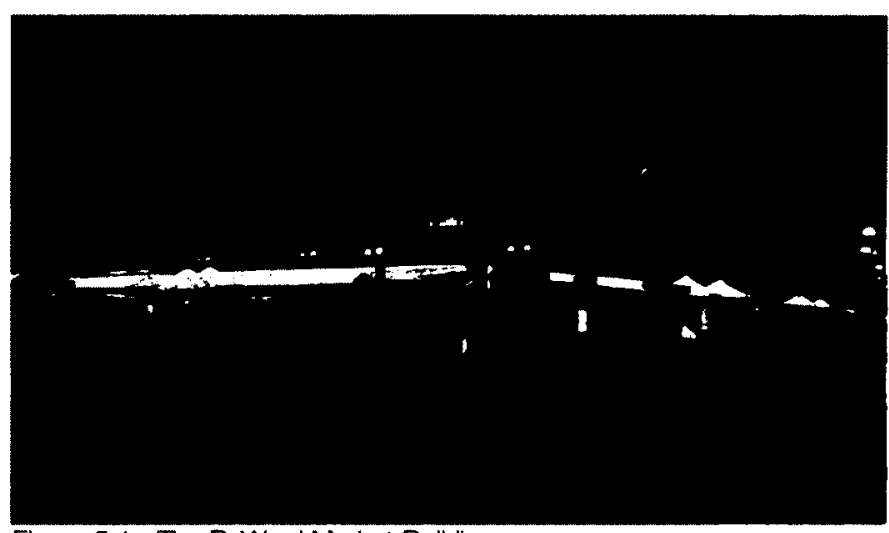

The approximately twenty-

block area around the market

building has become known as

the ByWard Market or simply

"the Market". Over the past

several decades the Market has

evolved into a key commercial,

entertainment and cultural district,

with an expanding residential

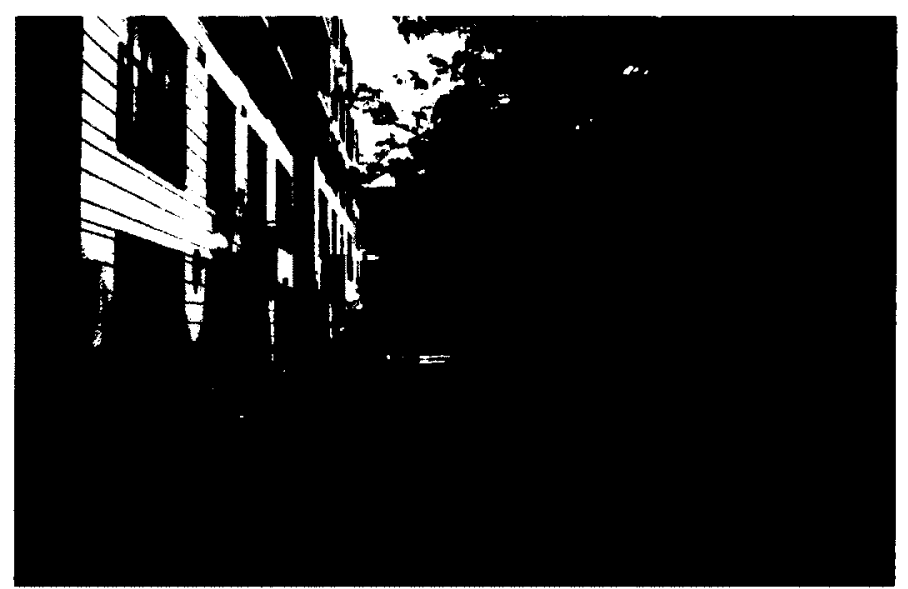

Figure 5.2 - Clarendon Courtyard, looking south

population. In addition to residents, the area attracts tourists, students and a range of local visitors. Despite being a major urban destination, however, the area provides few public spaces or pathways other than sidewalks, the Courtyards that run parallel to Sussex Dr. being a notable exception. The gradual implementation of a network of interconnected 
pedestrian spaces would greatly augment the identity of the ByWard Market, building on what is already happening in this pedestrian focused area. New routes and spaces will enable the area's many users to experience it in a more intimate and personal way, providing spaces to move through and go to. Though these connecting spaces may take various forms, they will work together to create an accessible, open and inviting environment, providing safe enjoyable places for the public.

\section{What's There?*}

The ByWard Market consists primarily of low-scale, street-oriented commercial buildings bounded by busy traffic routes. It sits north-east of Ottawa's central business district and immediately north of the University of Ottawa campus. The area supports an abundance of retail stores, restaurants and nightclubs, as well as several arts-focused venues. The Market is flanked by residential areas to the north and east, with an expanding cluster of residential towers to the southeast (see fig. 5.3 for building uses). While, moving west to east, businesses range from high- to low-end, several condominiums are now being built in the east, amongst lowincome housing, shelters and run-down stores. These higherdensity residential developments may represent an attempt by the City to mix income levels, consistent with Ottawa's Official Plan.

There are several main draws to the area for both tourists and locals. There is the market itself, for one. The

\footnotetext{
* See Appendix A for full set of analysis maps
} 


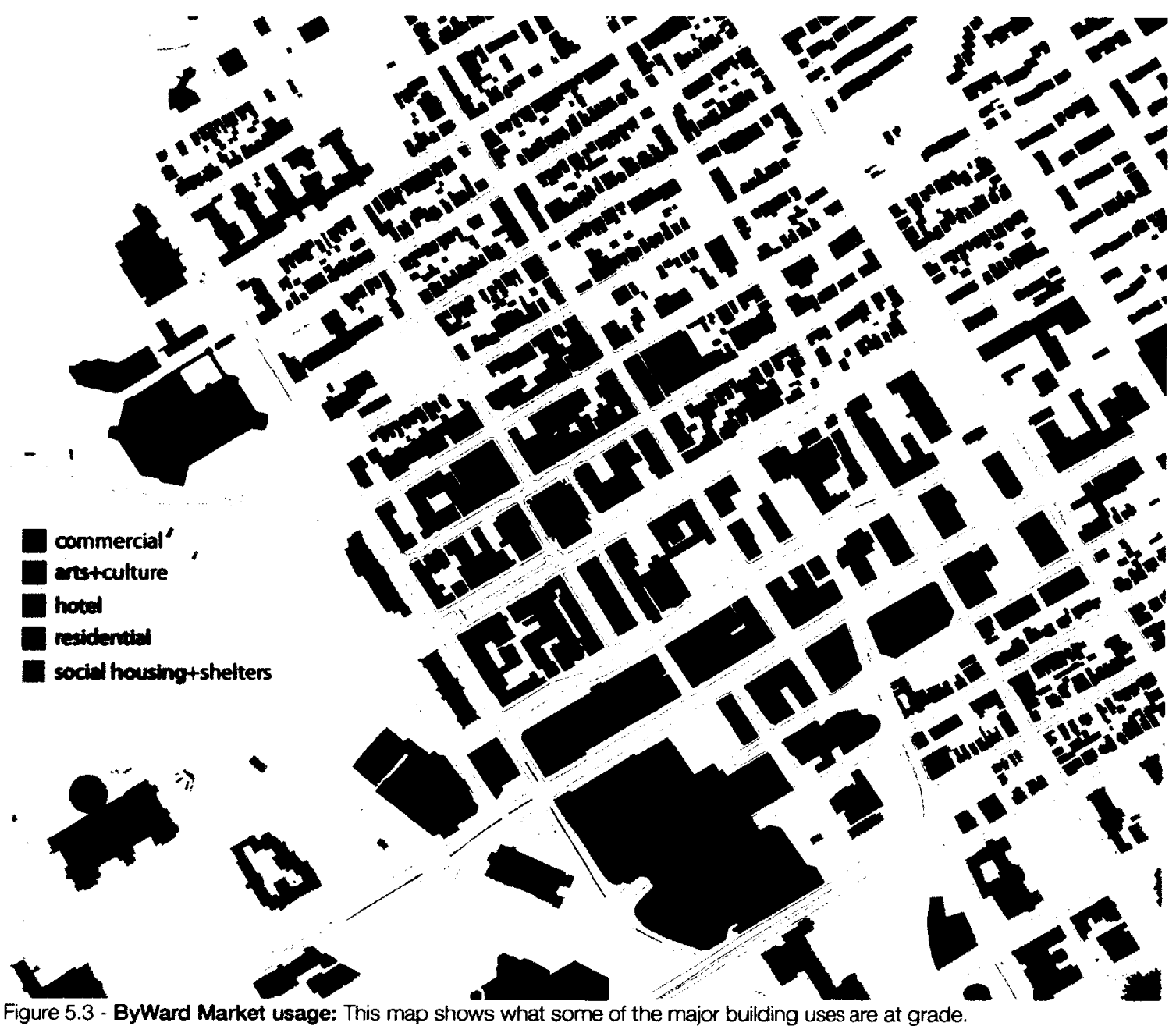

Figure 5.3 - ByWard Market usage: This map shows what some of the major building uses are at grade. 


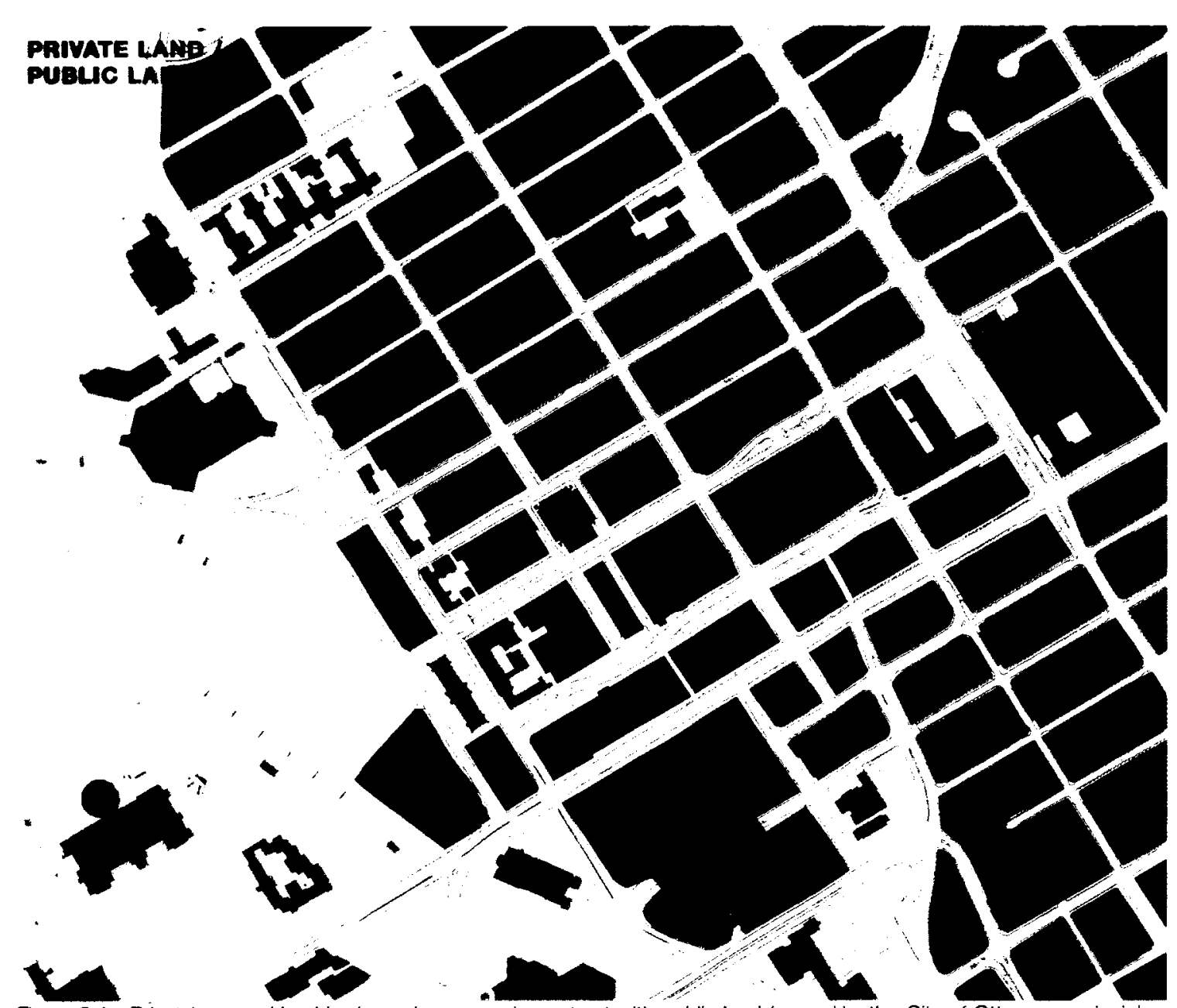

Figure 5.4 - Privately owned land is shown in orange, in contrast with public land (owned by the City of Ottawa, provincial or federal governments). 


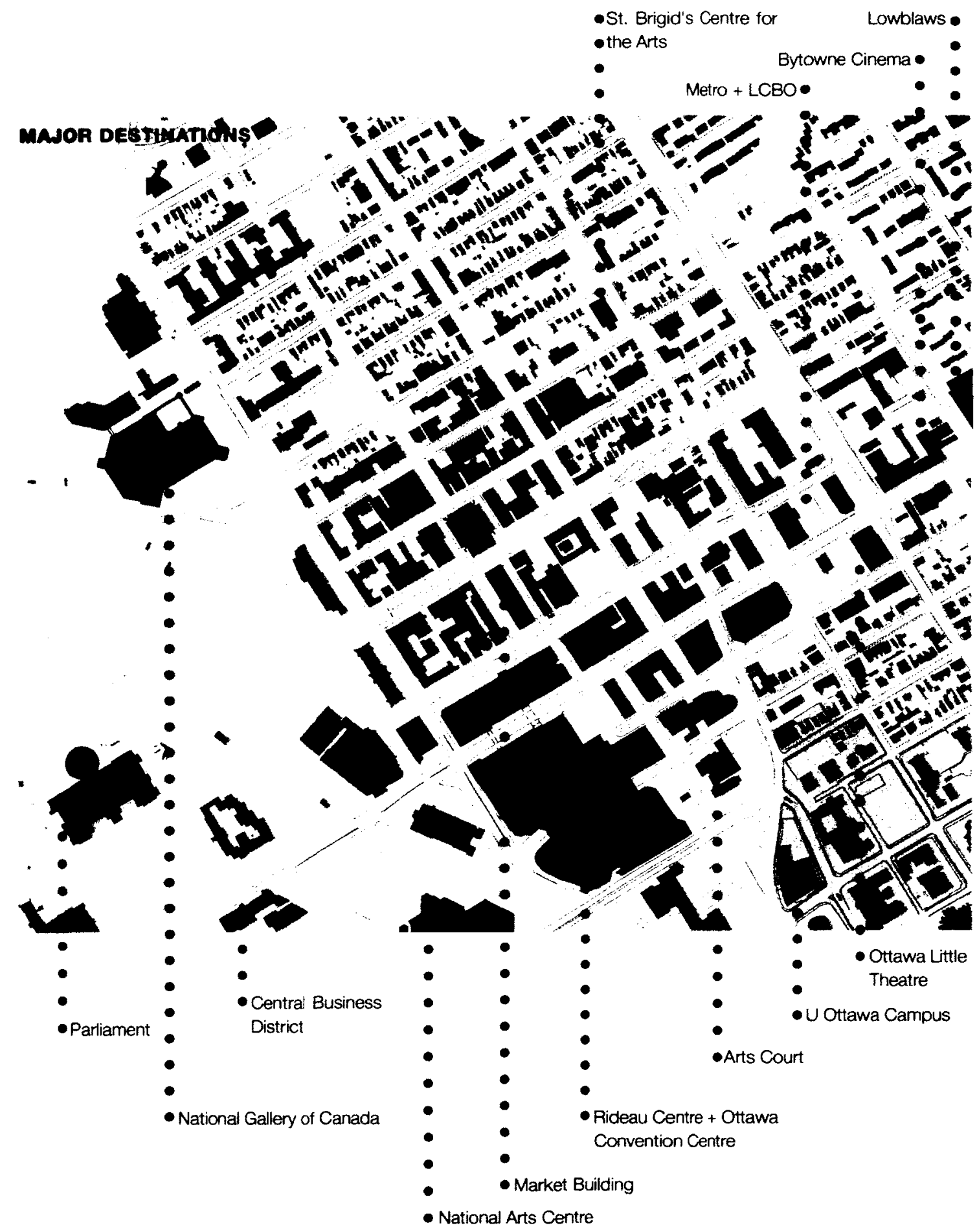

Figure 5.5 - Major Destinations around the ByWard Market 
market building houses several permanent outlets, while outdoor venders line the surrounding streets from May to October selling produce, arts and crafts. The National Gallery of Canada is located on Sussex Drive at the northwest corner of the Market area. Other arts venues include St. Brigid's Centre for the Arts, Art's Court and the Ottawa Little Theatre. Located on the south side of Rideau Street, the Rideau Centre shopping mall is major attractor to the area with over 170 stores, services and food retailers. Along Rideau Street, east of Dalhousie, there are two major grocery stores, a beer store and a liquor store that serve the greater area. Because the University of Ottawa sits at the southeast corner of the Market, many students live nearby and move through the area (fig. 5.5).

In addition to the Market's many attractions there are also features that may be considered as "detractors", particularly east of Dalhousie Street. This area accommodates several homeless shelters that, while providing a great service to the city, create concentrations of homeless people on the streets during the day. This is particularly apparent in the more gentrified western area of the Market. A better integration of housing types and public spaces (apart from sidewalks) throughout the market would aid in the integration of different classes and mixed social groups. Along Rideau Street there are several tattoo parlors and stores selling drug paraphernalia. The area east of Dalhousie mostly consists of rundown buildings but there is an increasing amount newer condos towers. This is in contrast to the centre and west area with mostly well-kept buildings and boutique stores between 
Dalhousie Street and Sussex Drive.

The Market area benefits from being a major bus transit hub for the City of Ottawa. Main transfer stops for both Ottawa and Gatineau city busses are located on Rideau St. (in front of the Rideau Centre), while one of the city's bus Transitways operates along Mackenzie King Bridge at the back (south) side of the Rideau Centre. Ottawa's new light rail system will travel under Rideau St. with a major stop at the Rideau Centre. This will eliminate or lessen the regional busses using the Mackenzie King Bridge and put more transit users onto Rideau Street.

There are currently several surface parking lots and parking garages in the Market area to serve people that come to the area by car. Many of these locations are likely to be redeveloped in the near future, with parking integrated into mixed-use buildings rather than on vacant lots. Many of the surface lots are also used by pedestrians as shortcuts through the Market.

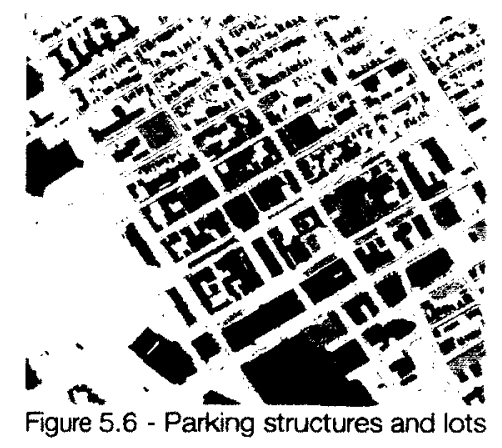

The aforementioned Sussex Courtyards provide pedestrian only space through the interior of four consecutive blocks. The Courtyards provide an alternate route to the sidewalks, with seating, greenery, artwork, restaurants, and shops. Some are more residential (Jeanne d'Arc Court) and others are more commercial. Clarendon Court, between George and York Streets, is the most active of the four. At ground level there is a mixture of restaurants, boutiques and a cafe, adjacent to an arts school on George Street. At this end, the Courtyards roughly line up with Freiman Mall, a passage 
through the Bay department store, from Rideau Street and the Rideau Centre. Going north from Clarendon Court the passages gradually shift closer to Sussex Drive ending across the street from the National Gallery of Canada. Pedestrians often shift onto Sussex Drive at York Street, likely due to the difficulty of navigating the mid-street parking lot along York Street. The entrance to the Jeanne d'Arc Court across York St. may also not be apparent to people that are not familiar with the area.

\section{ROOM FOR IMPROVEMENT}

Aside from the spaces controlled by the National Capital Commission (i.e., Sussex Drive and the Courtyards directly to its east) there is a noticeable lack of public seating throughout the Market area. Although there are many designated patio spaces associated with restaurants, these are fenced off and reserved for patrons. The general public is left to search for a rare ledge or something to lean against, should they wish to sit or rest while in the Market. While the lack of seating may be intentional due to the homeless population (who William Whyte has described as 'undesirables'), tourists and local users are also disadvantaged. Given limited resources to patrol the urban public realm, many cities opt not to provide seating that might attract undesirables. In part, this issue can be addressed through the idea of privately owed public space, where individual owners may be better able to monitor such spaces. Closer at hand than the examples provided in Midtown Manhattan are the Sussex Courtyards, where shop owners and residents have control over what goes on but 
where spaces are extended to the public at large, beyond the patron-only mentality. This same idea can be extended and built upon for the greater ByWard Market pedestrian network.

While the Market is largely retail-driven, a thoughtfully designed pedestrian network would add to leisure space within the urban environment, encouraging use of the public space beyond the typical commercial draw.

Adding to the existing through-block routes would create the finer-grained urban fabric that promotes interaction and builds community. Additional pedestrian circulation would also aid in increased patronage to adjacent businesses.

An improved pedestrian network through the ByWard Market would add to and strengthen the area's identity as a pedestrian-focused zone. More integrated public parking facilities, concentrated around the edges of the area, along with existing transit connections, will aide in the reduction of traffic and parking problems within the Market. Promoting cycling in the city and providing bike parking spaces can also help.

The width of York and George Streets coupled with the low buildings along them, gives the appearance of the street being vast and barren. More plantings and streetscaping could soften their appearance and strengthen their character. The somewhat ad hoc street network in the area makes crossing these streets confusing and difficult, particularly around the market building. In addition to through-block passages, a well-designed pedestrian network must include interesting, safe and legible ways to incorporate crosswalks. 


\section{What the City Wants}

Many of the proposed changes and aspirations outlined for the ByWard and Lowertown (between Dalhousie St. and King Edward St.) areas in the City of Ottawa's Official Plan (2003) are consistent with this pedestrian network plan I am proposing. The following is a summary of some of the key points from the Official Plan.

\section{The Market:}

- Maintain and increase predominately pedestrianoriented commercial use at street level.

- The pedestrian courtyards are to be enhanced and expanded with new infill.

- Parking should be incorporated into mixed-use buildings, ideally located near edges of the ByWard Market area, limiting surface parking and encouraging pedestrian traffic through the area, not vehicular.

- The ByWard Market parking structure is to be designated as the site of a future "landmark public building".

- The designation of York Street as a "distinctive street" and the main east-west promenade through the Market

- Maintain the low profile of buildings near the market centre and important view lines.

- Overall improvement of the public realm.

\section{Lowertown:}

- Maintain predominantly residential use with limited commercial use on Cumberland, Murray and St. Patrick.

- Maintain and enhance community facilities, services, 
spaces for interaction (including courtyards and small parks).

- Soften harsh street environments through streetscape design and tree planting.

- Waller Mall should be animated and connected to pedestrian corridors.

- York St. becomes a main pedestrian corridor, linking the east side to the ByWard Market. 


\section{THE PEDESTRIAN NETWORK}

Where does a path lead from and go to? A path should be positioned so as to encourage more intuitive pedestrian use by connecting known origins to likely destinations. Circulation should be the primary raison d'etre of a throughblock passage. When separated from the street, public space should be complimentary to the existing road network and not compete with it and businesses and services should continue to front onto adjacent streets, in addition to migrating into pedestrian passageways, some businesses may be entered from both the street and the passageway. These passageways should be an extension of the sidewalk space, enhancing pedestrian circulation in the city. Entrances to these spaces should be easily visible, inviting and accommodate sight lines though their length. Shorter blocks are more conducive to pedestrian circulation and are better able to support a mix of uses. Through-block passages divide large blocks in service of a more dynamic and integrated public environment. A mix of kinds of uses along blocks and passages will attract people to an area throughout the day and into the night, helping to assure that it does not become deserted for extended periods of time.

The first step in creating this network for the ByWard Market is to identify where pedestrian paths might be established, building on existing routes (both formal and informal). After analyzing the Market area and taking into consideration current pathways, short cuts and potential paths that are currently blocked (including sites that are likely to be

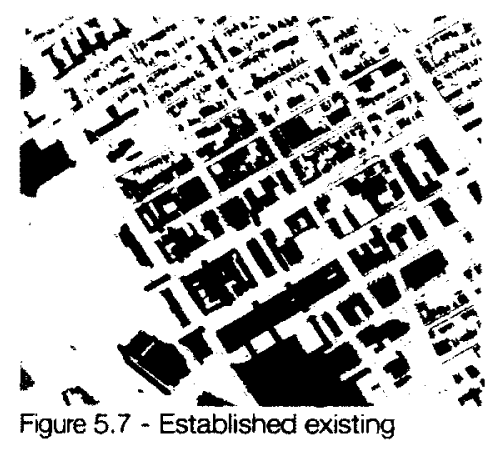
pedestrian paths

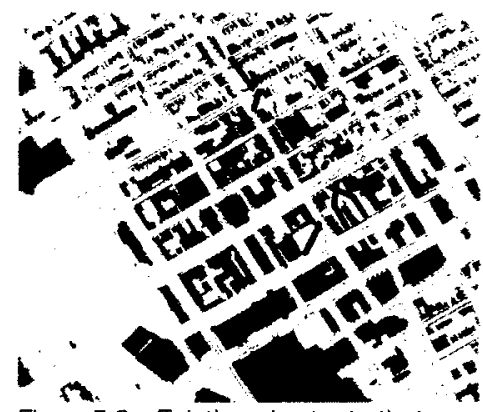
Figure 5.8 - Existing shortcuts that are not designated paths

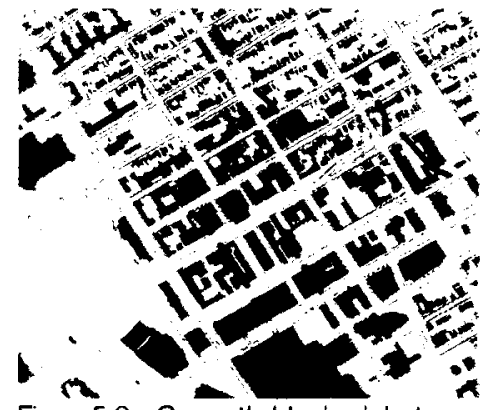
Figure 5.9 - Currently blocked, but potential pathways

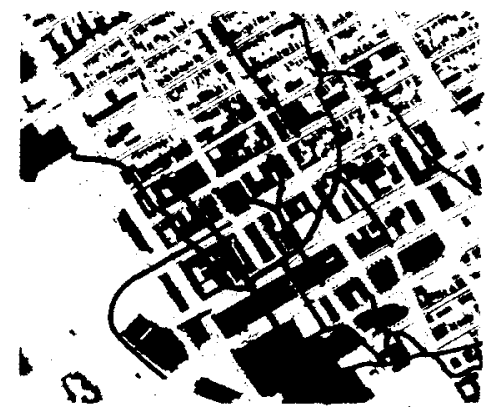

Figure 5.10 - The paths, shortcuts and potential connections combine together into a pedestrian network 
redeveloped), (fig. 5.7-5.9) I created a pedestrian network plan for the area, showing pedestrian movement through the blocks (fig. 5.10). There are several possibilities for new and improved pathways that would strengthen pedestrian connections throughout the Market.

There are several instances in the network where pathways converge with sidewalks and many places where they intersect. Sidewalks are, in most instances, the most important element of an urban pedestrian network - even a network that includes pedestrian streets and mid-block paths. As many of the sidewalks in the ByWard Market are in need of upgrading, any proposal for a pedestrian network must include improvements upgrades and improvements. For the purposes of this study, however, I have focused on spaces that are not currently in the public realm - with a particular emphasis on through-block paths across privately held land (e.g., parking lots and vacant lots).

A successful pathway system must begin with an understanding of 'desire lines', i.e., routes between major origins and destinations. When comparing the potential origins and destinations with existing paths and shortcuts through the Market, existing spaces can be linked together to form routes. Looking at the network plan, paths often jog diagonally across the Market from southeast to northwest, with a few on the opposite diagonal. Instead of imposing a network on the area, I propose to interpret, extrapolate and interpolate on existing patterns of pedestrian movement in the Market. The establishment of such pathways and shortcuts 
will be used to form "rights of way" that are designated for public access through agreements and incentives between the City and land owners. They will provide a blueprint for a lasting pedestrian network.

Path segments for the network:

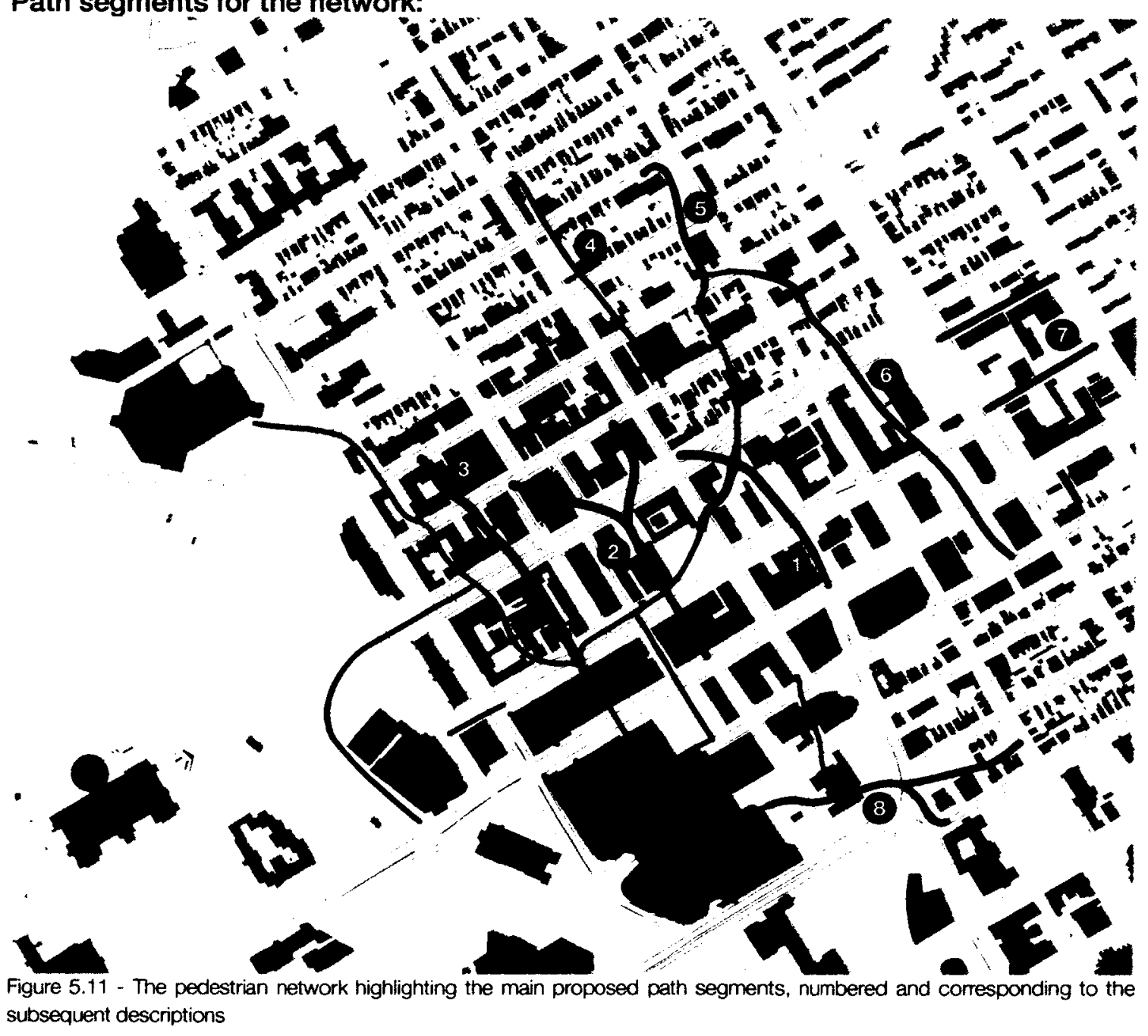


From the network map, I have identified eight potential segments for the pedestrian network and have described the locations and features of each:

\section{Segment 1}

- Extends north from Rideau St. through Waller Mall, then through a surface parking lot to York Street, near Dalhousie Street.

- Waller Mall is a pedestrian path between Rideau and George Streets. There are several "no loitering/no trespassing" signs along it.

- There is a connection going west, from the main block, to Dalhousie and through the hotel parking lot, towards George St. and the Market Building If the hotel site (on the west side of Dalhousie) is redeveloped the path could continue west through that block.

- There is a large amount of open space along this segment that is currently being used for parking.

- There are a variety of housing types near by (Condos, townhouses, working class, middle class).

- Waller Mall essentially connects two homeless shelters which could be a problem or an opportunity to improve public space for the whole community.

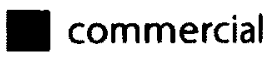

arts+culture

hotel

residential

social housing+shelters

$\square$ intersecting open areas

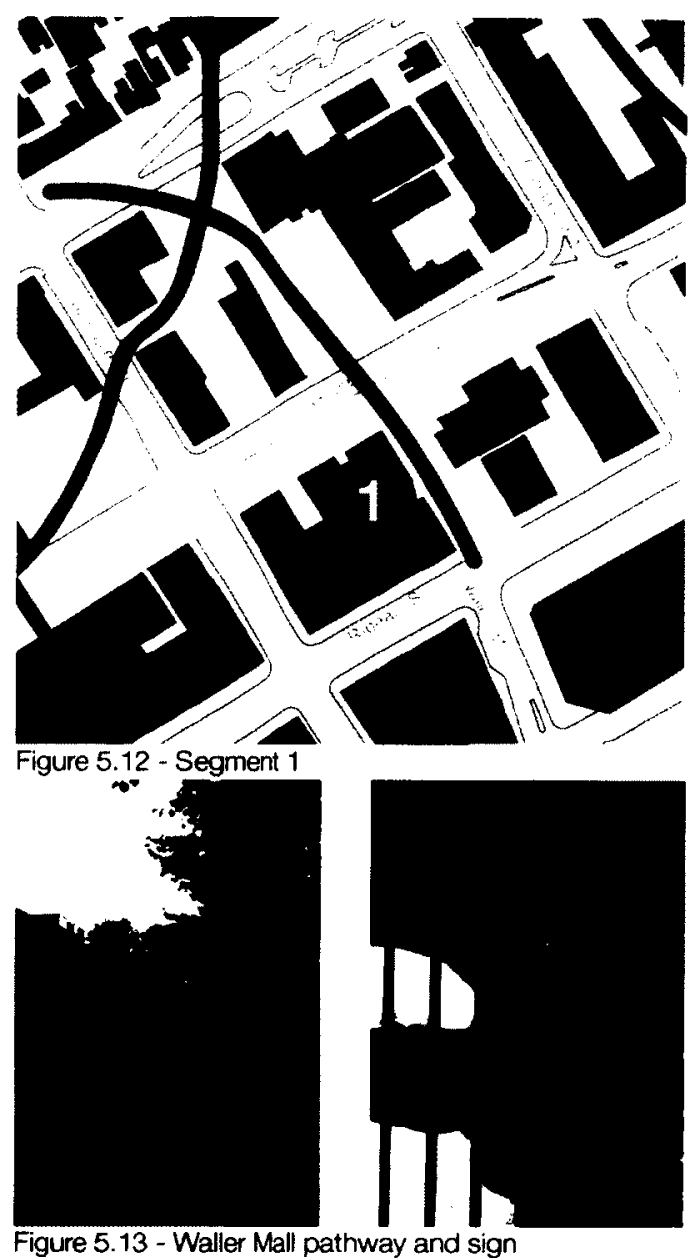

Figure 5.13 - Waller Mall pathway and sign

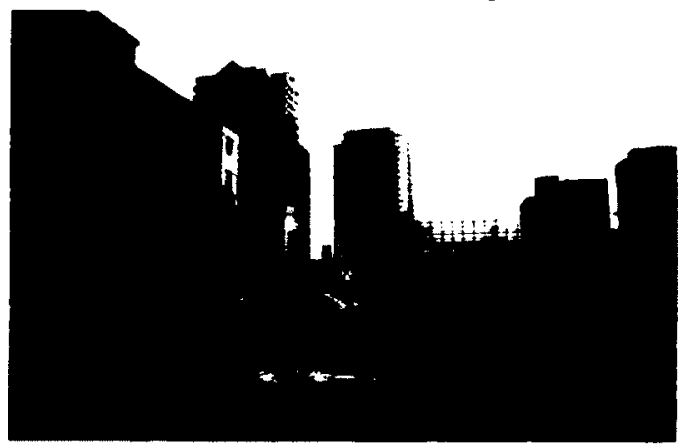

Figure 5.14 - View of path location, looking south from York St. 


\section{Segment 2}

- Proposes to re-open the passage through the A-Channel building to the public, with a potential southern connection through the ground level of the 90 George Condo building, to Rideau St.

- North connections could be possible to the east and west: one to Clarence St. and one to the current site of the ByWard Market parking structure.

- Redevelopment of the parking structure could allow for further extension of this path segment.

- Redevelopment of the hotel site (at the corner of Dalhousie and York could enable a better east-west connection through to Segment 1.

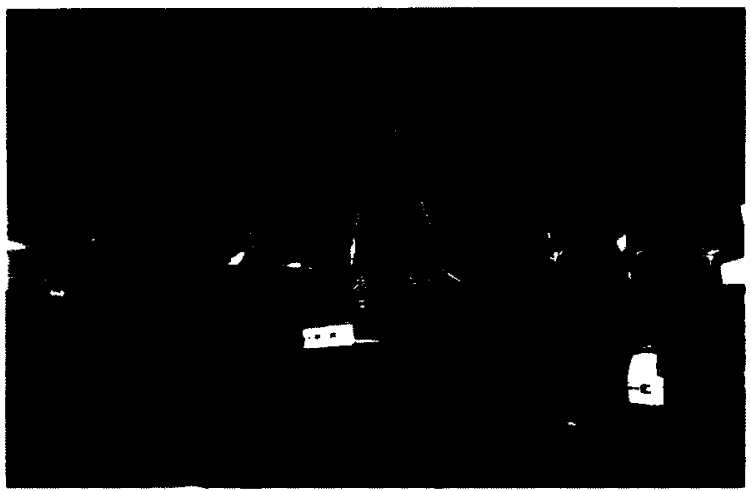

Figure 5.15 - The A-channel Media Market Mall - from in front of 90 George Street

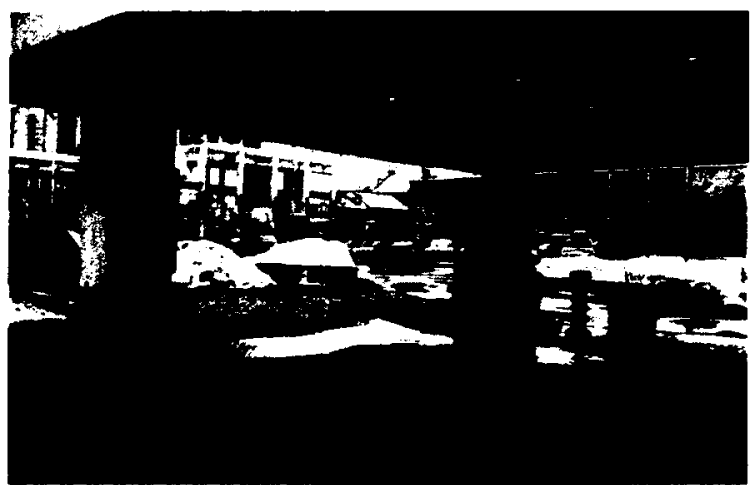

Figure 5.17 - View across hotel parking lot - from Dalhousie, towards George

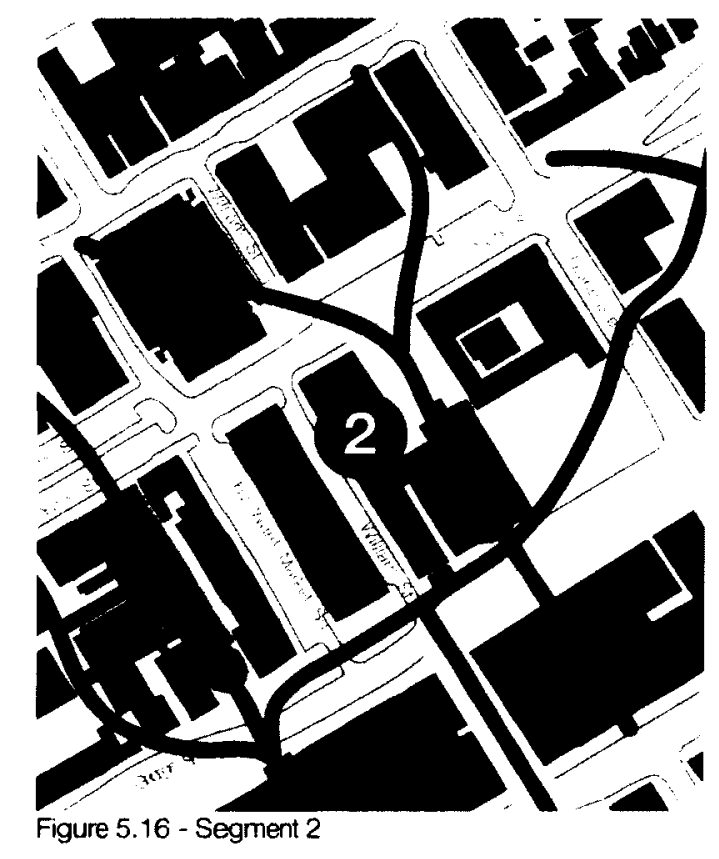

Figure 5.16 - Segment 2 


\section{Segment 3}

- Extending from Freiman Mall (between Rideau St. and George St.) and north through three blocks to Clarence St., this segment would go through the existing parking structure site and vacant lots that align with Freiman Mall. To the south, Freiman Mall connects to the Rideau Centre and through it to Mackenzie King Bridge.

- The development of the main block between George and York would be

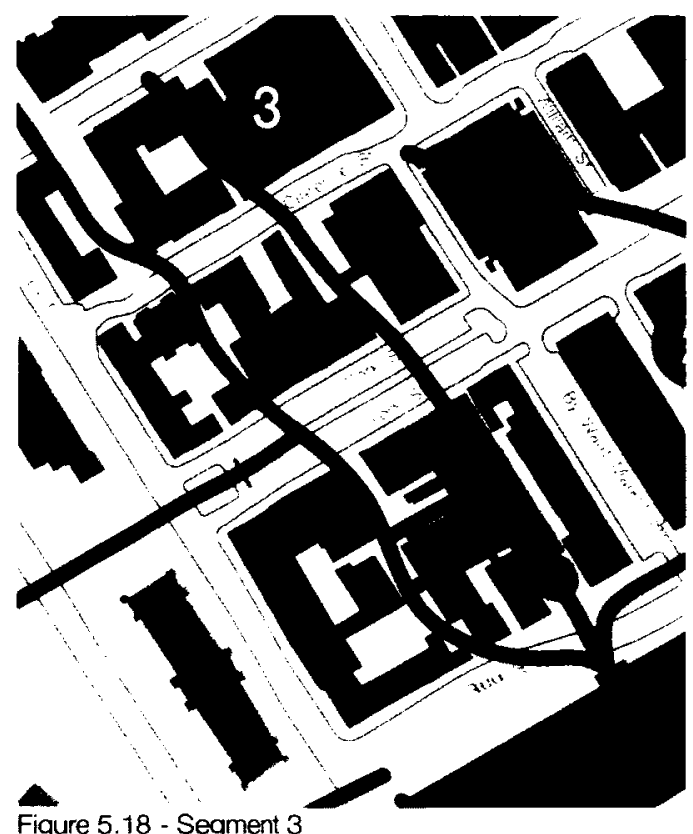
dependant on the removal/re-development of the parking structure.

- This is the high-end area of the Market containing many expensive stores, restaurants and small galleries (in addition to the National Gallery).

- This pathway is adjacent to the Sussex Courtyard system, which presents the possibility for connections with the Courtyards.

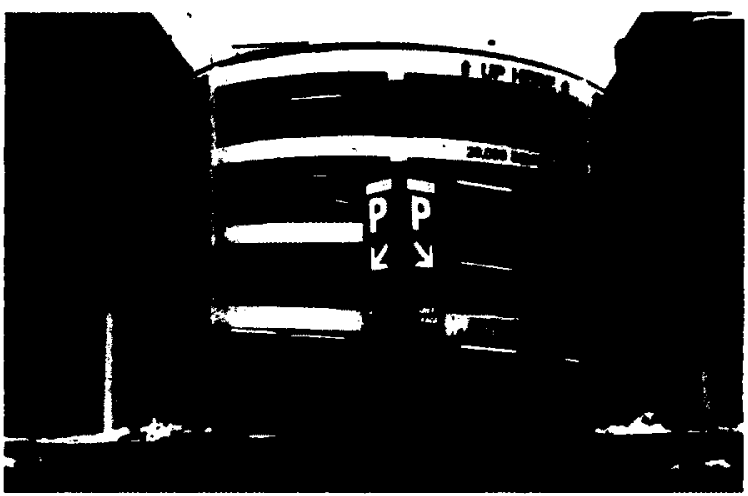

Figure 5.19 - Parking structure - from George Street

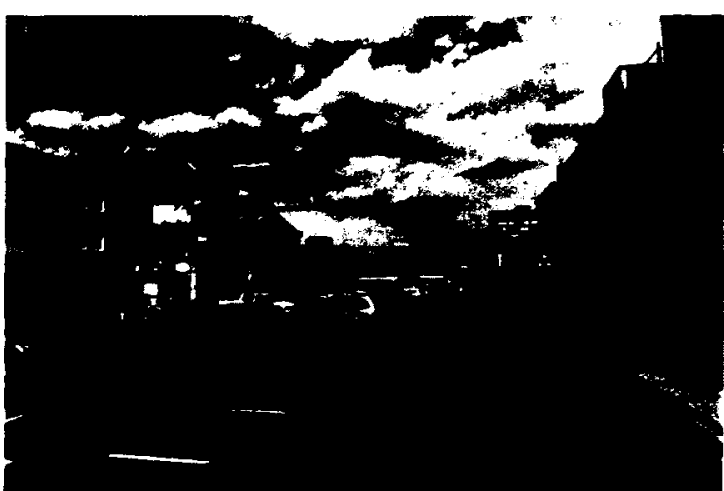

Figure 5.20 - York St. - looking east, with the other side of the parking structure on the left 


\section{Segment 4}

- This is a north-south pedestrian pathway from Clarence Street to St. Andrew, just east of Dalhousie.

- Development along Dalhousie could also face onto the pedestrian space behind.

- There are several trendy retail shops along the adjacent stretch of Dalhousie and mainly low scale retail on the east-west streets.

- Proximity to Dalhousie may be too close to support a secondary public space.

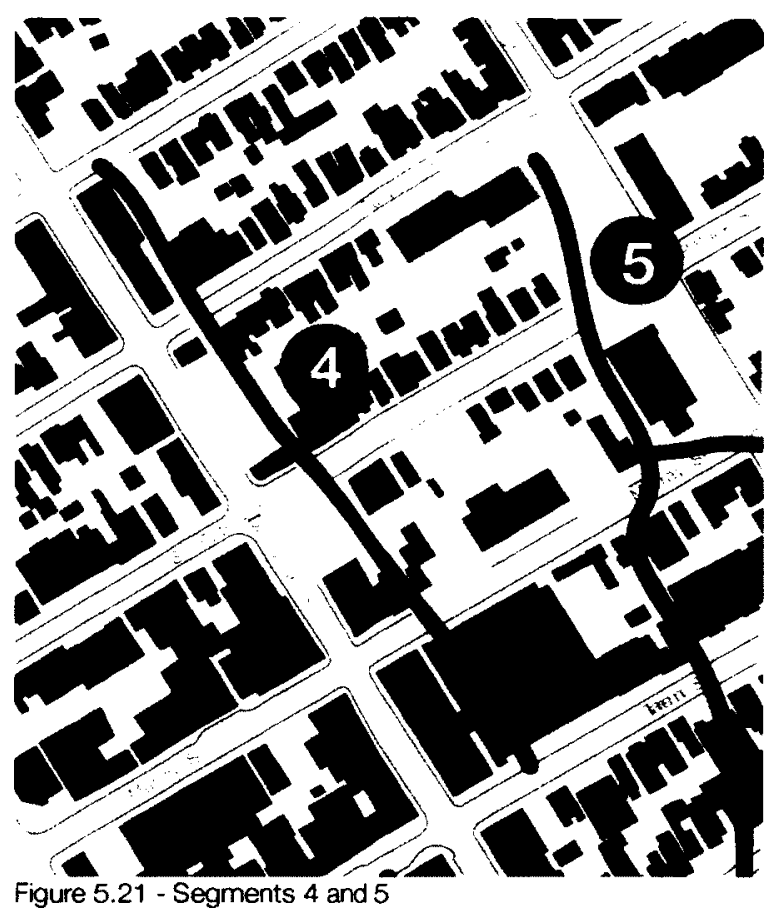

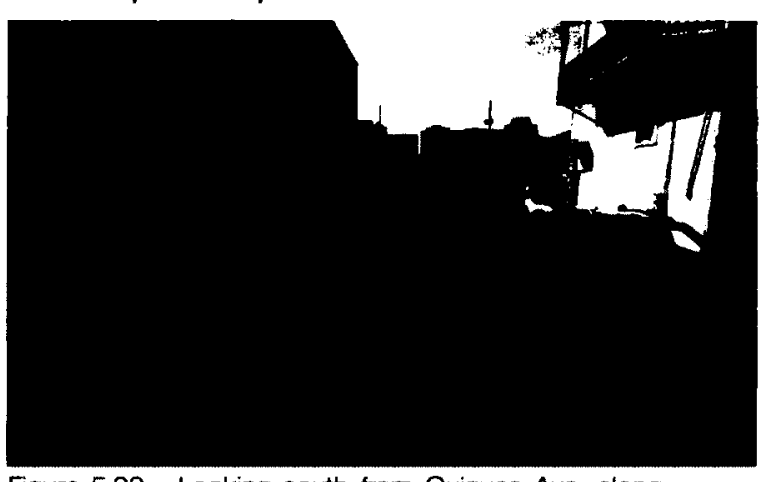

Figure 5.22 - Looking south from Guigues Ave. along potential network path (Segment 4)

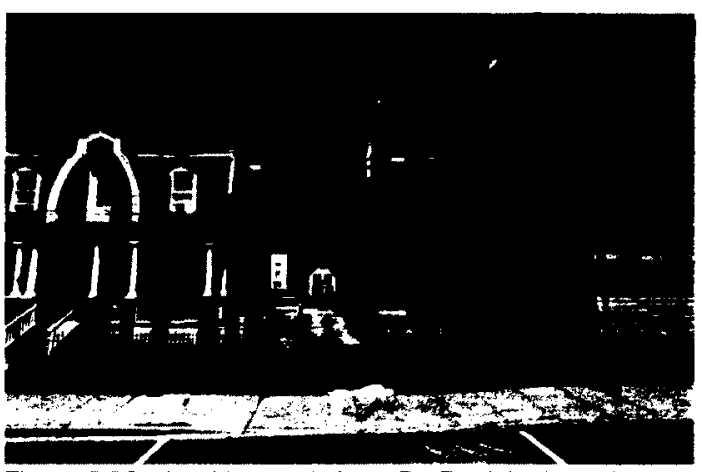

Figure 5.23 - Looking north from St. Patrick along the west side of St. Brigid's Centre for the Arts (Segment 5)

\section{Segment 5}

- This segment creates a pedestrian pathway from the Routhier Community Centre on Guigues Ave. south to St. Brigid's Centre for the Arts.

- Would connect to the north end of Segment 6 at Murray St.

- Potential for future connection south through two residential blocks, linking with the north end of Segment 1 at York St. 


\section{Segment 6}

- Connects from Besserer St. through a vacant lot to Rideau St., then between the LCBO and grocery store parking lot and between various buildings up to York St.

- There is also potential further connections north to Murray St. at Cumberland St., ending near St. Brigid's.

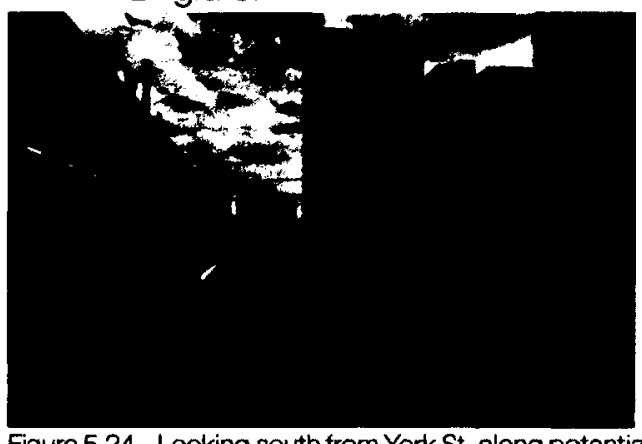

Figure 5.24 - Looking south from York St. along potential path location. There is a government building on the left and condos on the right.

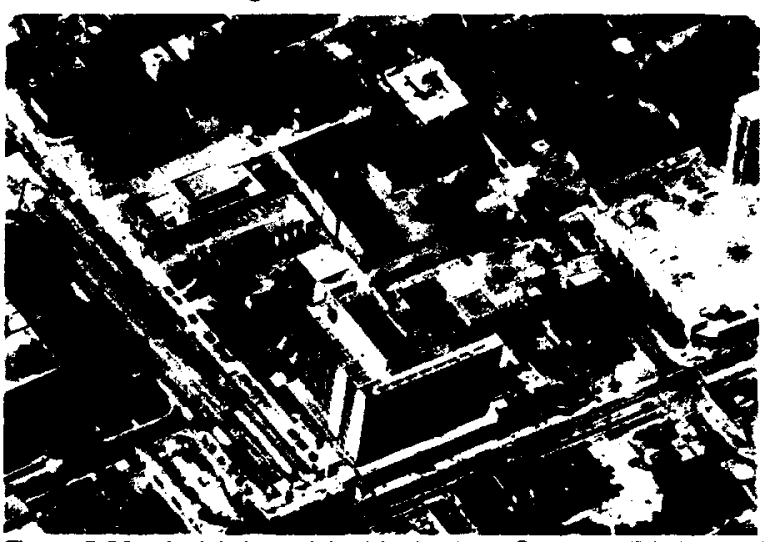

Figure 5.26 - Aerial view of the block where Segment 7 is located

\section{Segment 7}

- There could be two east-west pathways through this large block of scattered buildings and parking lots.
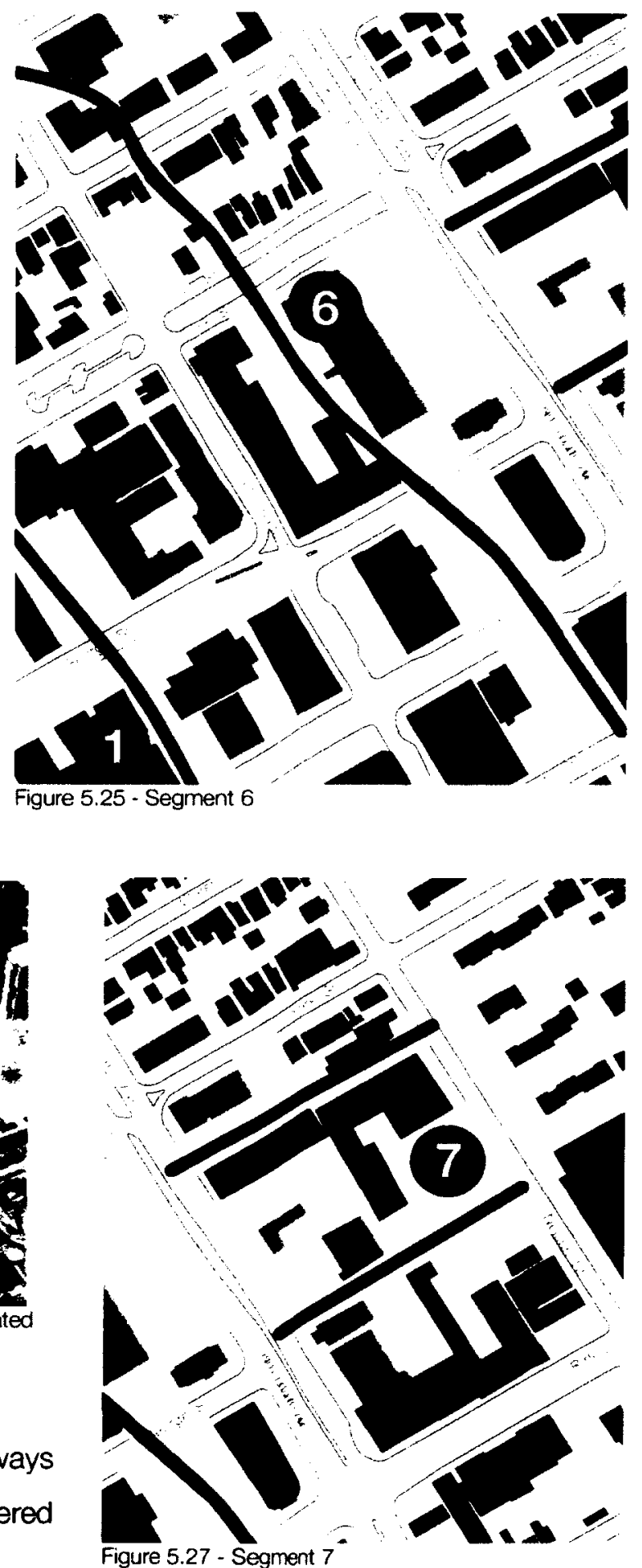

Figure 5.27 - Segment 7 
- The lower path would connect Lowblaws to King Edward Ave. and align with George St. The upper path would connect a residential area to King Edward near York St.

- There is potential for future redevelopment throughout the block and one or both of these pathways could be incorporated.

\section{Segment 8}

- Connects through the Arts Court site, from the University of Ottawa campus to the Rideau Centre.

- There are redevelopment plans currently in progress for the Arts Court site with the intent to incorporate pedestrian paths.

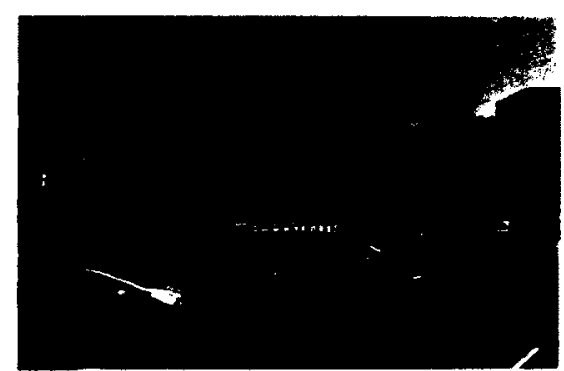

Figure 5.28 - The Arts Court building from Nicholas St, at Daly Ave.

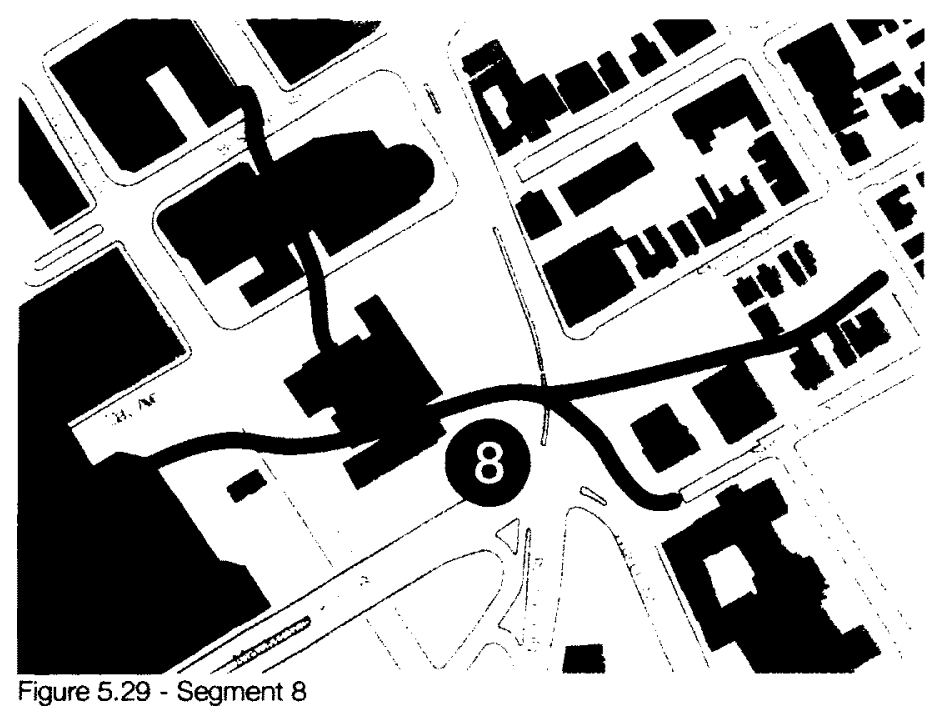

While most sites along the network would remain under private ownership, incentives or other agreements with the City would make them accessible to the public with the understanding that they would be maintained by the owner according to guidelines and regulations enforced by the City. This would ensure a standard of quality, design, and safety for the publicly accessible areas. 
For the purposes of this study I have focussed on the paths that traverse the long east-west blocks separating George and York Streets, and will then look at one block in particular to display the ideas further. The City has designated York Street as a main east-west axis and pedestrian route through the Market. The points where proposed pathways intersect York St. have the opportunity to become nodes along the street. Although different in character, the three main paths that go between York and George (Segments 1, 2,and 3) are similar in their orientation and points of intersection with the street. The development of Segment 3 through this block would depend on the redevelopment of the parking garage site. With the removal of the parking garage

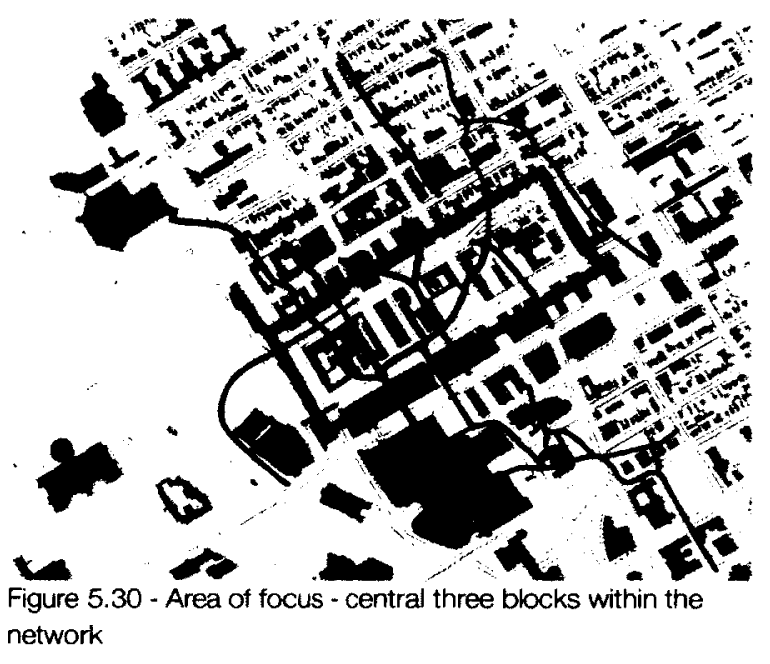
a connection between Segment 3 and the existing adjacent courtyard would be opened. There is also opportunity for an east-west link between Segments 1 and 2, crossing Dalhousie Street, if the hotel site is redeveloped. Within the segments of the network there are primarily three types of space; mid-block passages, mid-block nodes (often where paths intersect), and street-crossings (where paths intersect the grid of streets and sidewalks). Mid-block passages can be both through and between buildings (interior and exterior). In order to better define the path spaces and designate buildable areas, I have identified build-to lines that limit the encroachment of adjacent buildings on these designated rights of way. The implementation of these build-to lines along 
with right of way enforcement will ensure that the pedestrian

paths remain open and accessible as the surrounding neighborhood transforms.

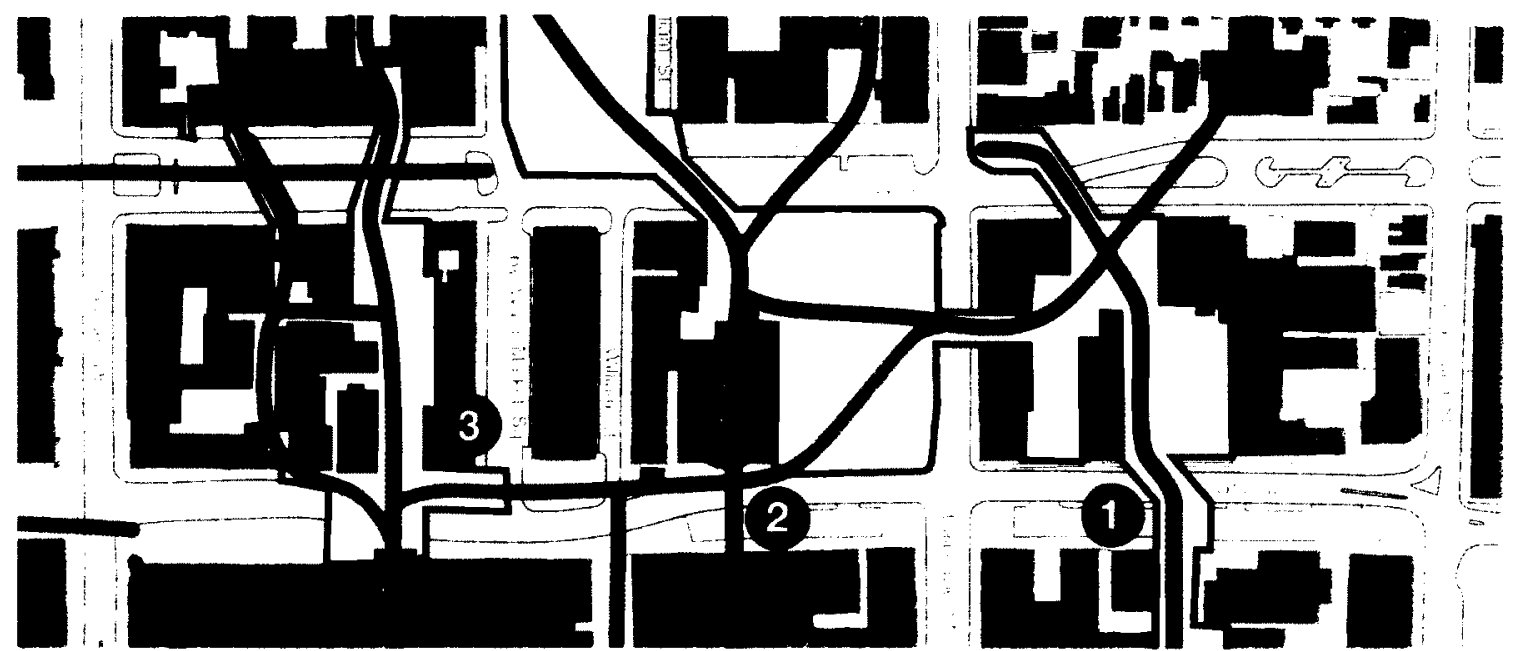

Figure 5.31 - The Network: the pedestrian paths going through the three central blocks and the adjacent open space. Segments of focus shown in dark orange.

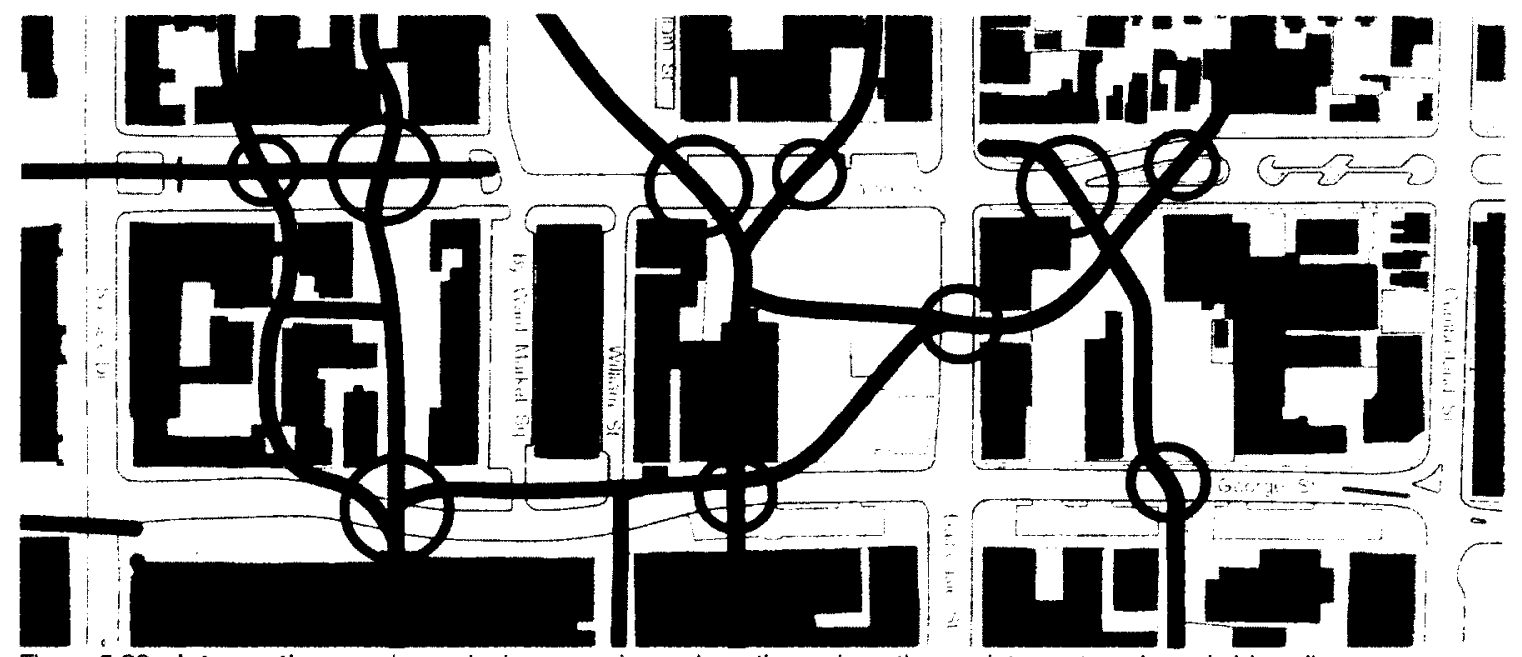

Figure 5.32 - Intersections: major and minor crossings where the main pathways intersect roads and sidewalks. 

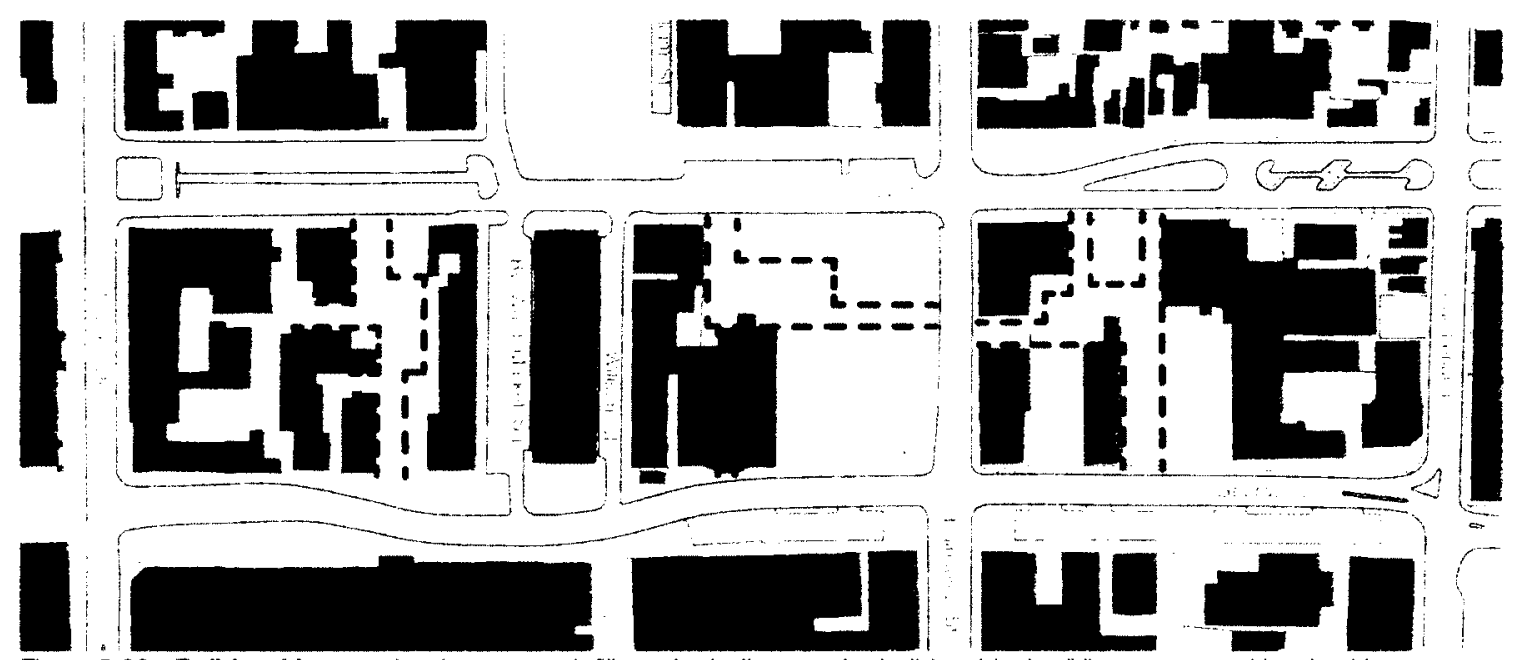

Figure 5.33 - Build-to Lines: redevelopment or infill can be built up to the build-to (dashed) lines at ground level, with the resulting open space being for the pedestrian network.
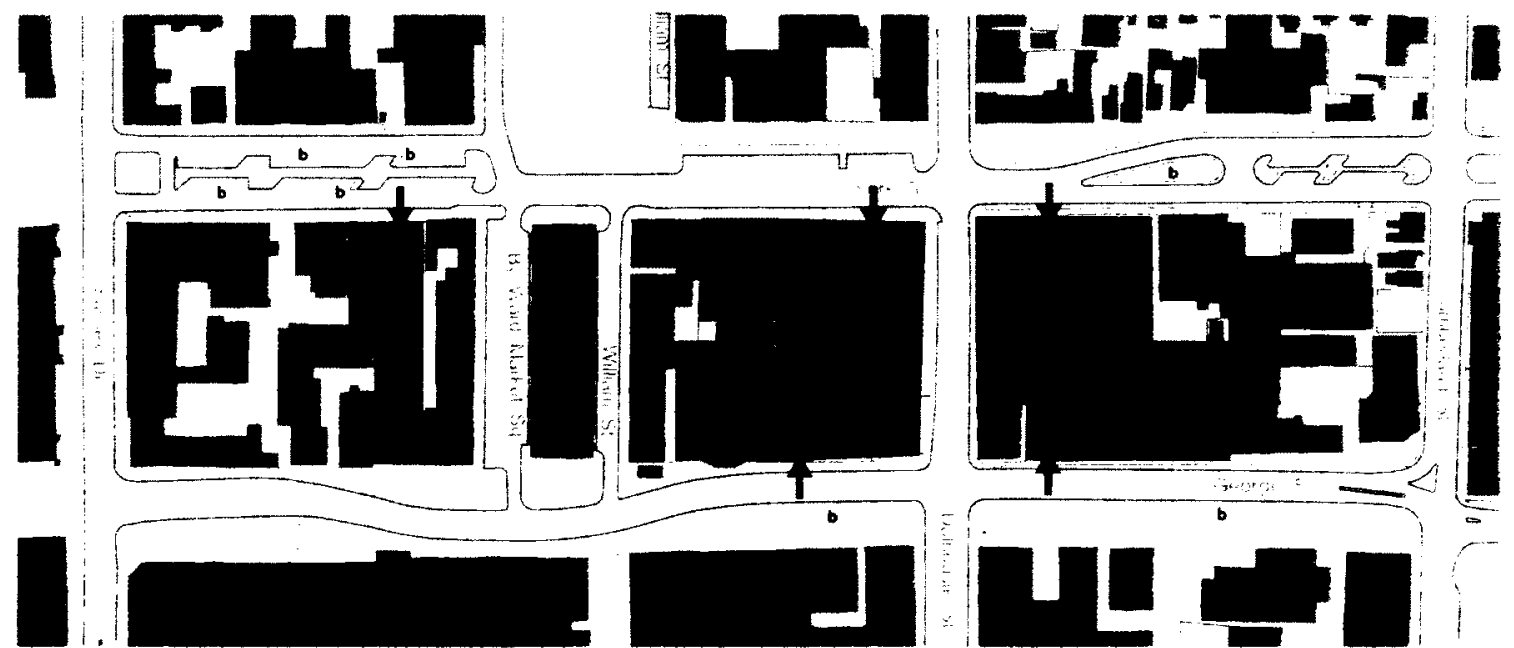

Figure 5.34 - Parking: the sites of development or re-development also represent locations for the integration of underground public parking. Removed surface parking along George and reconfigured parking along York, with designated bicycle parking 


\section{THE SITE}

[Segment no.1 Between York and George Streets, east of Daihousie ]

Based on current conditions, Segment 1 - from Waller Mall north to York St. at Dalhousie - is likely the easiest to realize at this time. As such, it will be used as a "proof-ofconcept." No buildings would need to be moved or changed to accommodate the path as the site is currently being used as a parking lot. This site will be used to develop guidelines and steps for the implementation of the greater network, demonstrating the essential process that would be used to create all network spaces.

This block is currently occupied by a variety of uses: two bars, an office building (recently bought by a developer), an organic market, Salvation Army, and a few restaurants and shops along Dalhousie. There is also some low and mid-rise housing within the same block, just east of the proposed location of the throughblock passageway. The open areas of the site are currently used for parking, spanning from George Street to York Street and there currently is a blocked-off driveway between the tall office building on Dalhouse at York, and the low-rise restaurants/shops on Dalhousie. The zoning of this block allows for a much greater density than

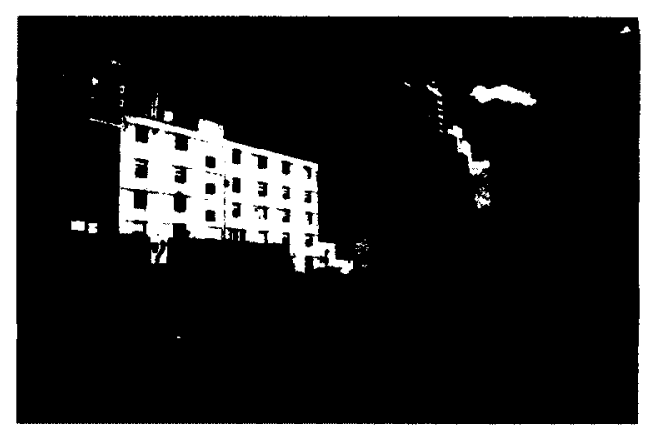

Figure 5.35 - Looking at the site from York Street

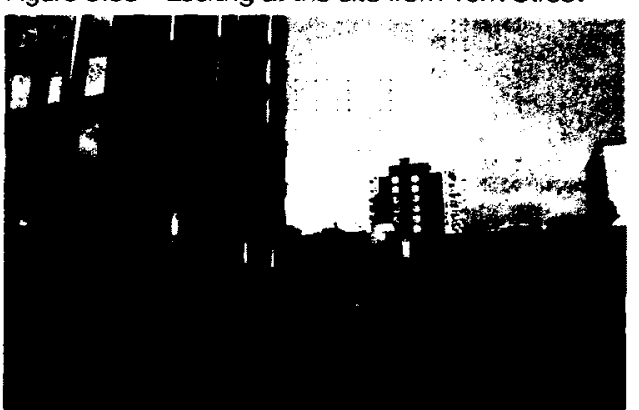

Figure 5.36 - Looking at the site from Dalhousie St.

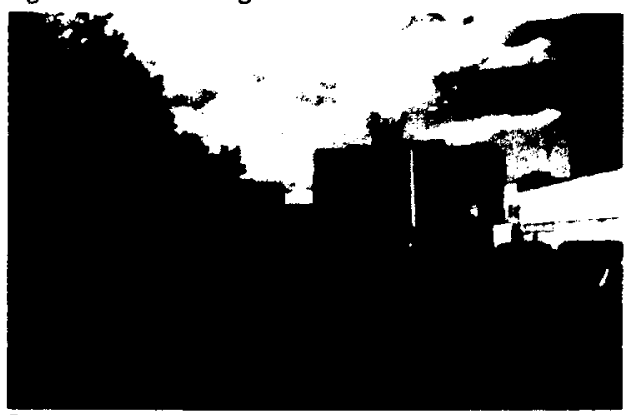

Figure 5.37 - Looking at the site from George St. 


$$
\vec{x}
$$


Residential Zone

Mixed Use Downtown Zone

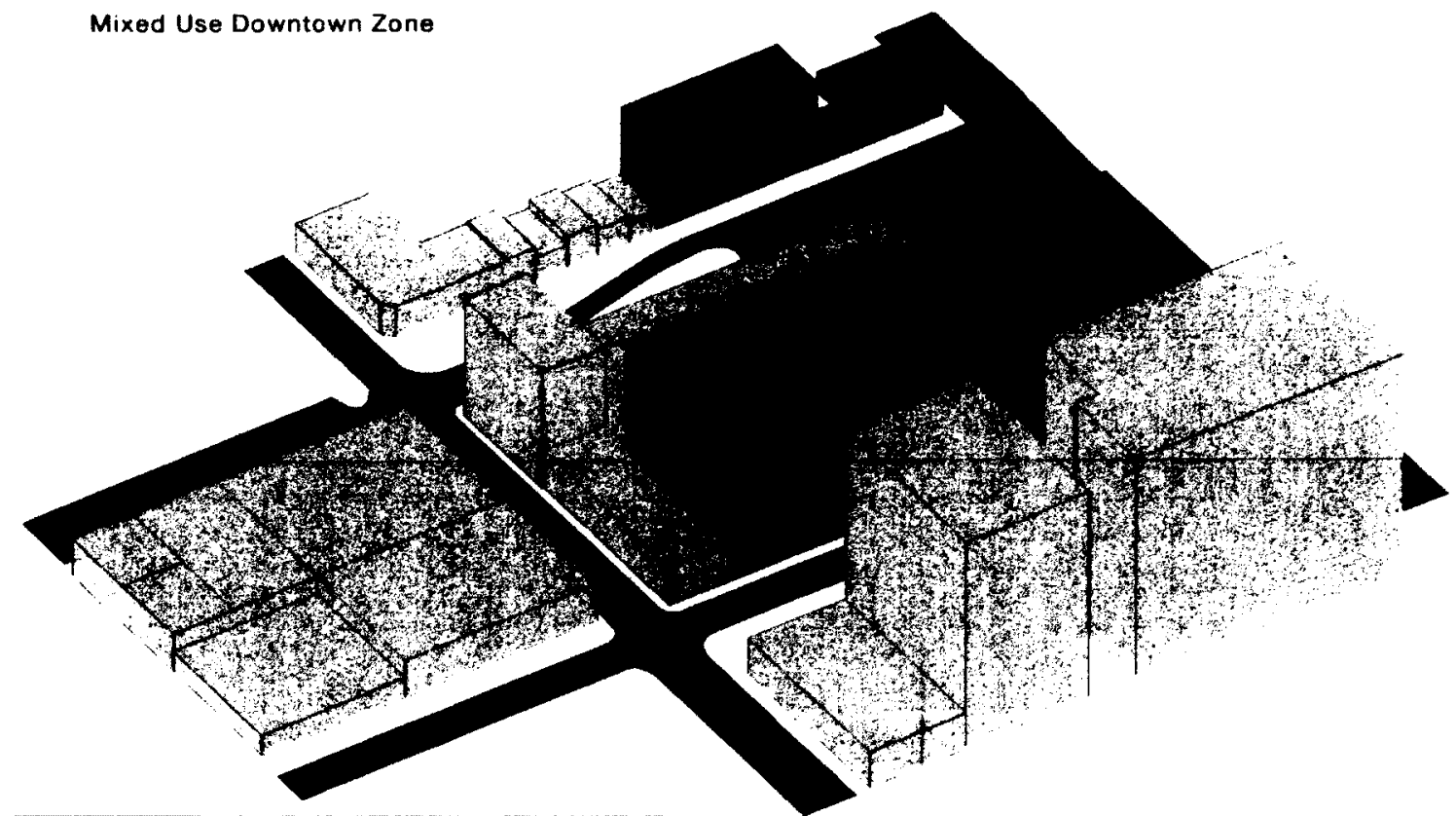

Figure 5.40 - Massing with zoned uses currently allowed in the Ottawa ByLaws

what is currently built, with areas of the site zoned as both Mixed-Use Downtown and Residential Fifth Density (which allows for mid to high rise residential buildings to be built). Some re-zoning or revisions to current zoning may be required to ensure public-oriented services and commercial uses are maintained at ground level.

\section{A Closer look at Segment 1}

I chose to elaborate on a portion of Segment 1 in order to better identify issues, formulate design guidelines, and articulate a phased system of implementation for an expanded pedestrian network. See Fig. 5.12. 
In principle, Segment 1 begins as far south as the University of Ottawa, corresponding to the path taken by students between campus and the Market area. Students heading into the eastern portion of the Market frequently walk down Waller to Rideau St. This portion of the pedestrian route is in need of major upgrading. The combination of heavy truck traffic and extremely narrow sidewalks along Waller St. makes this route as dangerous and unpleasant as it is convenient.

Crossing Rideau St. at a traffic light, Waller St. becomes a pedestrian mall. Along with William St. and the right of way through the Hudson's Bay Company to the east, Waller Mall is one of three "recognized" pedestrian routes connecting Rideau and George Streets. A fourth route, through the Chapters bookstore, is heavily used when the store is open and I have proposed a $5^{\text {th }}$ passage, namely a route though the 90 George condo building, as part of Segment 2 (see Fig. 5.16).

Waller Mall, owned and operated by the City of Ottawa, is currently gated off between the hours of $11 \mathrm{pm}$ and $5 \mathrm{am}$. The blank walls along the west side of the path could be painted with murals or used to display art or installations until such a time as the stores behind them are renovated to include entrances and windows onto the mall. I am

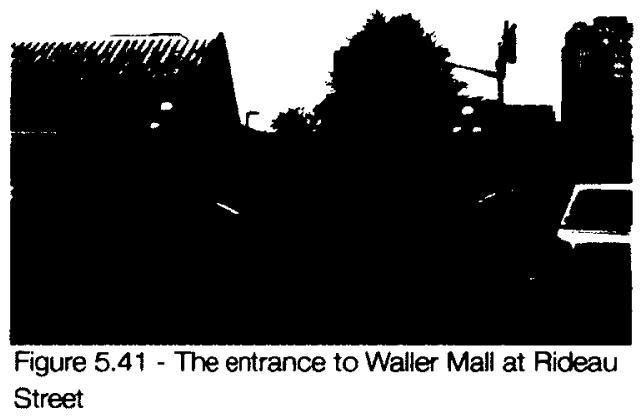
recommending bicycle parking along a widened sidewalk on the south side of George St.

Segment 1 includes a new pedestrian crosswalk at George St. at the northern end of Waller Mall. Rather than 
a stop sign or stoplight, I would recommend

a blinking yellow light (if necessary) with a sign indicating that cars are to stop for pedestrians. Alternatively, the surface of the crosswalk could be raised to create a speed table. The crossing would be further denoted by a series of reflective dots organized in diagonal bands to be recognizable as zebra crossing.

A prominent info board would be placed across George St. opposite Waller Mall to invite pedestrians into the sequence of mid-block spaces proposed for the vacant lots between George and

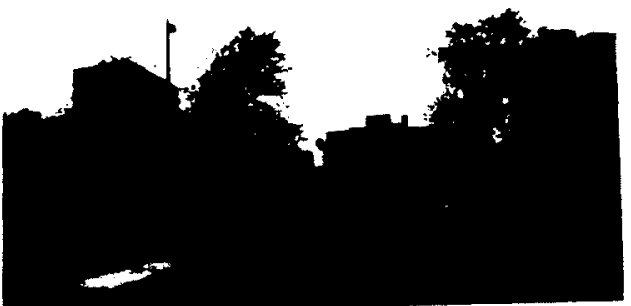

Figure 5.42 - The other end of Waller Mall at George Street with the parking lot across the street

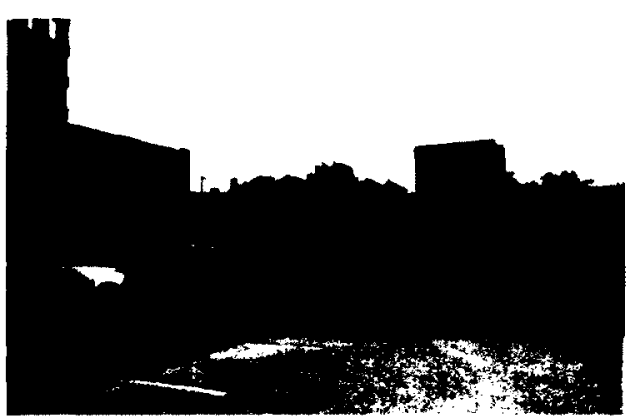

Figure 5.43 - Approaching York Street from the parking lot

York Streets. Signage would not only list the names of businesses, etc. accessible in the mid-block spaces, but would provide maps of the larger pedestrian system through the Market. Signage should be a key part of a larger branding exercise for this network.

As described below, Segment 1 proposes a phased transformation of what are currently a series of parking lots between George and York Streets. Throughout all phases of the transformation, buildings facing onto these mid-block spaces would include public-oriented retail and services at ground level, encouraging use of the spaces for more than just circulation. Were it possible for a community centre to be built along George St., the centre could play an active role in programming activities in the spaces, reinforcing the open and public nature of the network. Seating, planters, and trees throughout the spaces will help to create a more 
inviting environment. The proposal, further described in the following section, also includes connections to Dalhousie St., anticipating that the hotel on the west side of the street will be redeveloped in the not-too-distant future. Pedestrian crosswalks - similar to the one proposed for George St. - will be provided where the mid-block pedestrian system connects to Dalhousie and York Streets.

Given that they occur on private property, the proposed improvements and publicly accessible rights-ofway along Segment 1 between George and York Streets will require agreements between the City and the landowners. These are necessary not only to set aside the spaces for public use - the terms of reference for which would need to be negotiated - but to promote high-quality design and to ensure safety standards. Claridge Homes owns much of the property in question. As per the development application filed with the City of Ottawa in December 2012," Claridge's plans are quite congruent with my vision for the site. They have proposed that the office tower on the corner of Dalhousie and York Streets be converted into a hotel and that a new condo tower (with ground floor retail) be constructed on the lot currently occupied by the Honest Lawyer. The developer's plans include a mid-block pedestrian path connecting George and York Streets, along which is a small courtyard. As per my proposal for Segment 1, the developer has also incorporated an east-west access to Dalhousie St.

Although, for the purposes of this exercise, I assumed

\footnotetext{
* See <http://app01.ottawa.ca/postingplans/appDetails.jsf?lang=en\&appld=_8E3BLV>. Note: this development application appeared well after the majority of work on this thesis had been completed.
} 
that the heritage overlay would preclude a discussion of density bonusing, the development application includes a request for heights close to $20 \mathrm{~m}$ higher than what current zoning allows. 


\section{THE PROCESS OF IMPLEMENTATION}

The implementation of pedestrian pathways would be done in phases, allowing for a more natural integration into the city and into the everyday lives of people in the Market. The Phases are:

Phase 1: Path Indication - visual identification of network path spaces

Phase 2: Occupying the Site - the introduction of elements such as seating, planters and popup shops

Phase 3: Infill - buildings are built along the designated path spaces and more permanent features are introduced

These three phases are flexible so that phases might change and overlap depending on need and the availability of the various sites within the greater network. The implementation of segments in the network can be concurrent or consecutive depending on the opportunities and forces at play. 

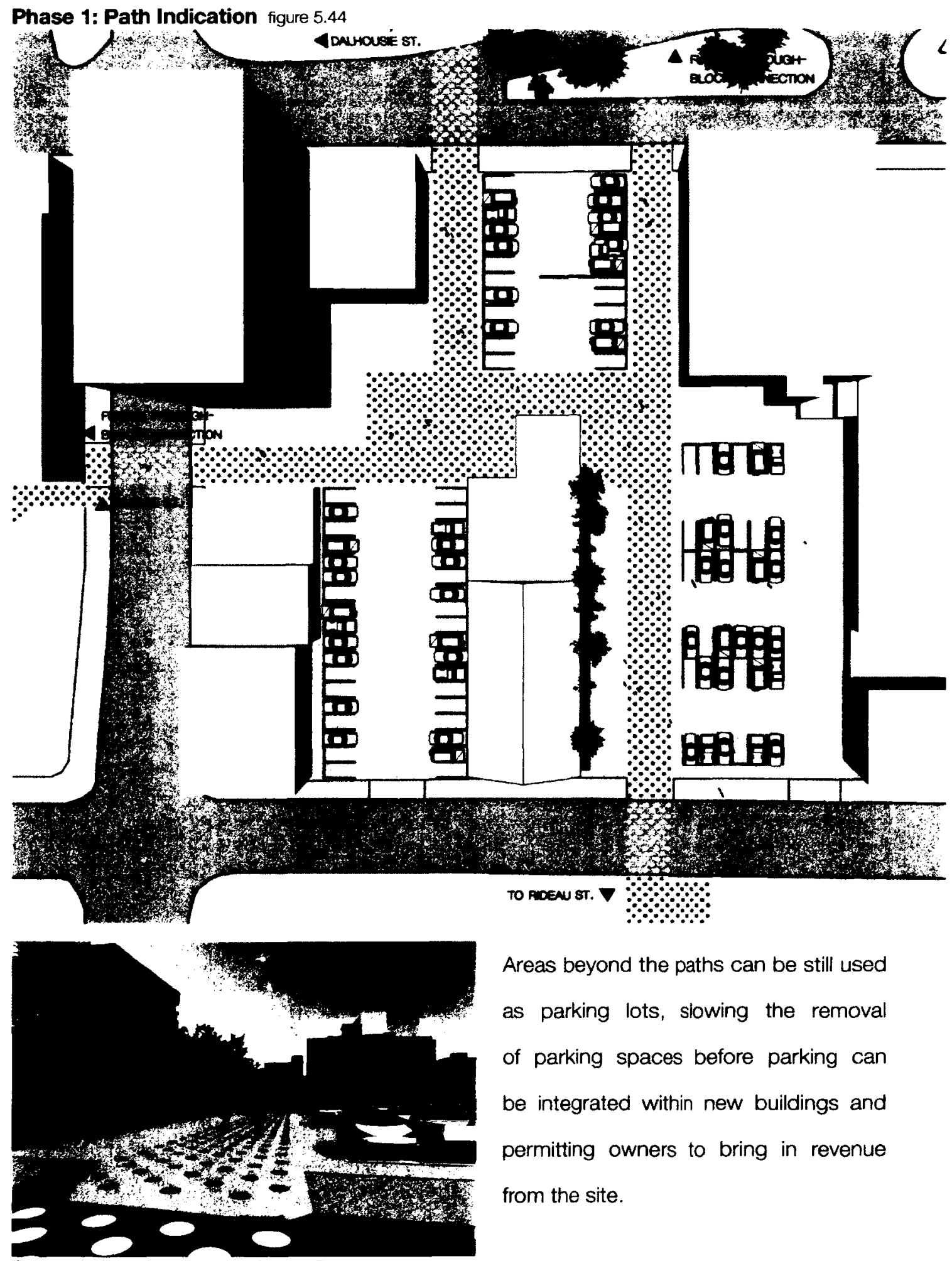

Areas beyond the paths can be still used as parking lots, slowing the removal of parking spaces before parking can be integrated within new buildings and permitting owners to bring in revenue from the site.

Figure 5.45 - Looking north from George Street 


\section{Phase 1: Path Indication}

After a cleanup of the area, (removing any debris, fencing, etc.) the path is to be identified by a pattern of red dots painted on the ground with a durable epoxy paint. This provides a visual cue to the public that a path is there. The dots would continue along the paths, crossing streets, making the path more visible to public and to passing traffic while giving an identity to the network. At street-crossings the pattern acts as a pedestrian crosswalk, and variations in the sidewalk and paving should emphasize this. On busy streets additional signage or lights may also be requited for a safe crossing. This establishes the paths within the urban environment.

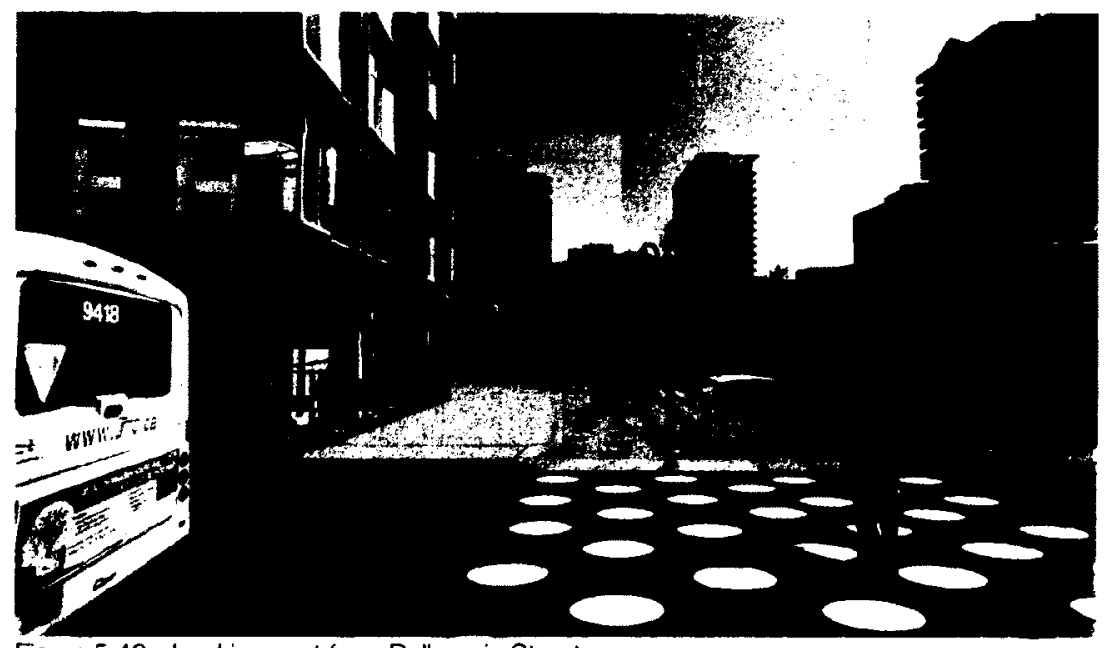

Figure 5.46 - Looking east from Dalhousie Street 
Phase 2: Occupying the Site figure 5.47

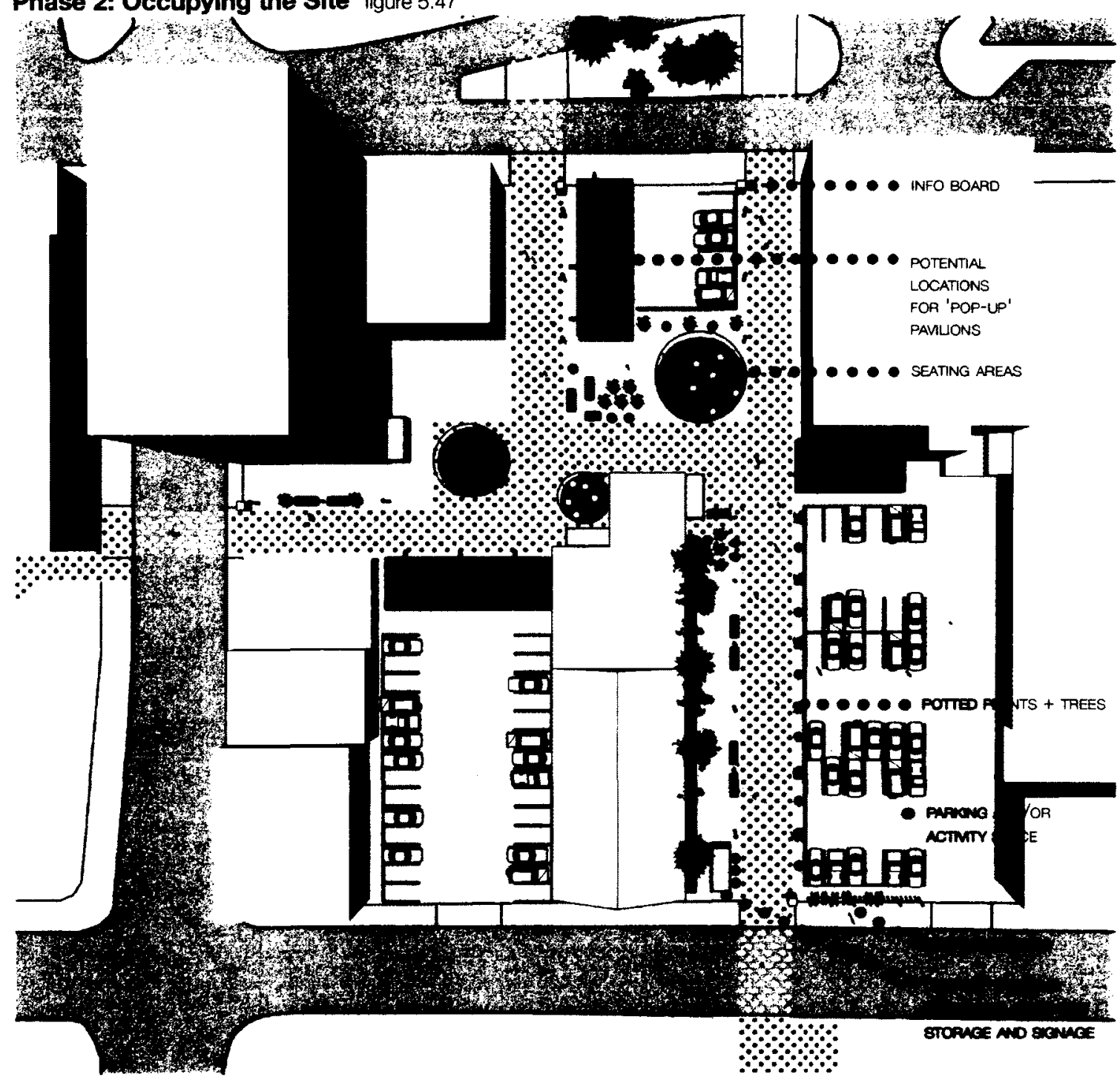

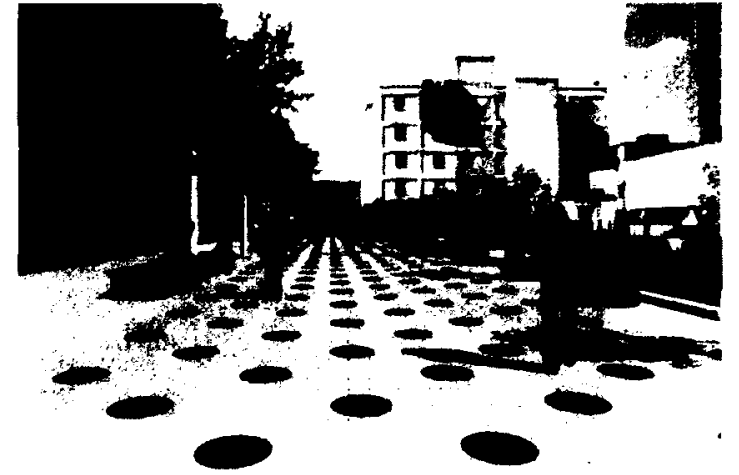

Figure 5.48 - Looking north from George Street

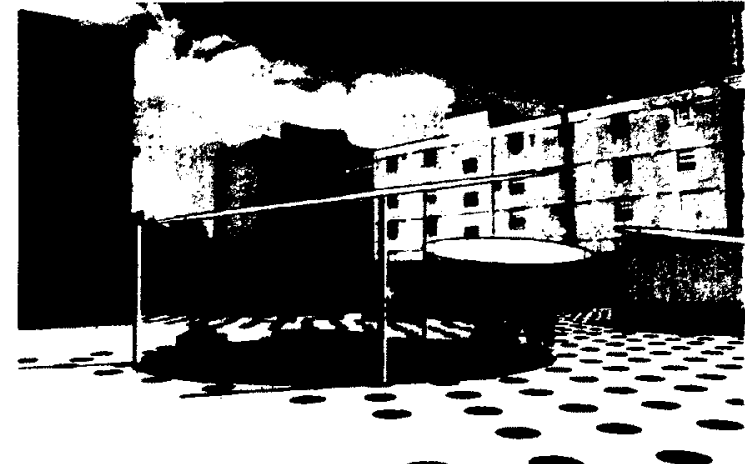

Figure 5.49 - Looking north-west, just in from Dalhousie Street 


\section{Phase 2: Occupying the Site}

In this phase temporary or semi-permanent structures will be introduced along the pathway. Pavilions can serve as "pop-up" shops, restaurants or exhibition spaces, for example, to draw the public through the site. Structures should be placed to be easily accessible from and close to the pathway. They could serve as temporary units until permanent infill is built or they could evolve into permanent pavilions, with flexible uses as needs change. Temporary structures would be prefabricated, allowing them to be installed on site as required and moved to new locations within the network as further development of the site occurs.

To make the spaces more inhabitable, furnishings would be introduced along the pathway. A kit of parts (the KIT) would be provided for the basic fit-up of the public space. Things like seating, signage and planters would be included in the KIT (see fig. 5.53). Seating should be located along the pathways and in nodes along the through-block passages. Given the abundance of open space in this particular block, areas could be set aside for activities such as basketball, pick-up soccer, outdoor movie showings or other activities, by way of encouraging the community to take "ownership" of the site. Sculpture or other art works could be installed, including designated "graffiti walls" for public enjoyment and creative engagement on the part of the community.

As this new level of occupancy will limit the site's current use as a parking lot, some areas would continue to remain available for parking during designated hours and as 
activity space the rest of the time with the ultimate goal of moving parking underground within mixed-use buildings as the site is further developed.

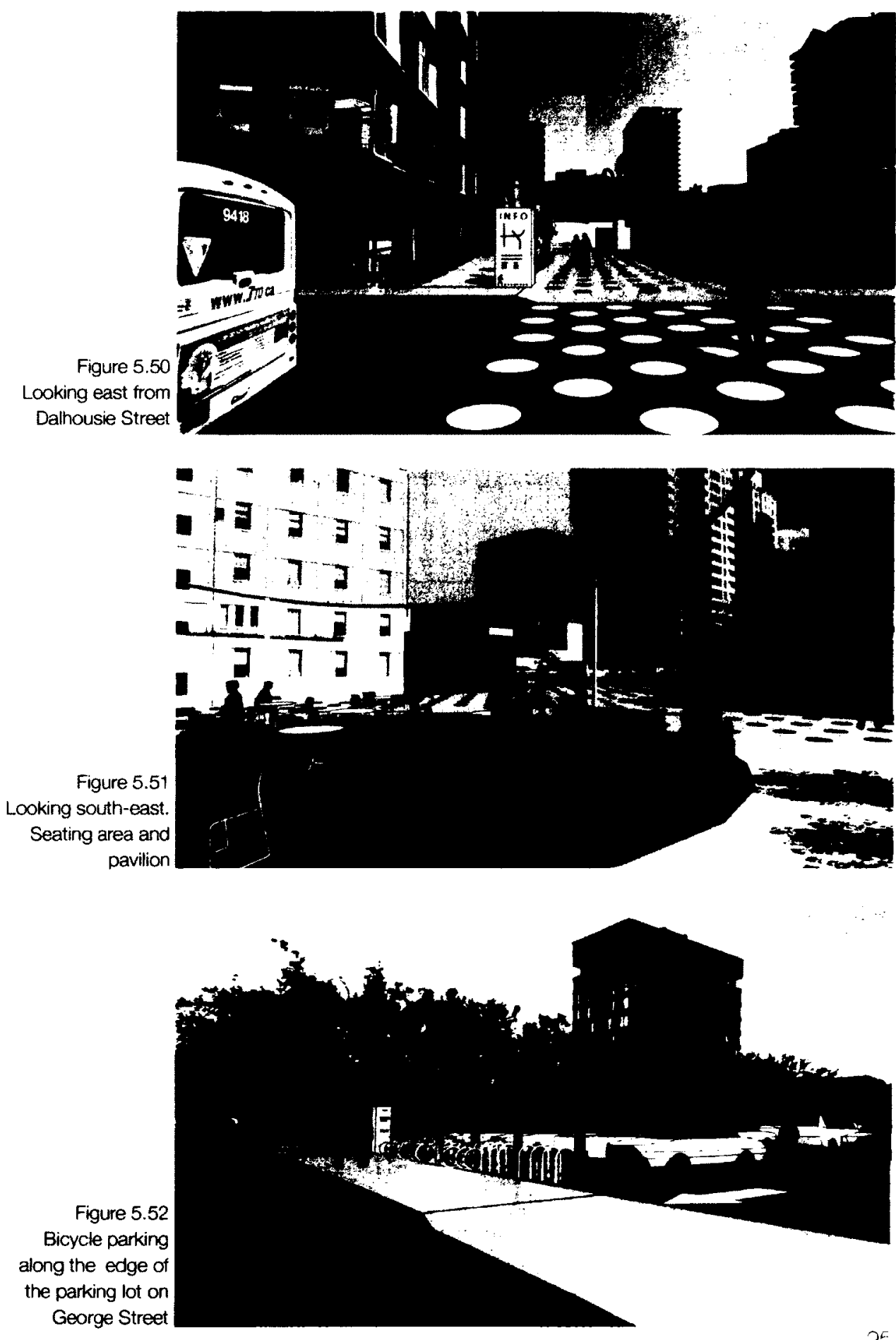




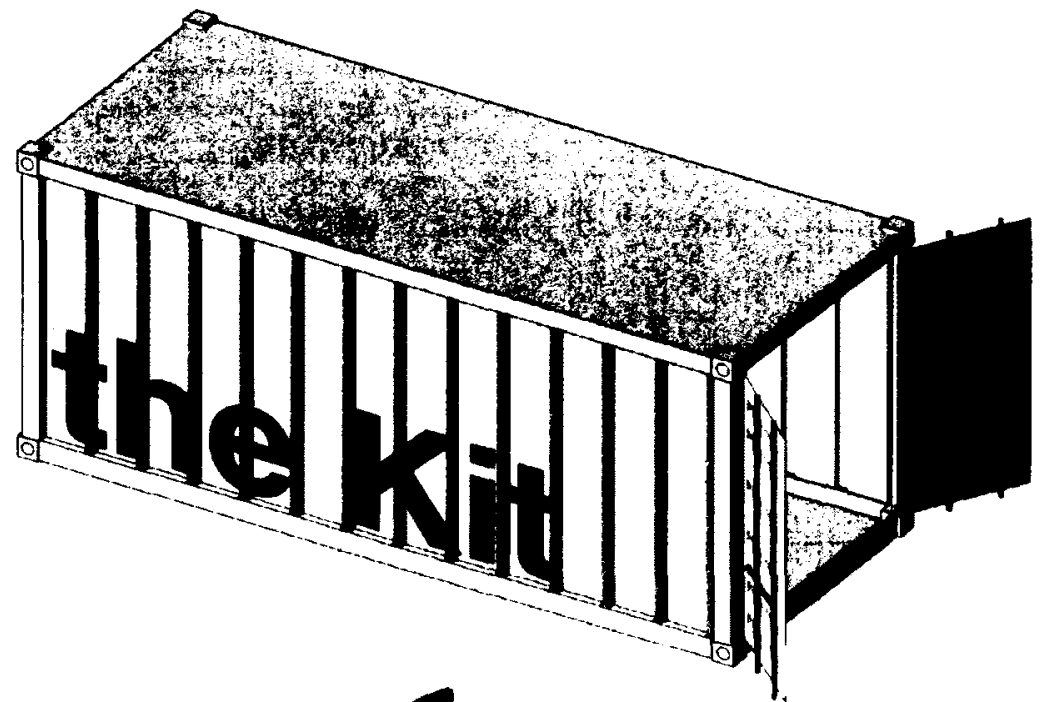

2

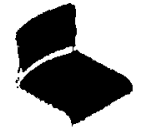

(1)
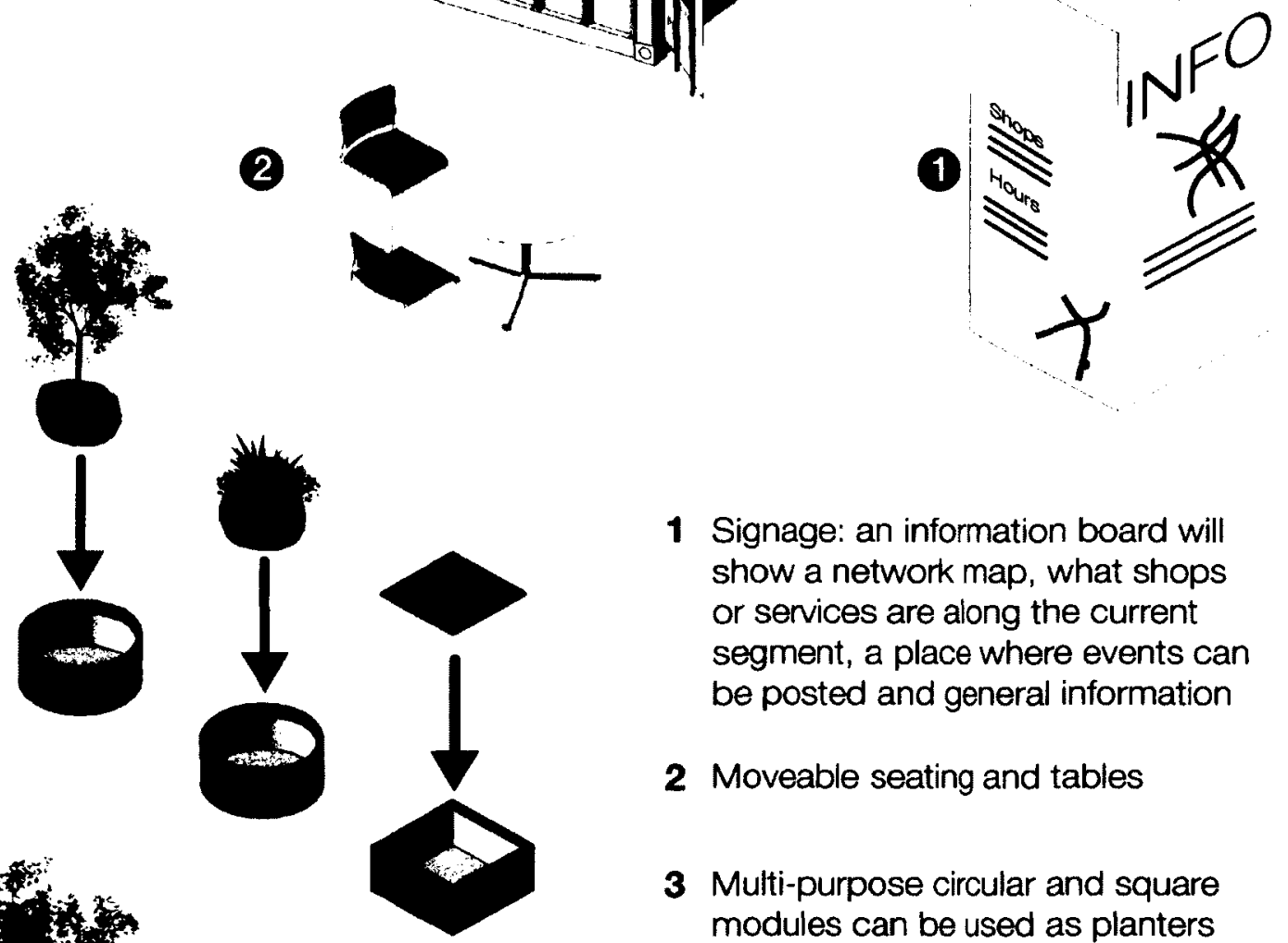

1 Signage: an information board will show a network map, what shops or services are along the current segment, a place where events can be posted and general information

2 Moveable seating and tables

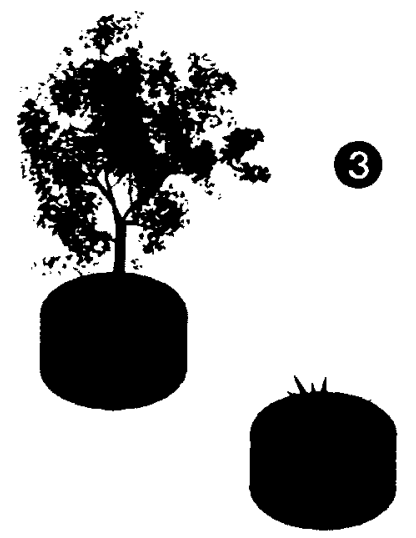

Figure 5.53 - the KIT

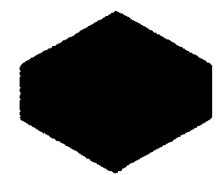

3 Multi-purpose circular and square modules can be used as planters or bench style seating, either alone or grouped together

One (or more) of the containers that the KIT is delivered in can be left on site to secure movable tables and chairs or other objects overnight if it is neccessary to secure them.

Quantities of iterns for each site will varny by the size of the site 

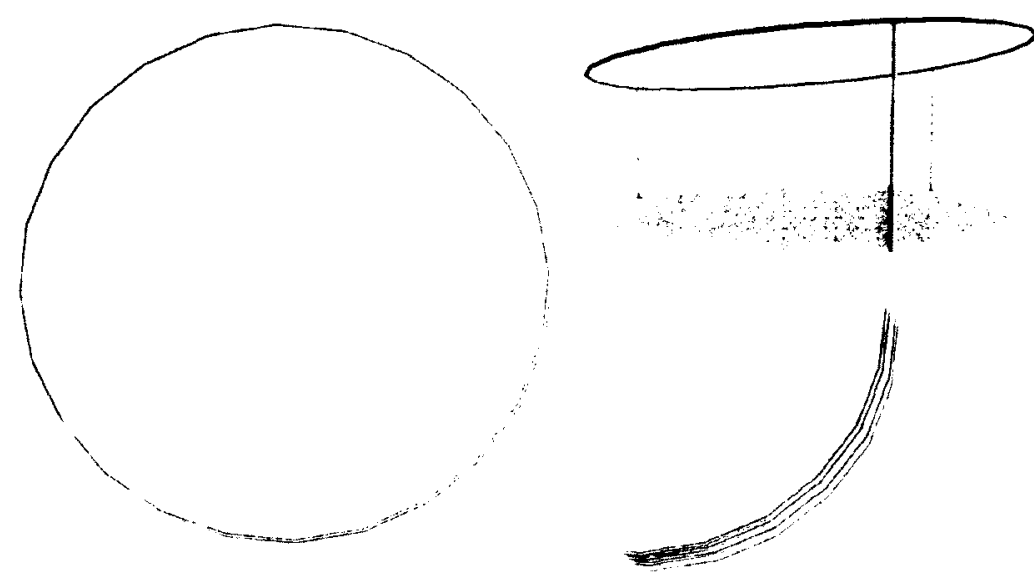

\section{Canopies:}

Shade canopies are made of a translucent and water resistant fabric, stretched on a collapsible metal frame and supported by 3 (or more) posts. The canopies could be used seasonally and stored in the collapsed form when not in use.

\section{Pop-up Structures:}

Made from prefabricated structural panels, these multi-functional 'pop-up' pavilions would be able to be easily transported to and assembled on site and then disassembled and relocated when not needed any more. The basic size of these structures is $7.2 \mathrm{mx}$ $7.2 \mathrm{~m}$ but more (or less) panels can be used to change the depth of the structure.
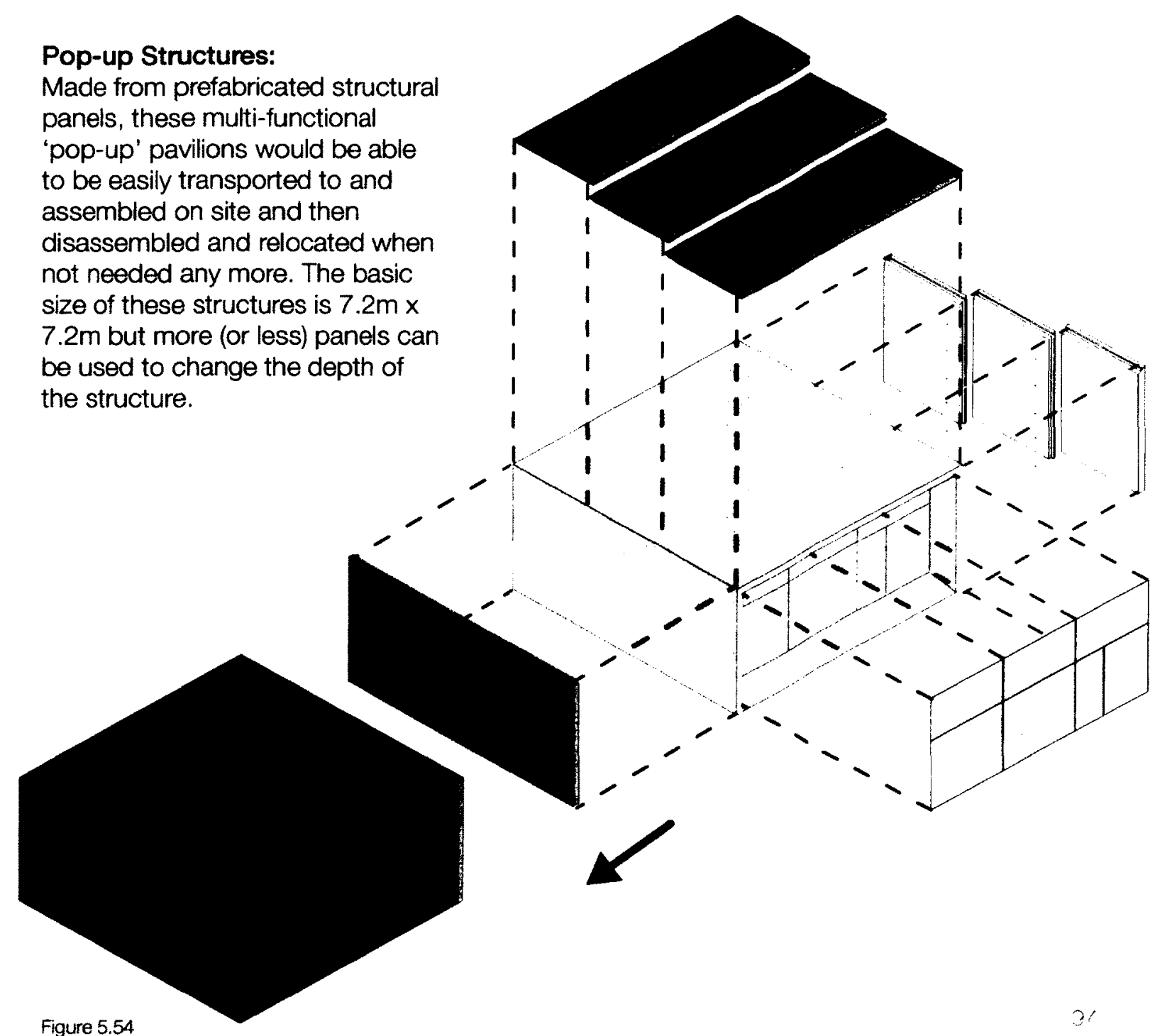
Phase 3: Infill figure 5.55
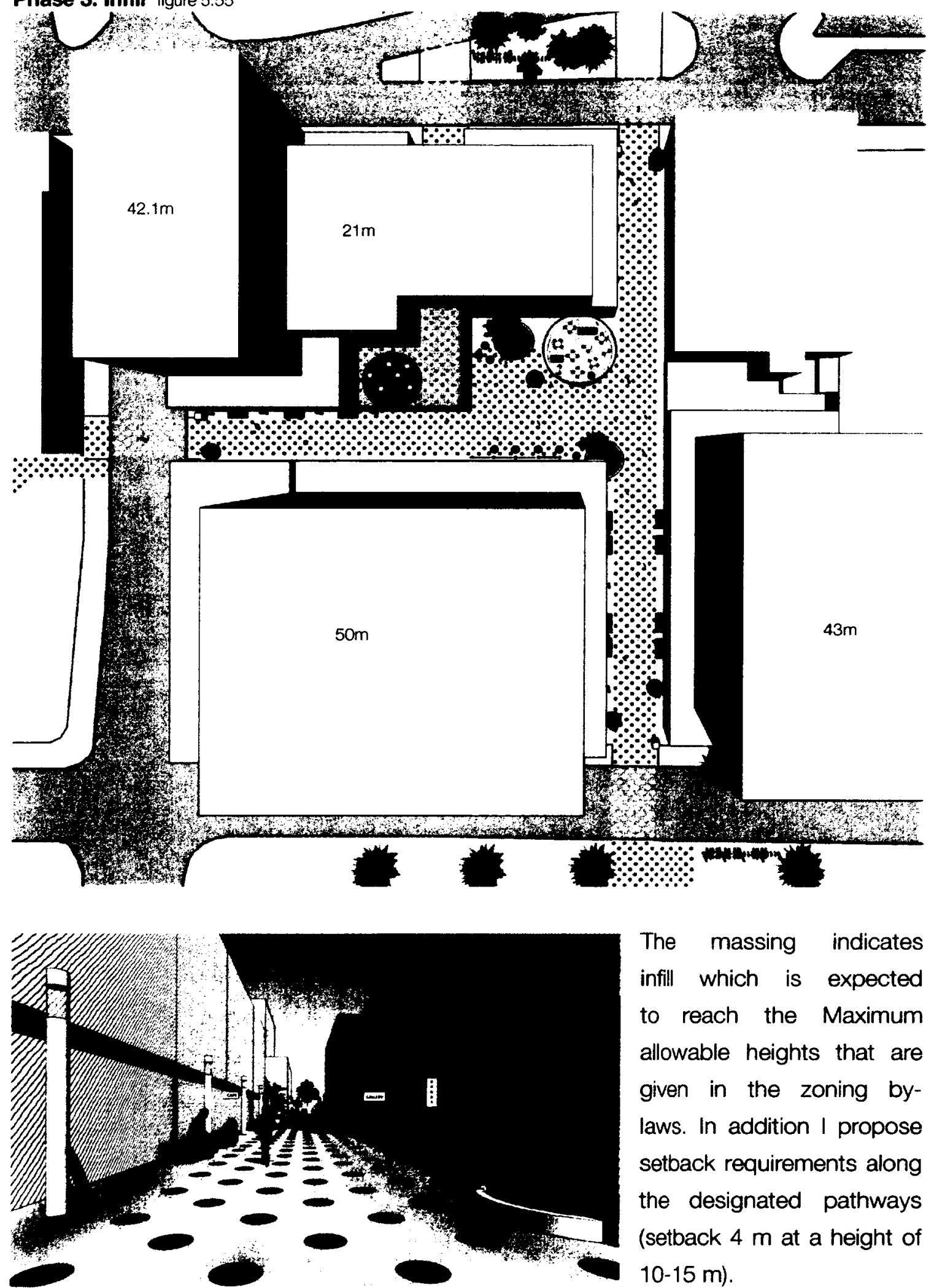

The massing indicates infill which is expected to reach the Maximum allowable heights that are given in the zoning bylaws. In addition I propose setback requirements along the designated pathways (setback $4 \mathrm{~m}$ at a height of 10-15 m).

Figure 5.56 - Looking north from George 


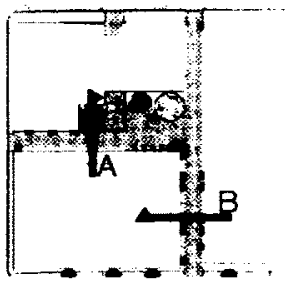

Figure 5.57 - Sections through two parts of the block showing the pathway and setbacks of adjacent buildings

\section{A}

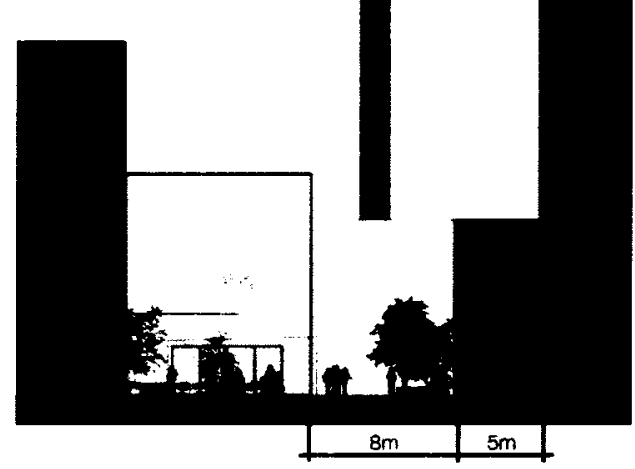

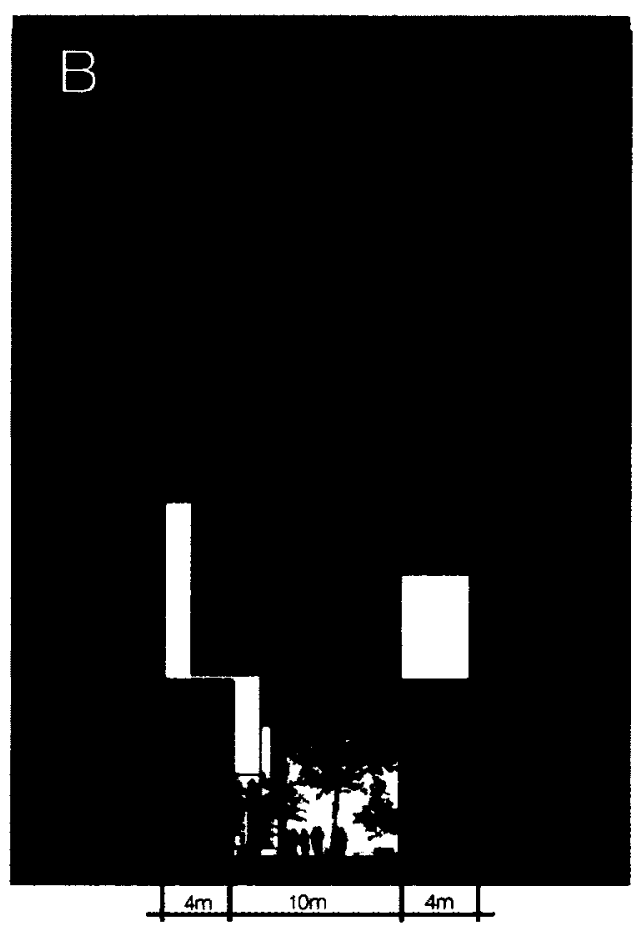

Phase 3: Infill

The next step - although not final, as cities are continuously evolving - is for permanent infill to be added to the site. At ground level any new buildings will be required to respect the established build-to lines so that the space of the path remains open and accessible. Portions of the path, however, may be enclosed, forming interior through-block passages and atrium spaces. Any interior portions of the network must remain accessible to the public, with the space between the build-to line representing what must be kept open. A variety of types of space may be designed as a part of the network, different types of space will support a greater 
variety of uses and work better in conjunction with each other. Indoor or covered spaces may be a desirable asset as usable public space during the winter or inclement weather.

New buildings will further define the pedestrian paths and associated public spaces and will introduce additional pedestrian-oriented uses at grade. This will help promote pedestrian traffic throughout the ByWard Market. It is important to incorporate community and cultural programmes into the infill, in addition to commercial uses, in order to better support the neighbourhood and community. This site might benefit from a recreation facility, community centre or other community based amenities, as well as hard and/or softscaped park space.

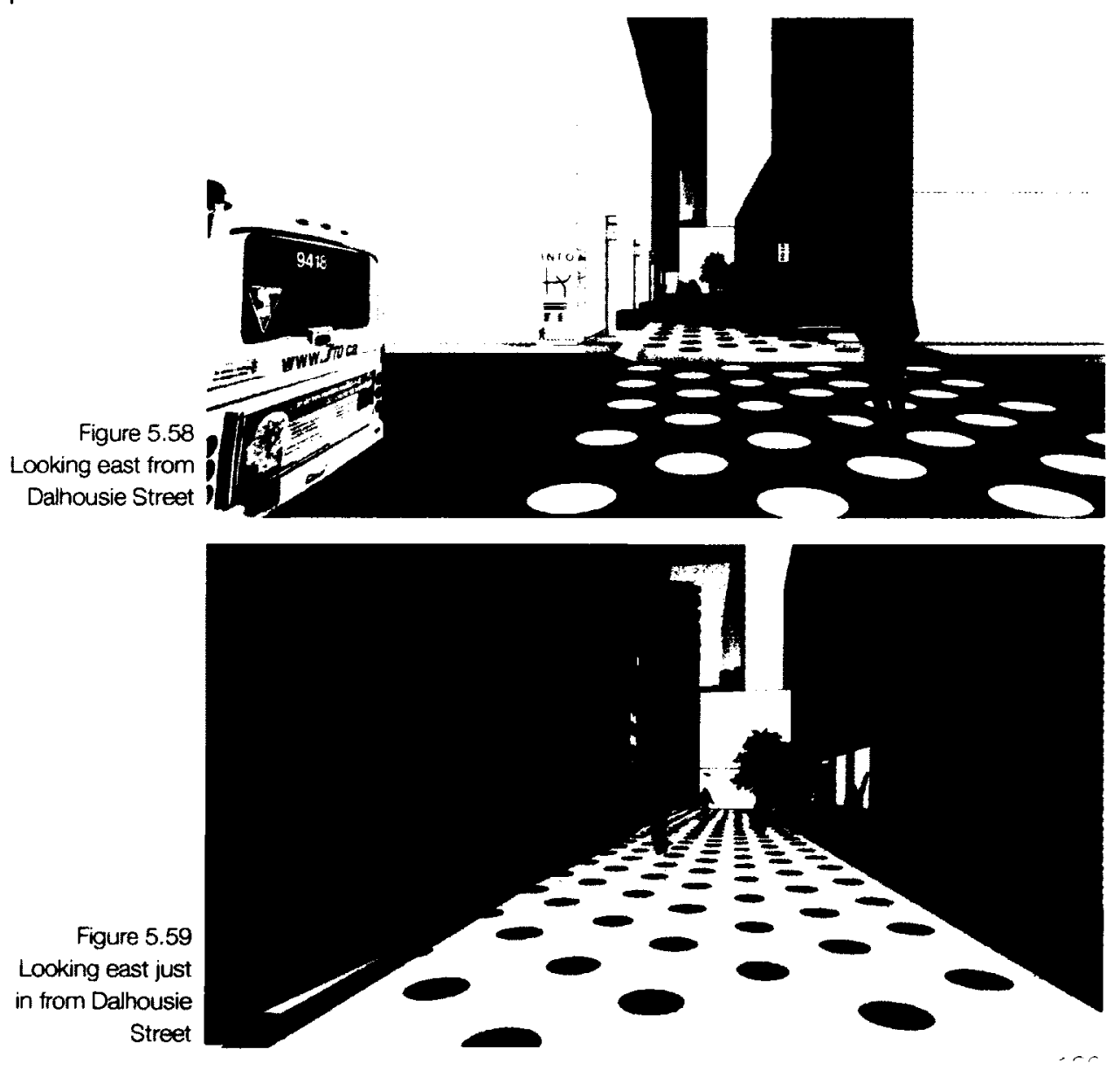




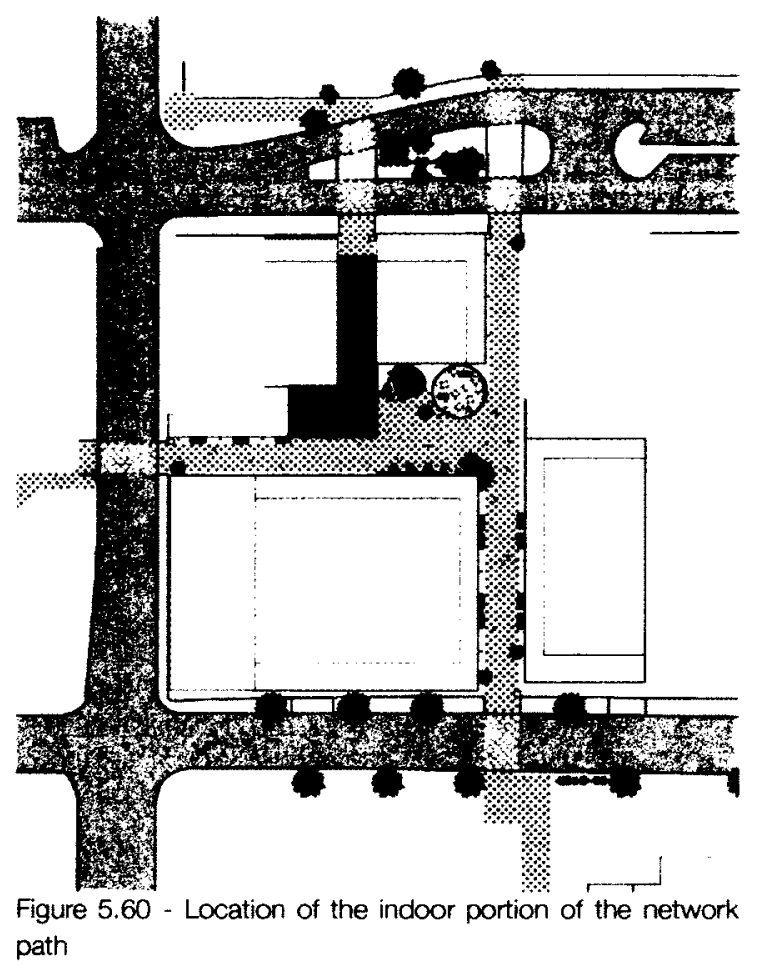

Site Features:

A portion of the pedestrian path is indoors (fig. $X X X)$. The designated path space is to say as public space. These types of spaces could be locked late at night but must be publicly accessible throughout the day.

In order to address the need for parking, underground parking should be incorporated under all three areas of new buildings (fig. $X X X$ ), and should include both public parking and tenant/resident parking.

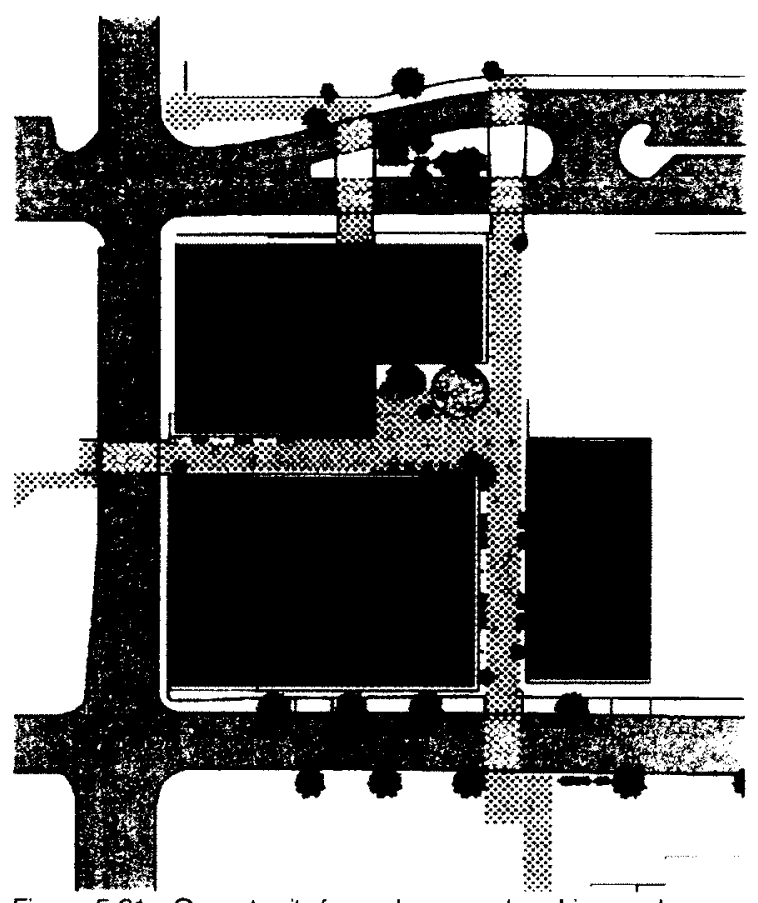

Figure 5.61 - Opportunity for underground parking under new buildings

Potential surfacing options for the pathway include:

- Paving stones with dot pattern inlaid

- Cement with coloured cement pattern

- Cement with epoxy paint pattern

- Rubber surfacing with coloured pattern

To maximize year round use outdoor portions of the pathways the walking surface should be heated. This keeps paths ice and snow free in the winter and can even reduce long-term costs of snow removal and injury from icy conditions.

Figure 5.62

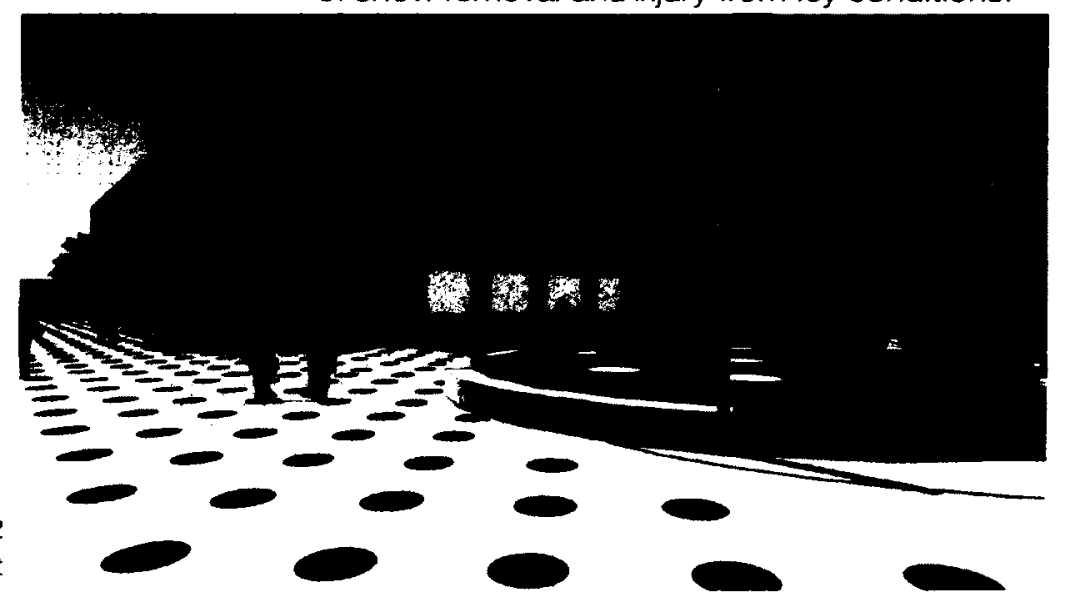




\section{THE GUIDELINES}

Learning from precedents, like New York City's POPS, and from the ByWard Market site, I have compiled a list of guidelines for the implementation of pedestrian networks. These guidelines are to be used by property owners and enforced by municipalities to ensure the quality, safety and accessibility of spaces associated with pedestrian networks. Both the guidelines and the phased system were created with the intention of being generally applicable to a range of cities and districts for the integration of lasting pedestrian spaces into the urban fabric. These guidelines have largely been adapted from New York City's Plaza Design Standards (for POPS) and William Whyte's observations in The Social Life of Small Urban Spaces to apply to the through-block passages.

Dimensions: All path spaces should have a minimum width of 4 metres. To avoid disproportionately tall buildings from towering over pathways any buildings built next to an outdoor path space must have a setback of at least four metres at a height of 10 to 15 metres. This will keep spaces at a human scale and allow for better natural light and air circulation.

Configuration: A through-block path should be located as close to the center of the block as possible, as opposed to closer to a street. This help to distinguish the path as separate from the street, complimenting the street grid rather than competing with it. Entrances and exits from the path space should be clear both from the street and from within the block. 
Elevation: Changes in elevation should be kept to a minimum, sunken or raised spaces are often unappealing. Changes should be no greater than 60 centimeters, unless necessitated by the terrain. Steps or ledges created from change in elevation can act as seating.

Obstructions: Large visual obstructions that may pose safety concerns and objects that impede movement along pathways should be avoided. Amenities like seating, trees, planters should be positioned so as to not block or hinder circulatory spaces.

Seating: As a crucial component of public space, sitting space should not be limited to conventional seating. There are several types of seating that can be used including movable seating, fixed individual seats, benches, and ledges, which are best used in combination with each other (at least two types should be used) providing options for both social/ group seating and for individuals. For comfort, sitting surfaces should be between $40 \mathrm{~cm}$ and $50 \mathrm{~cm}$ high (however there may be a greater variation in ledges). A minimum of one linear metre of seating per 10 square metres of open space should be provided. Ledge type seating should account for no more than $25 \%$ of total seating. Seating should be located near pathways and other areas of activity as people like to be near people and to see what is going on around them.

Trees and Plants: Greenery is another important feature to be included in public spaces. It can soften spaces, make 
them more inviting, provide shade and clean the air, which is especially beneficial in an urban environment. Trees can be planted flush to grade with surrounding permeable surface or in low planters with other plants. Some re-locatable planters may also be beneficial too and augment permanent planting beds, particularly during the second phase of implementation so they can me moved as required while construction is being done.

Lighting: A well lit space is an inviting space. Not only is it safer but it is more enjoyable; access to sunlight is a key aspect of public spaces. Natural lighting must be supplemented with artificial lighting along paths and nodes in the network to ensure an adequate level of lighting when the areas are accessible to the public. In the design of lighting it is important to ensure that any point sources of lighting would not impair a person's vision and it is alto important for there to be enough lighting so that no areas are left in shadow. Interior portions of the network must also utilize natural lighting as the main source of lighting during the day, this can be done through glass roofs, skylights, clerestories or large widows.

Pavilions: Small pavilions are to be provided as a part of Phase 2 for use as temporary retail or service outlets. Uses may include clothing or home stores, cafes or galleries. Pavilions should be made of prefabricated parts so they can be easily assembled and disassembled. 
Signage: Passages through each block should have clearly visible signs at each entrance indicating that they are a part of the network. Hours of operation should be clearly marked. The signage should be of consistent design throughout the network for easy identification. Additional information may also be provided regarding what can be found along the path (retail, services, etc.), current events, a map of the area showing the path network, etc.

Additional Amenities: In addition to what is listed above, the following elements should be considered, understanding that requirements might vary by site: newspaper kiosks, food trucks/venders, bicycle rental and parking, artwork.

\section{Operation and Building uses at Ground Level:}

These spaces, though privately owned, are intended to be used by the public. Although most spaces should be accessible 24 hours a day, some areas or segments might be closed to the public overnight, particularly indoor areas or areas with a residential concentration.

The ground floors of buildings along public spaces should contain a majority of public-oriented uses (minimum of $60 \%$ of building frontage should be retail or services). These may include restaurants, retail, grocery or convenience stores, galleries, libraries, museums or community centres. The uses should both reflect and enhance the character of the area. 


\section{CONCLUSION}

In the continuing evolution of cities, there will always be a need for urban public space. As the density of cities increase so must the quantity and quality of public space. By investigating alternative forms and approaches to the provision of public space in dense urban areas, I have been able to identify key strategies to apply to the design of a through-block pedestrian network. Portions of the same open lots that represent potential for added density to the ByWard Market could be secured for public use by the City though incentive between the City and with land owners. By defining pedestrian networks, both in advance of and in tandem with intensification, cities can protect and enhance the quality of urban life. Drawing on existing pedestrian paths, spaces that are already being used as shortcuts by pedestrians, and desire lines, I was able to divine a network from the existing fabric of Ottawa's ByWard Market.

Using the ByWard Market as a case study, I have demonstrated a system of paths might be introduced. Phasing the appearance of pathways will encourage a more organic integration of pedestrian space both into the urban fabric and into people's daily routines. Establishing build-to lines will assure that future construction respects and enhances designated paths and spaces. Learning from cities like Paris, New York City and Bologna, the strategies proposed are intended to protect and augment the quality and extent of urban pedestrian space in Ottawa's ByWard Market, and 
be transposable to other neighbourhoods and cities facing densification.

My research was largely focused on what has been done in the past in other cities. Reviewing key source materials and focusing on projects that might be applicable to Ottawa, my goal was to learn from the past to create a lasting project for the future. Additional research might include interviewing City representatives to solicit ideas and gain a better understanding of what has and hasn't been attempted/ successful in the past. It would also be useful to speak with major developers in the area to determine how receptive they might be to incentives for the inclusion of space for public use, and under what terms of reference.

Overall I believe I have presented a viable and dynamic approach to incorporating urban pedestrian spaces that work together as a network. Allowing for densification around the designated pedestrian spaces and smooth integration into the urban fabric. 


\section{APPENDIX A - BYWARD MARKET ANALYSIS MAPS}

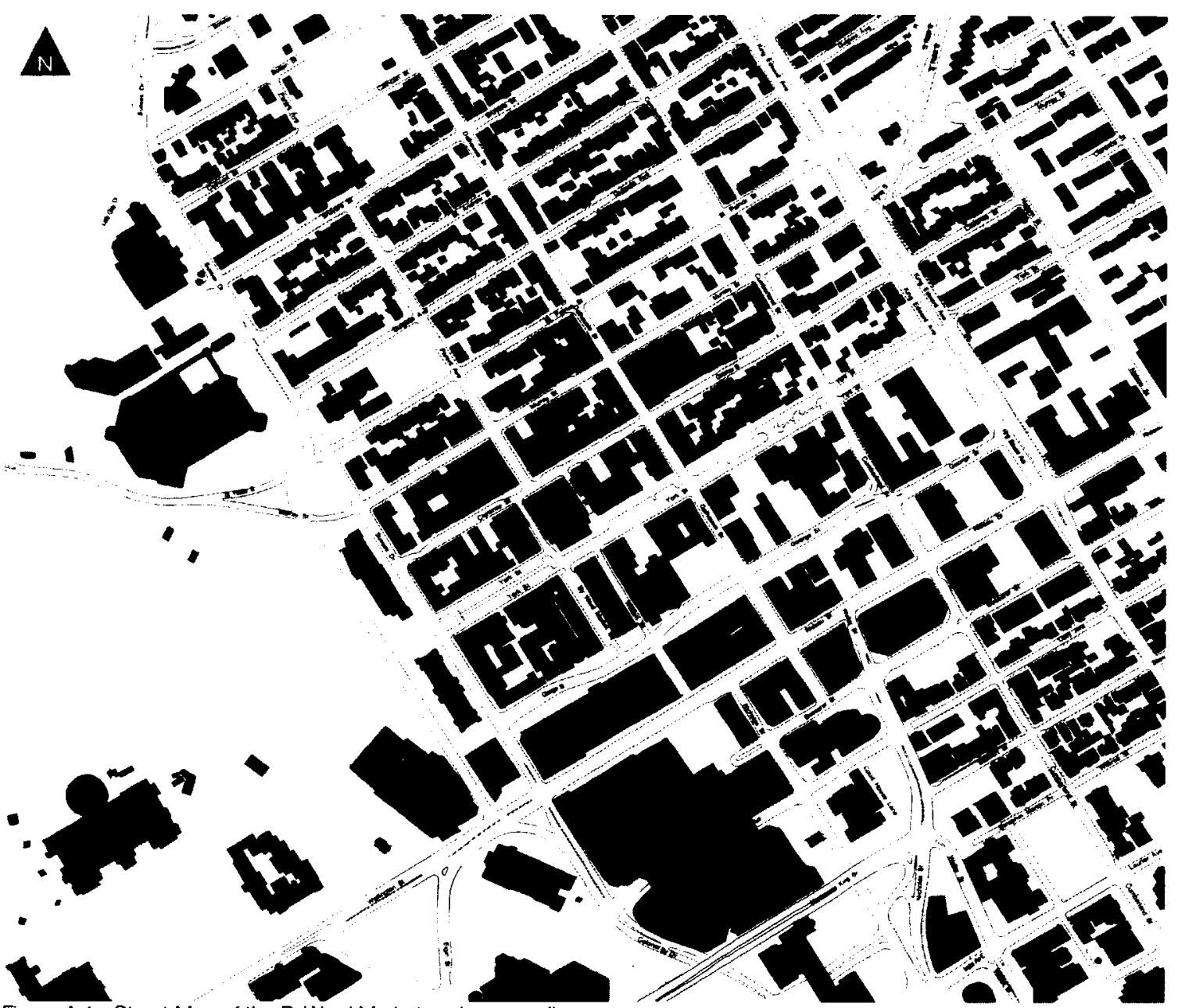

Figure A.1 - Street Map of the ByWard Market and surrounding area

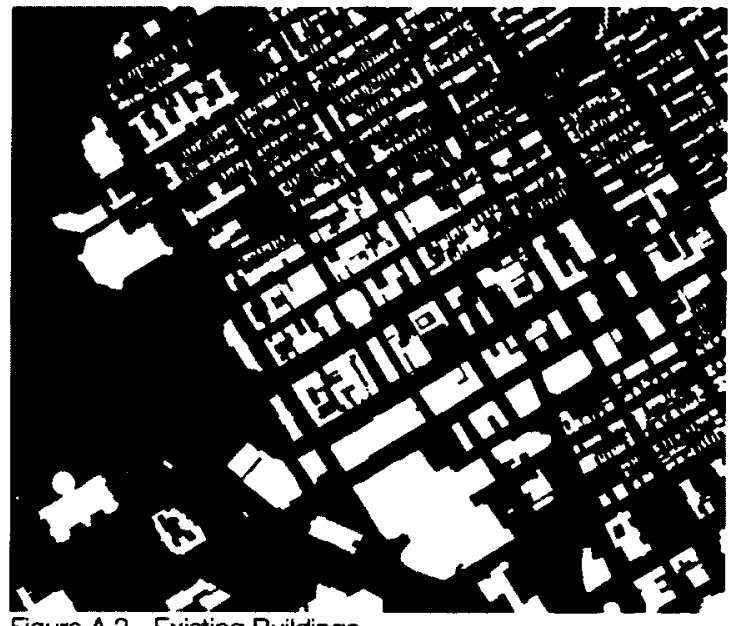

Figure A.2 - Existing Buildings

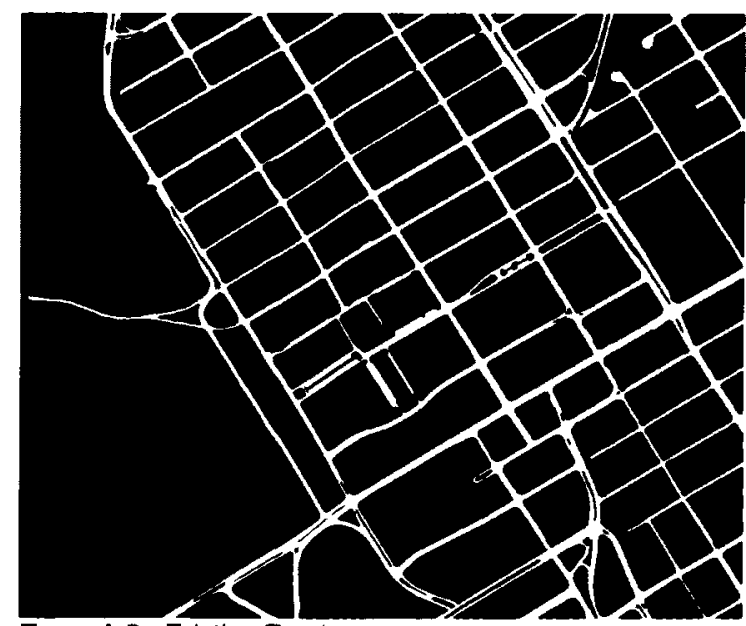

Figure A.3 - Existing Roacways 


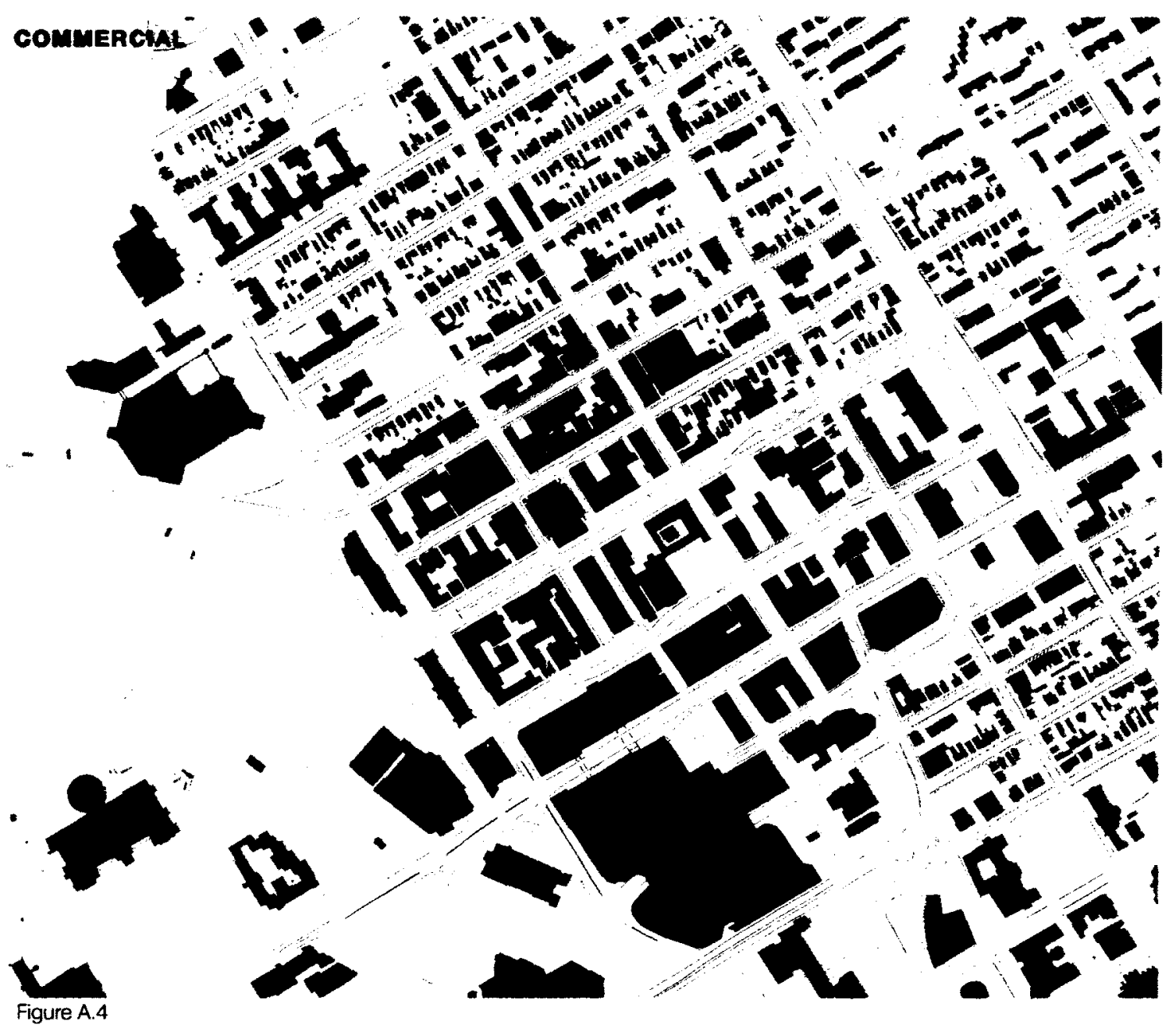




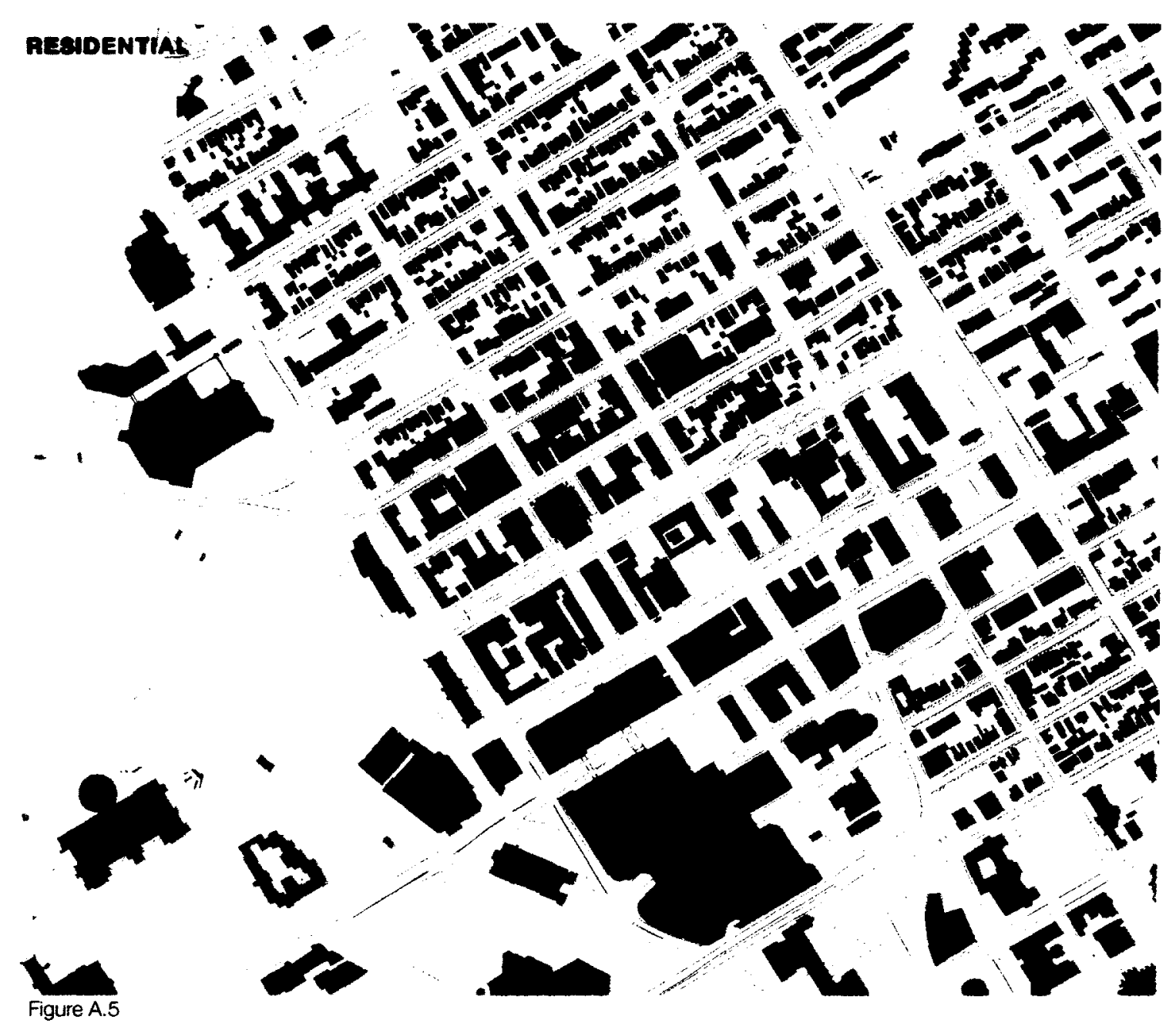




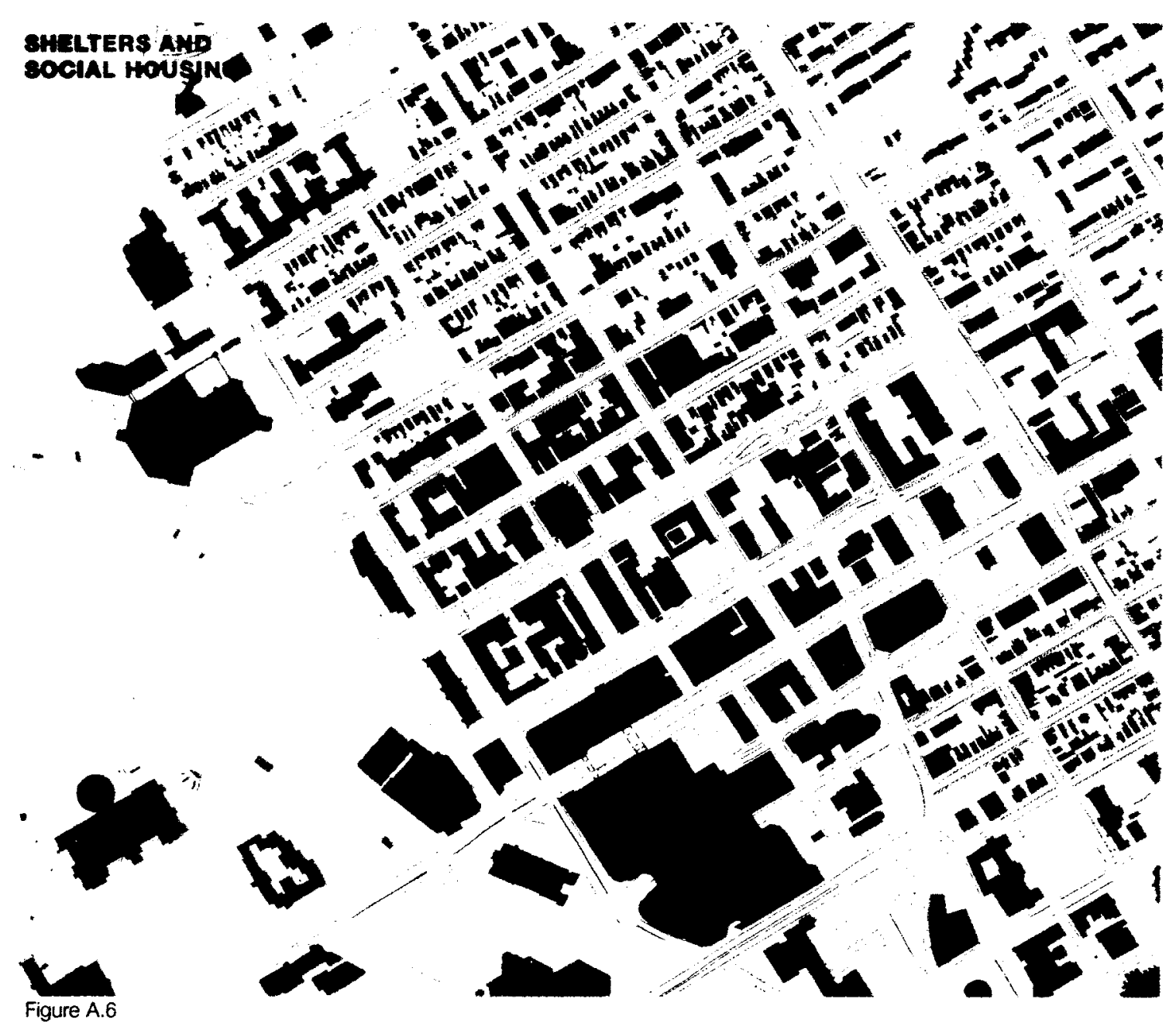




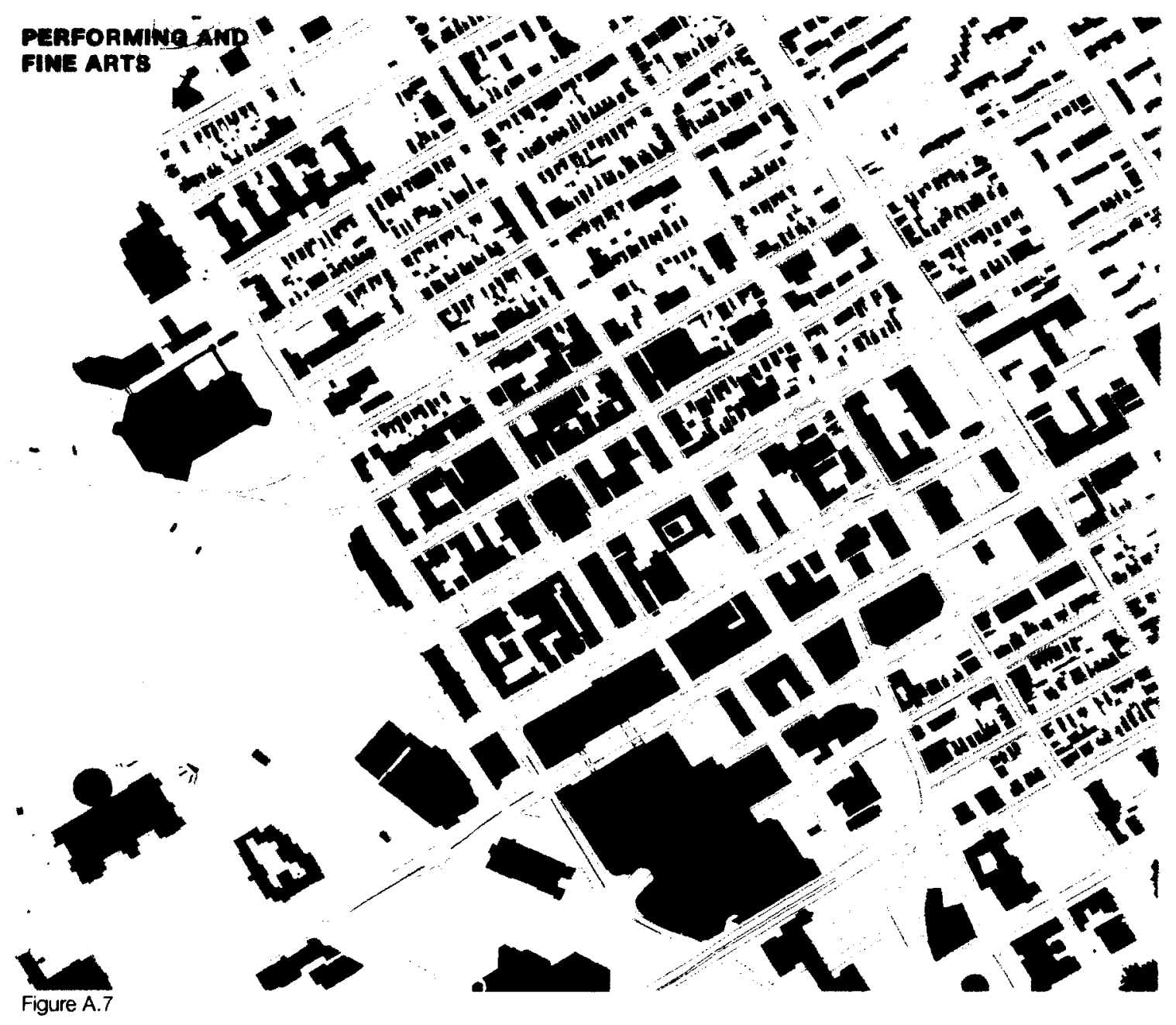




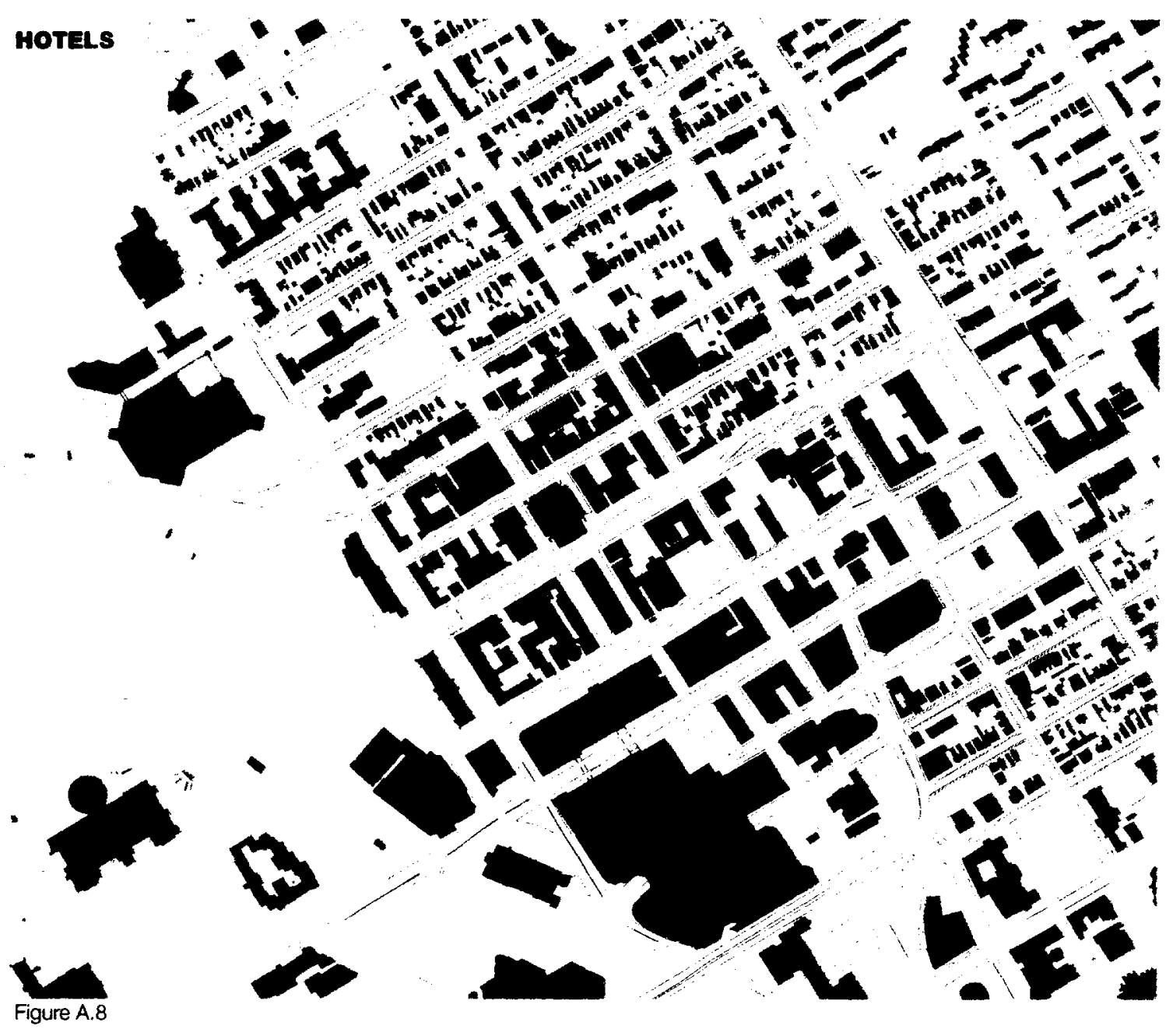




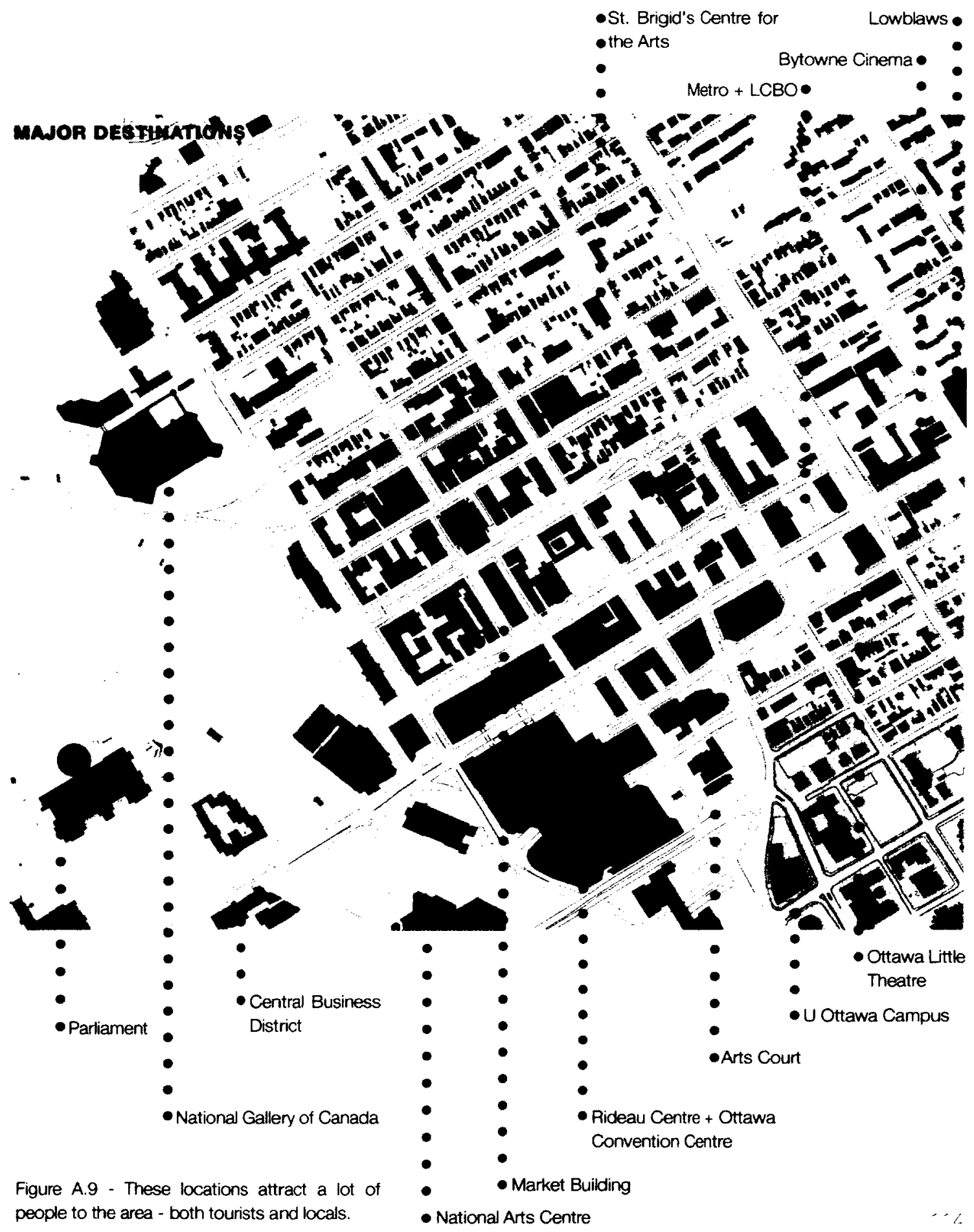




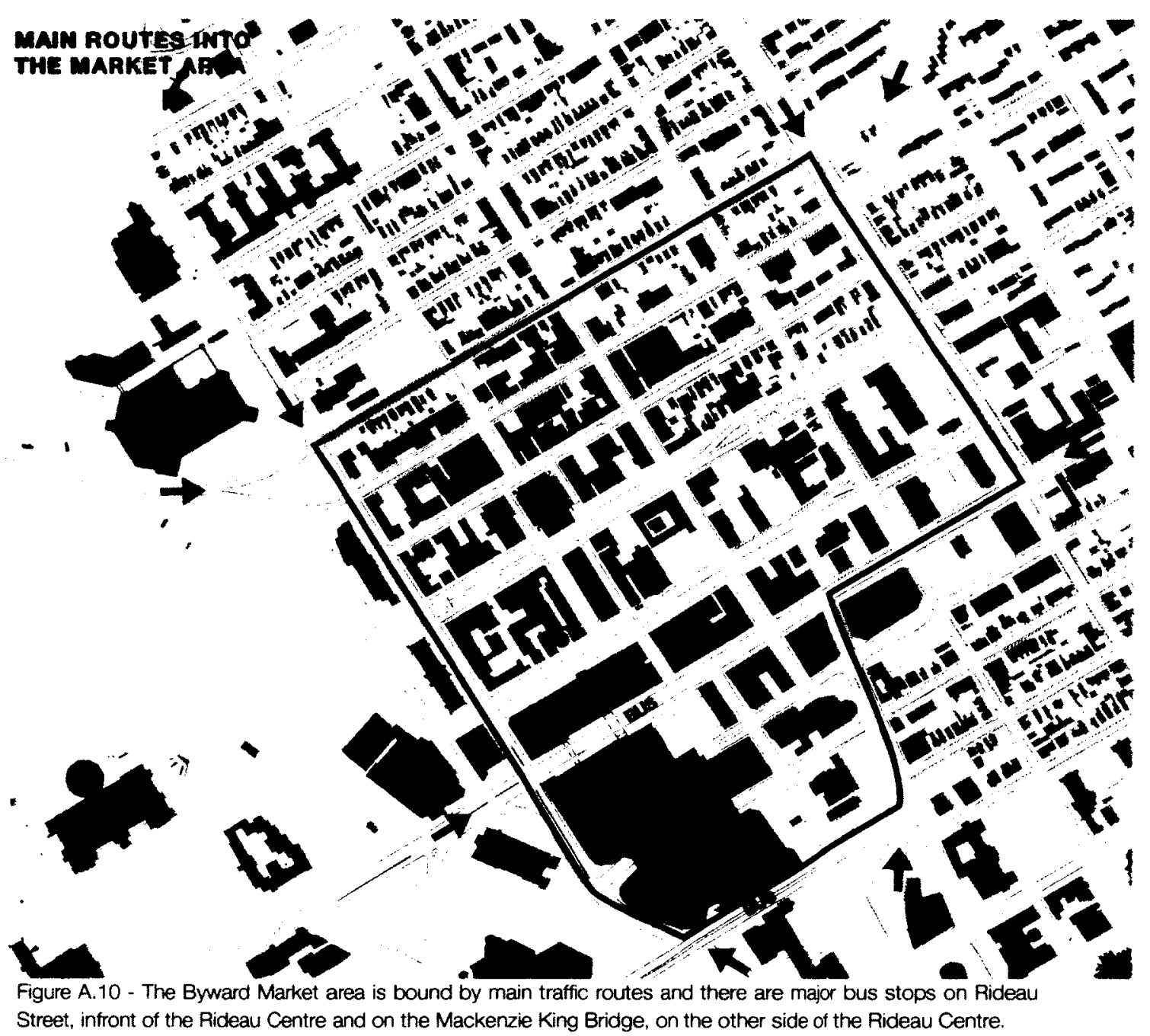




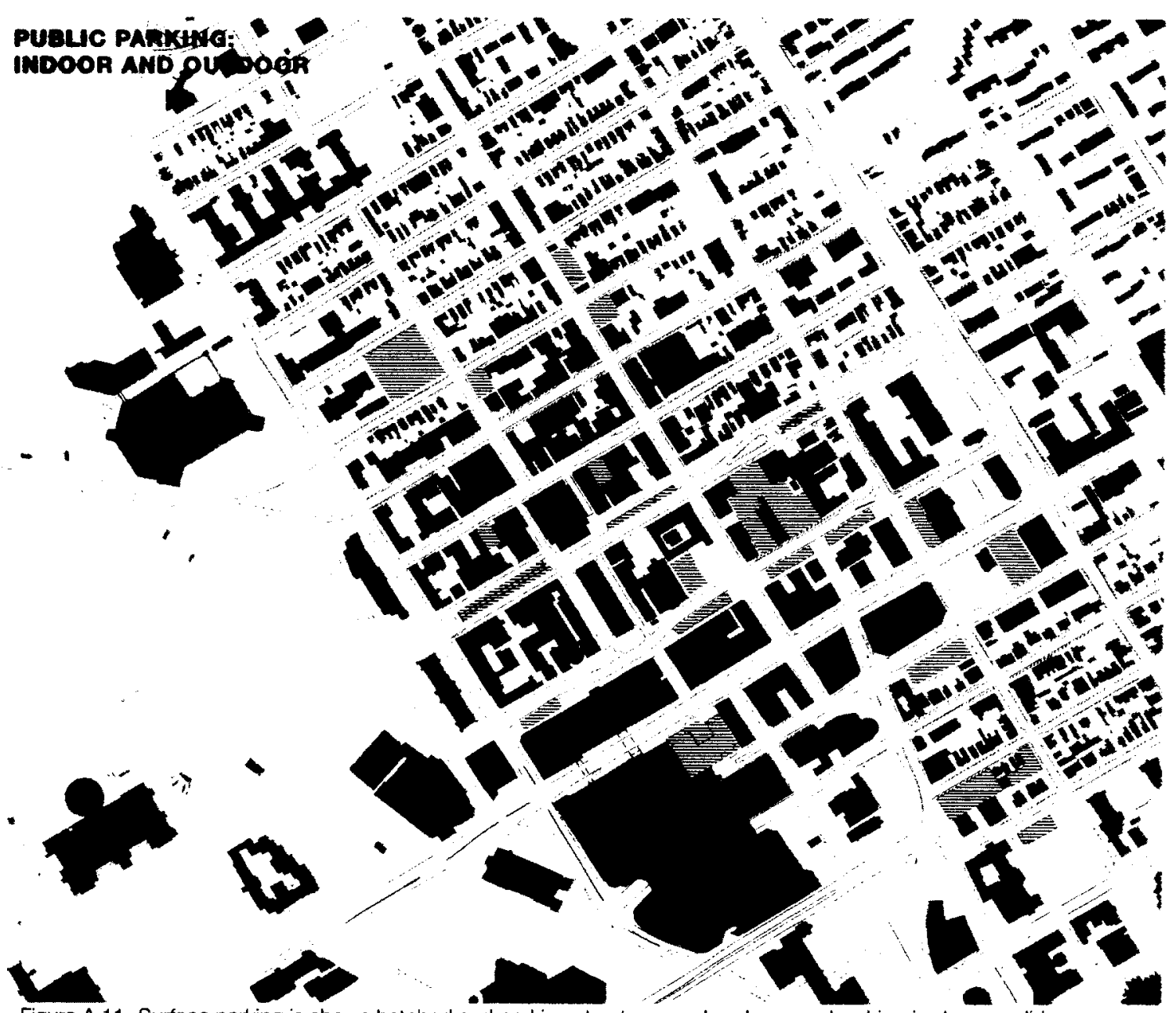

Figure A.11- Surface parking is shown hatched and parking structures and underground parking is shown solid. 


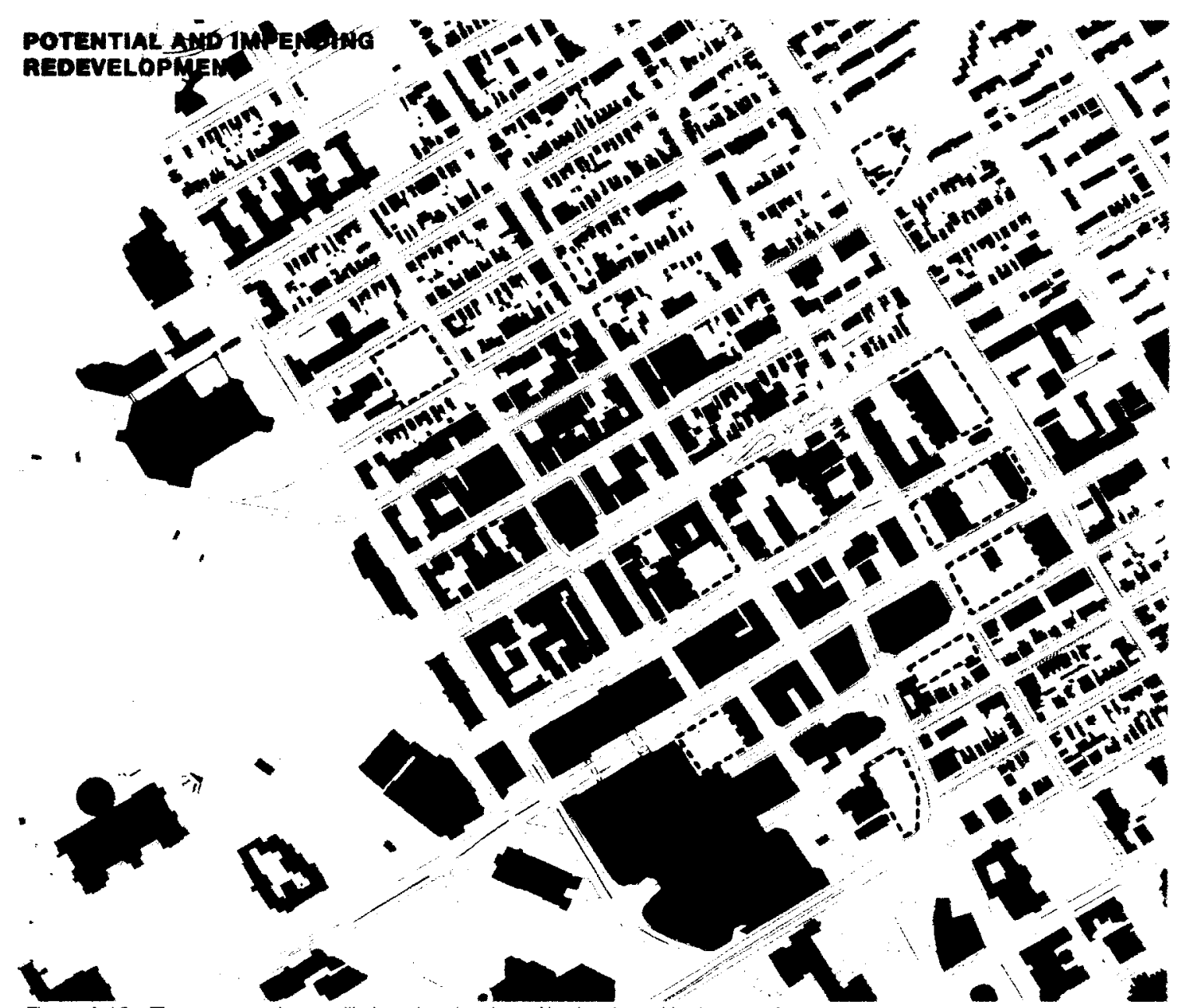

Figure A.12 - These properties are likely to be developed/redeveloped in the near future. 


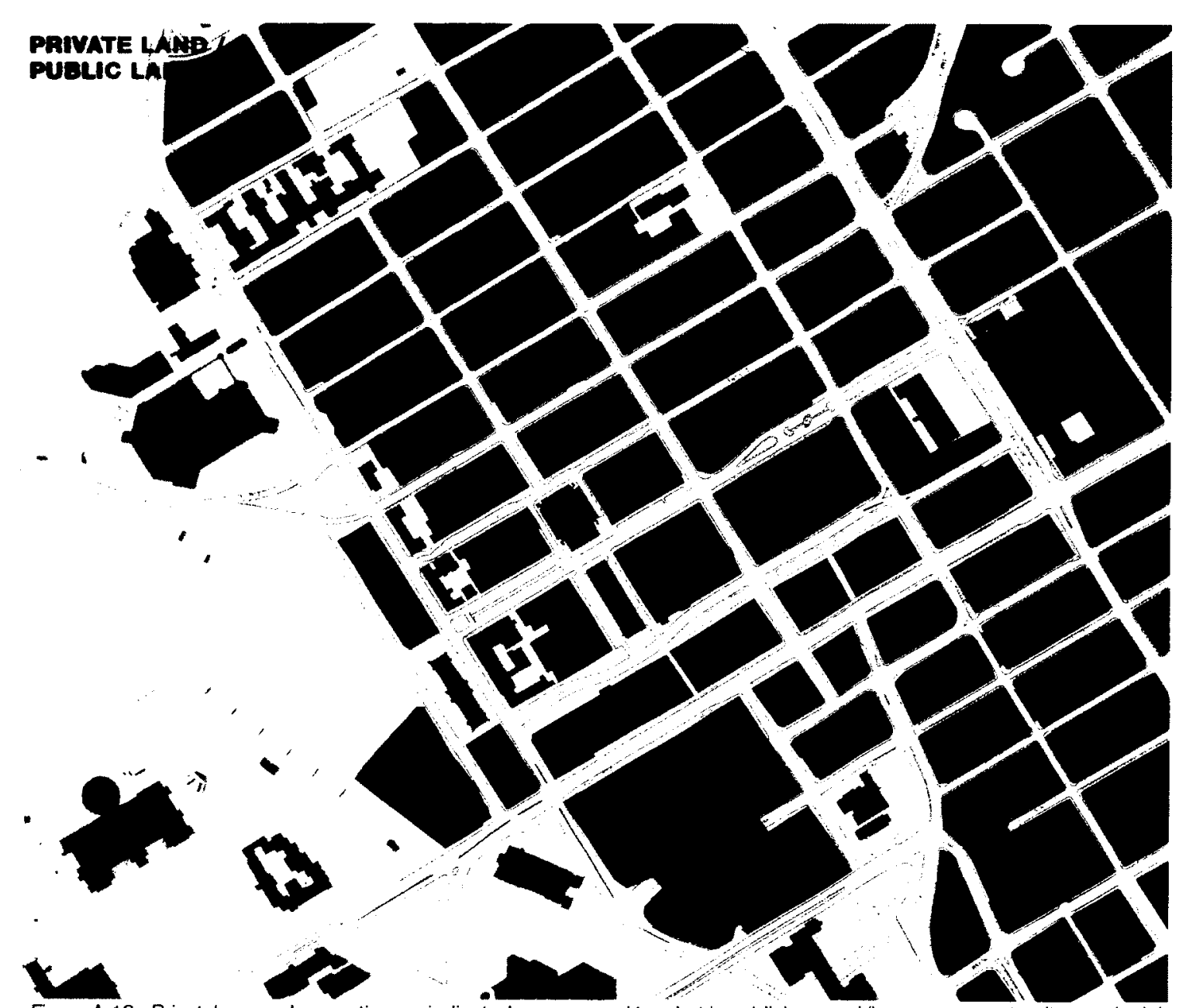

Figure A.13 - Privately owned properties are indicated, as opposed to what is publicly owned (i.e. government - city, provincial, federal owned. 


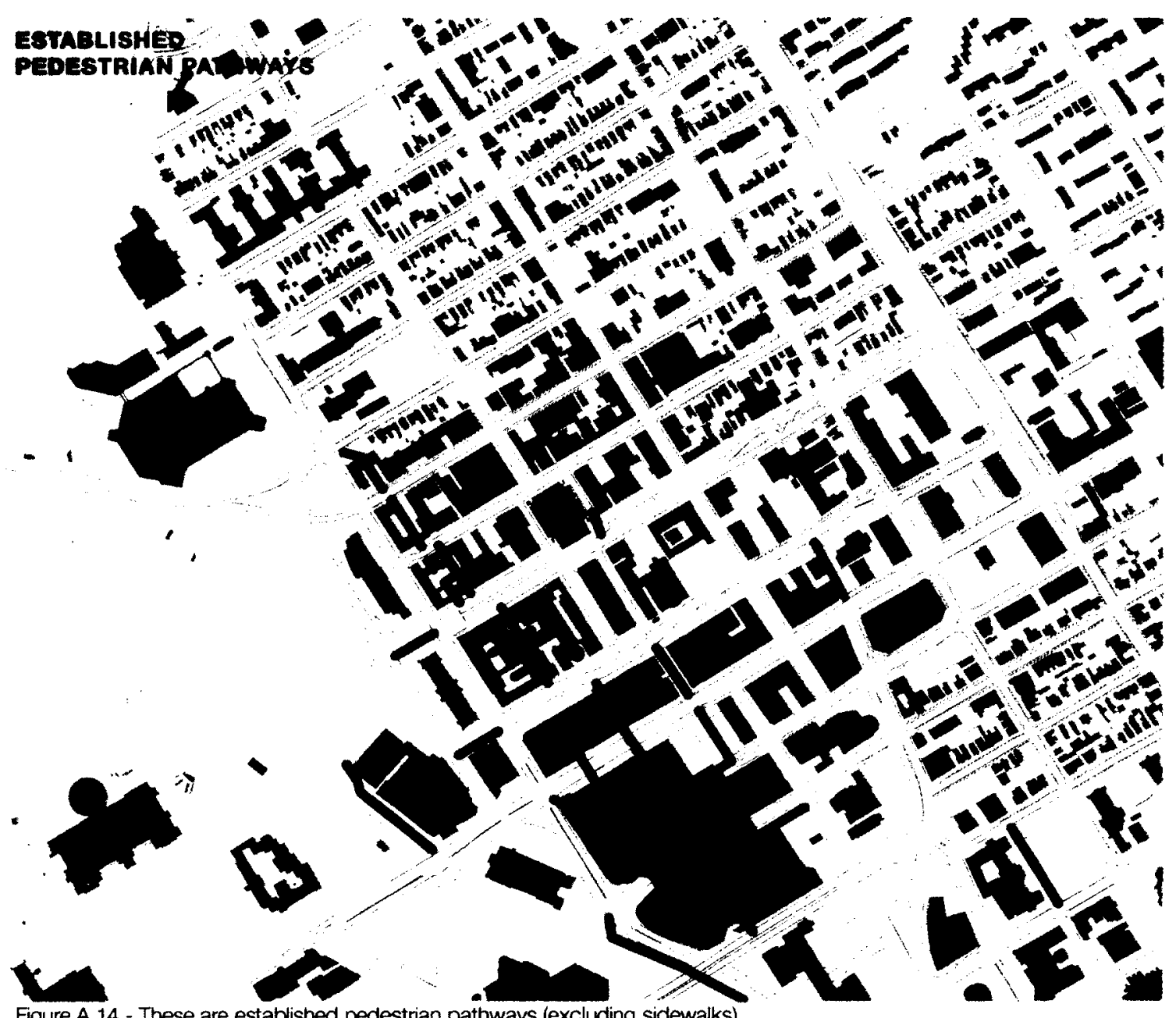

Figure A.14 - These are established pedestrian pathways (excluding sidewalks). 


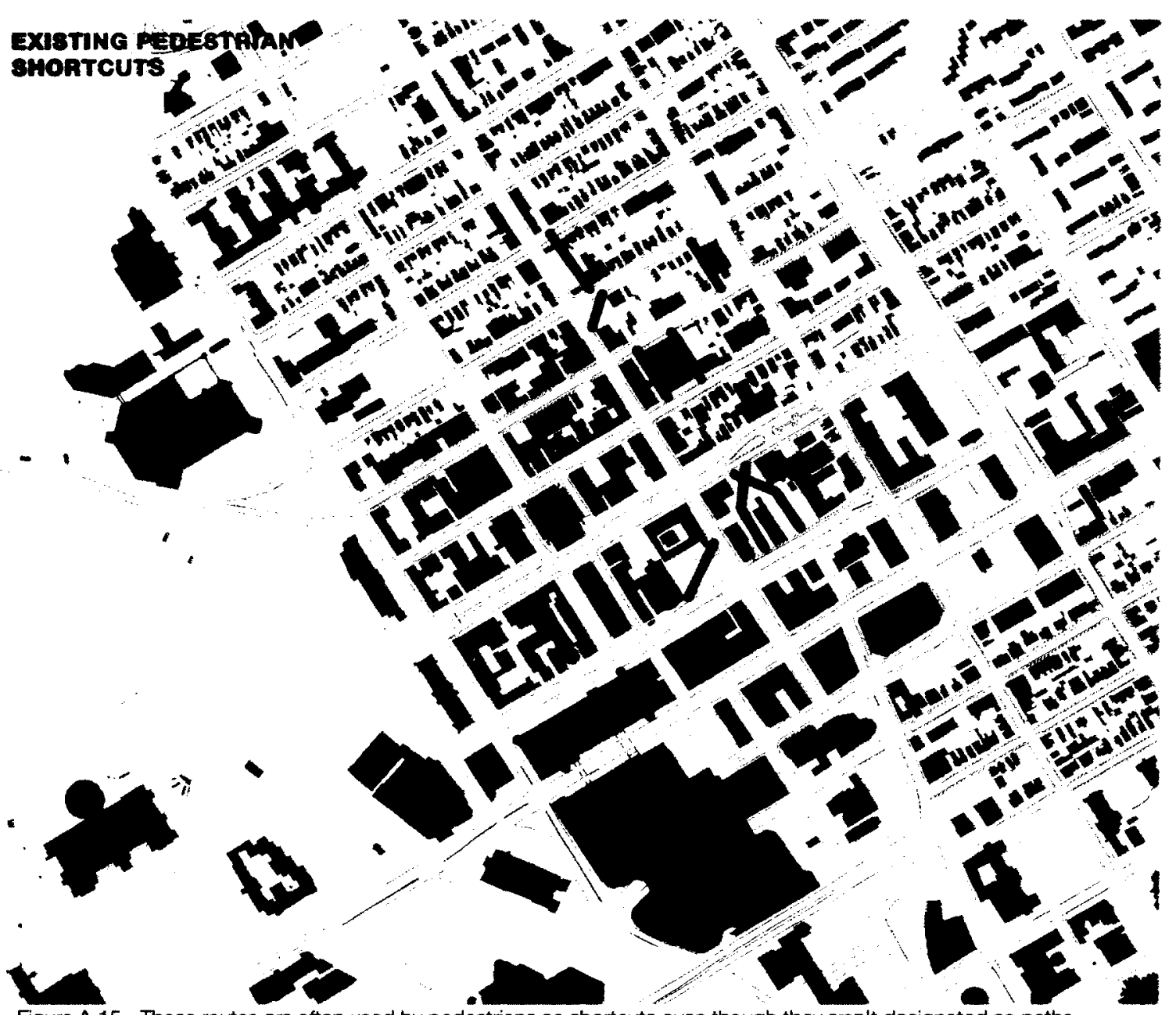

Figure A.15 - These routes are often used by pedestrians as shortcuts even though they aren't designated as paths. 


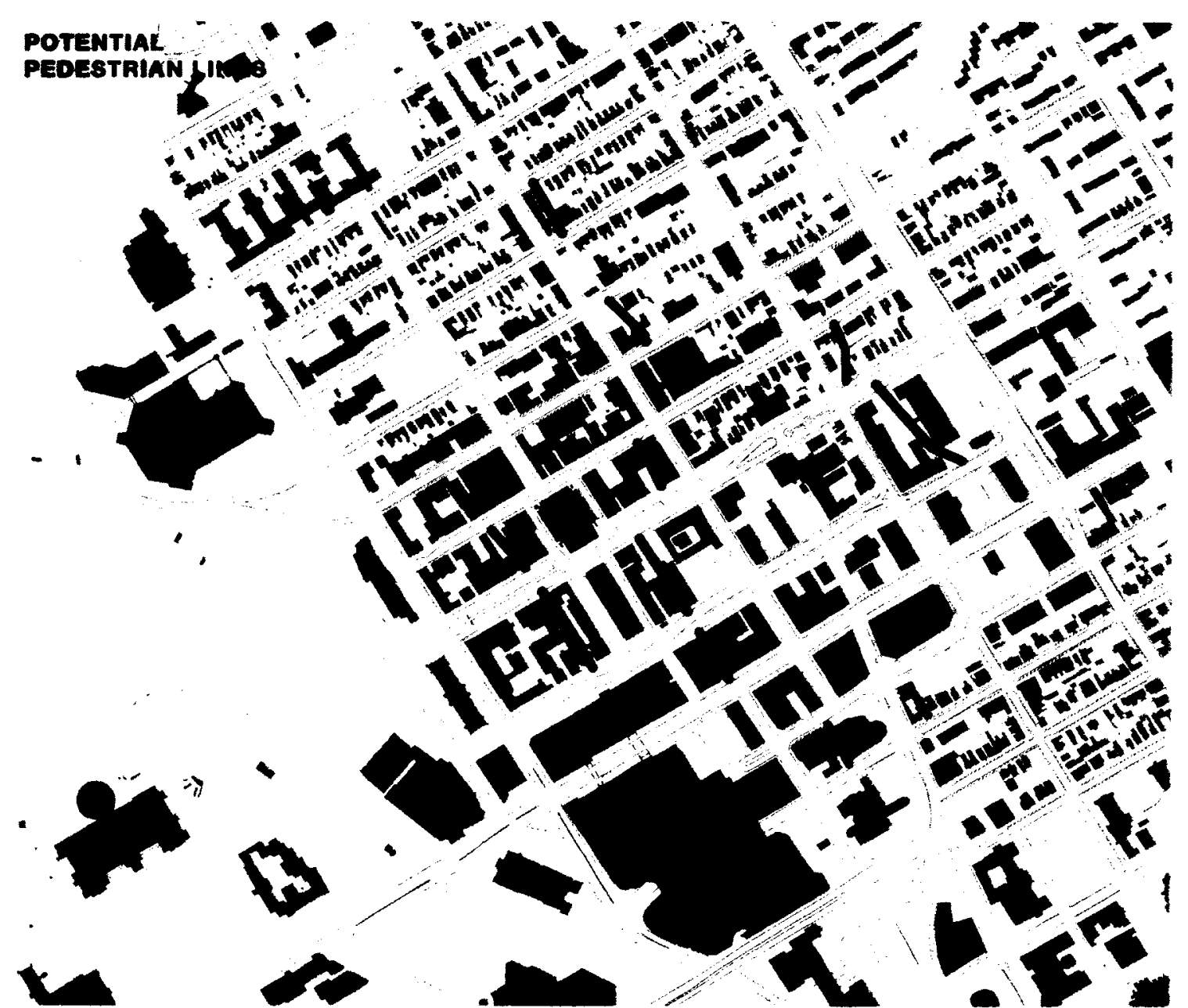

Figure A.16 - There are several locations with the potential for pedestrian paths but that are currently blocked or its prevented by the current use. 


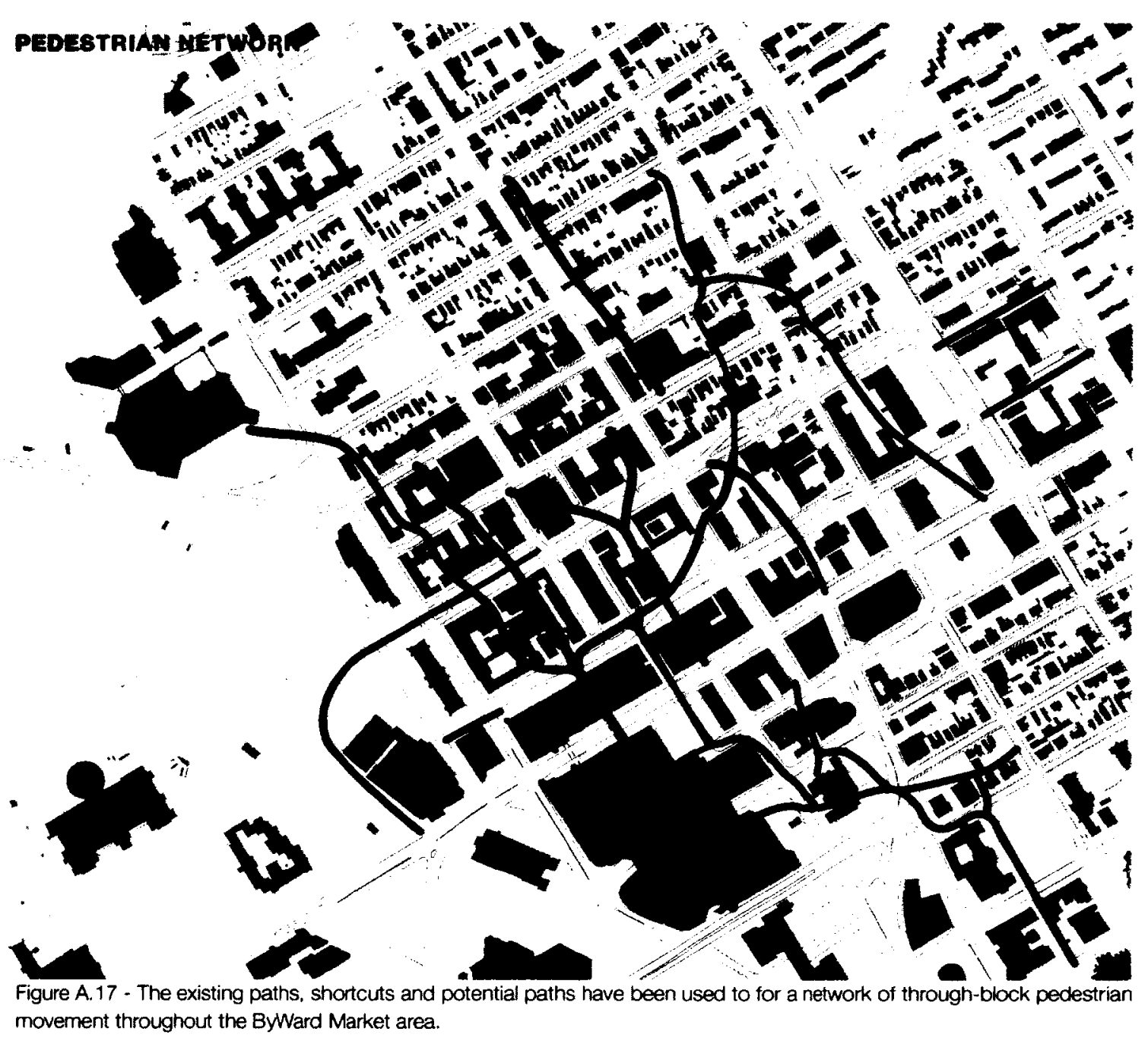




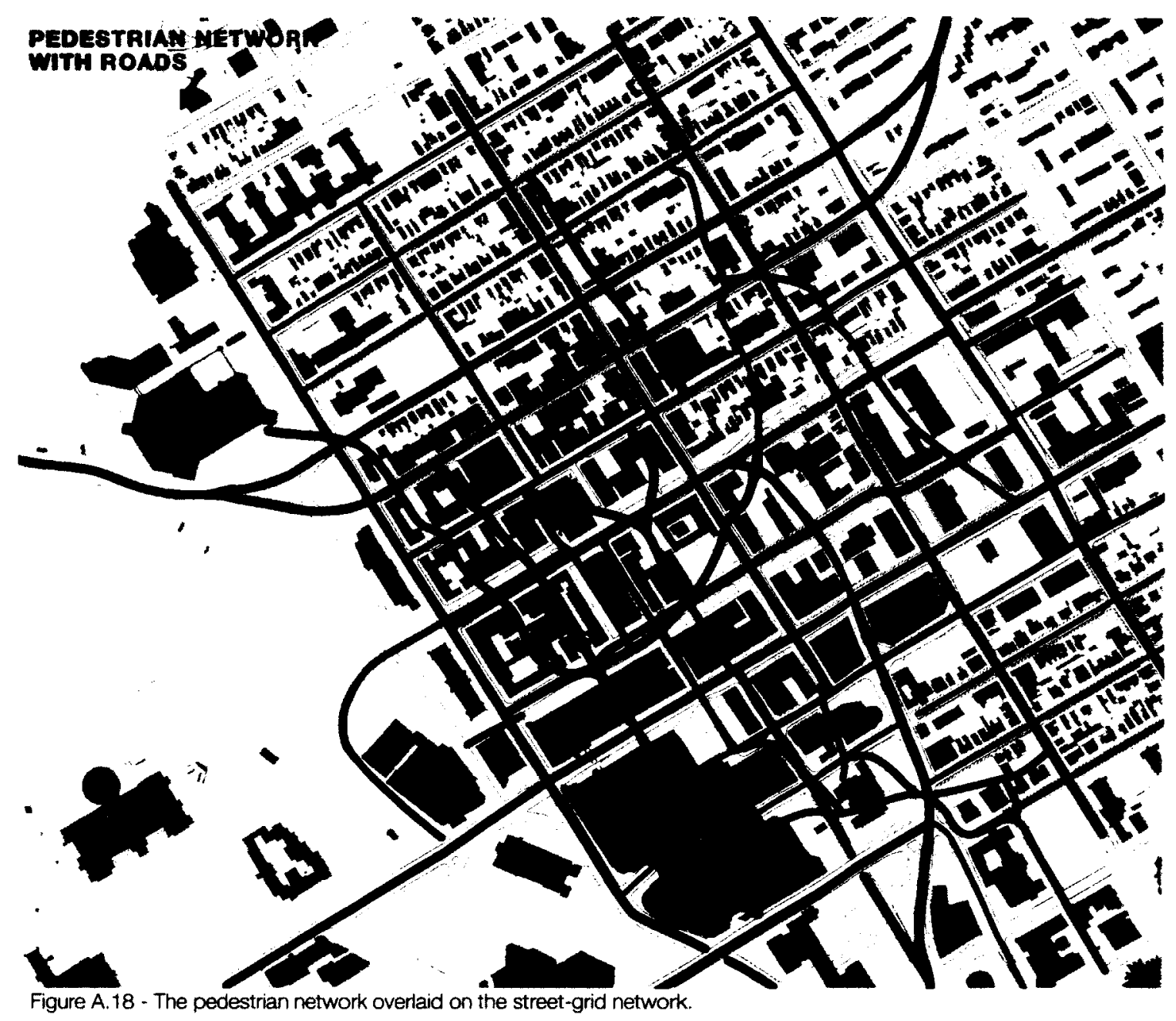




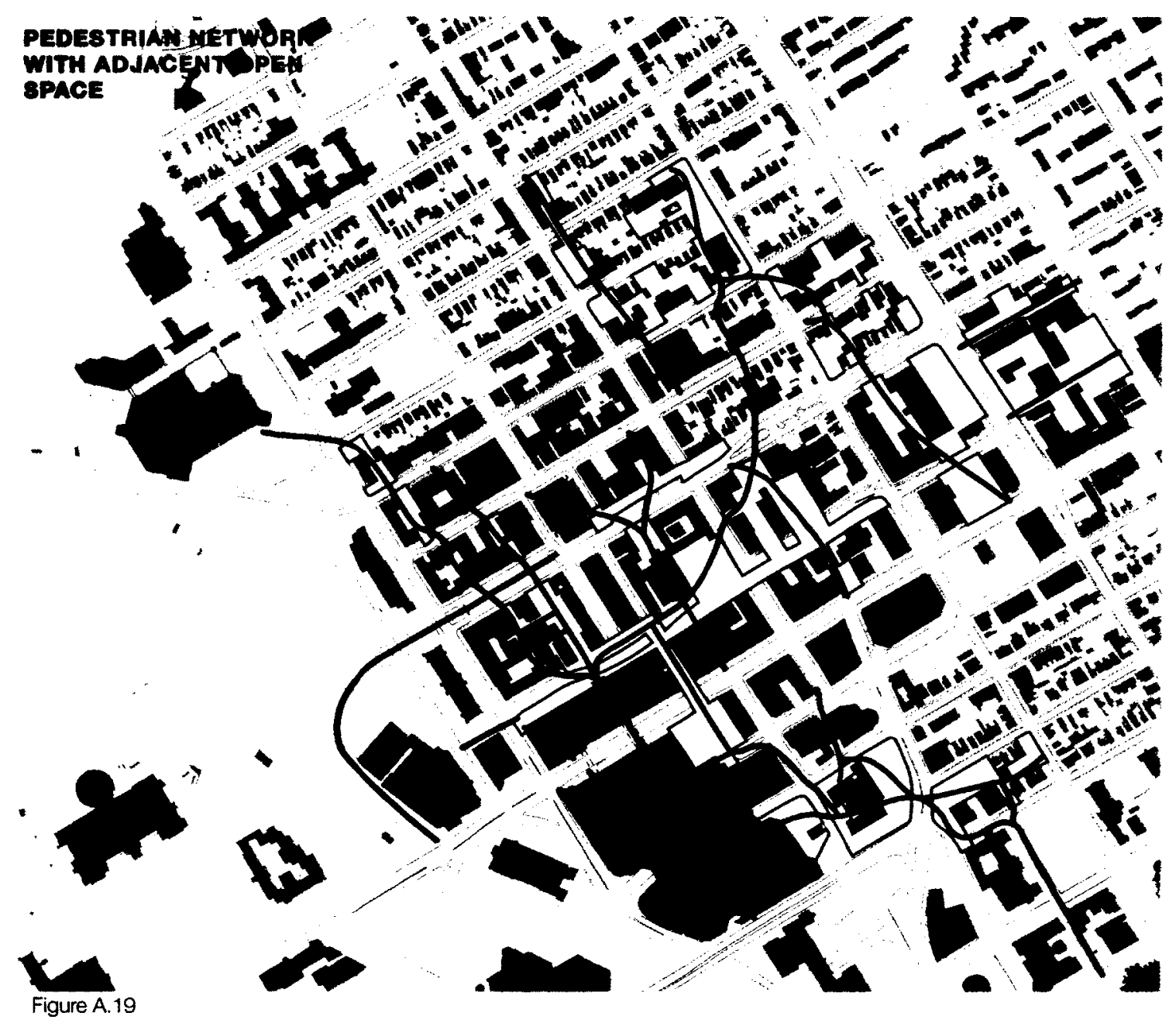




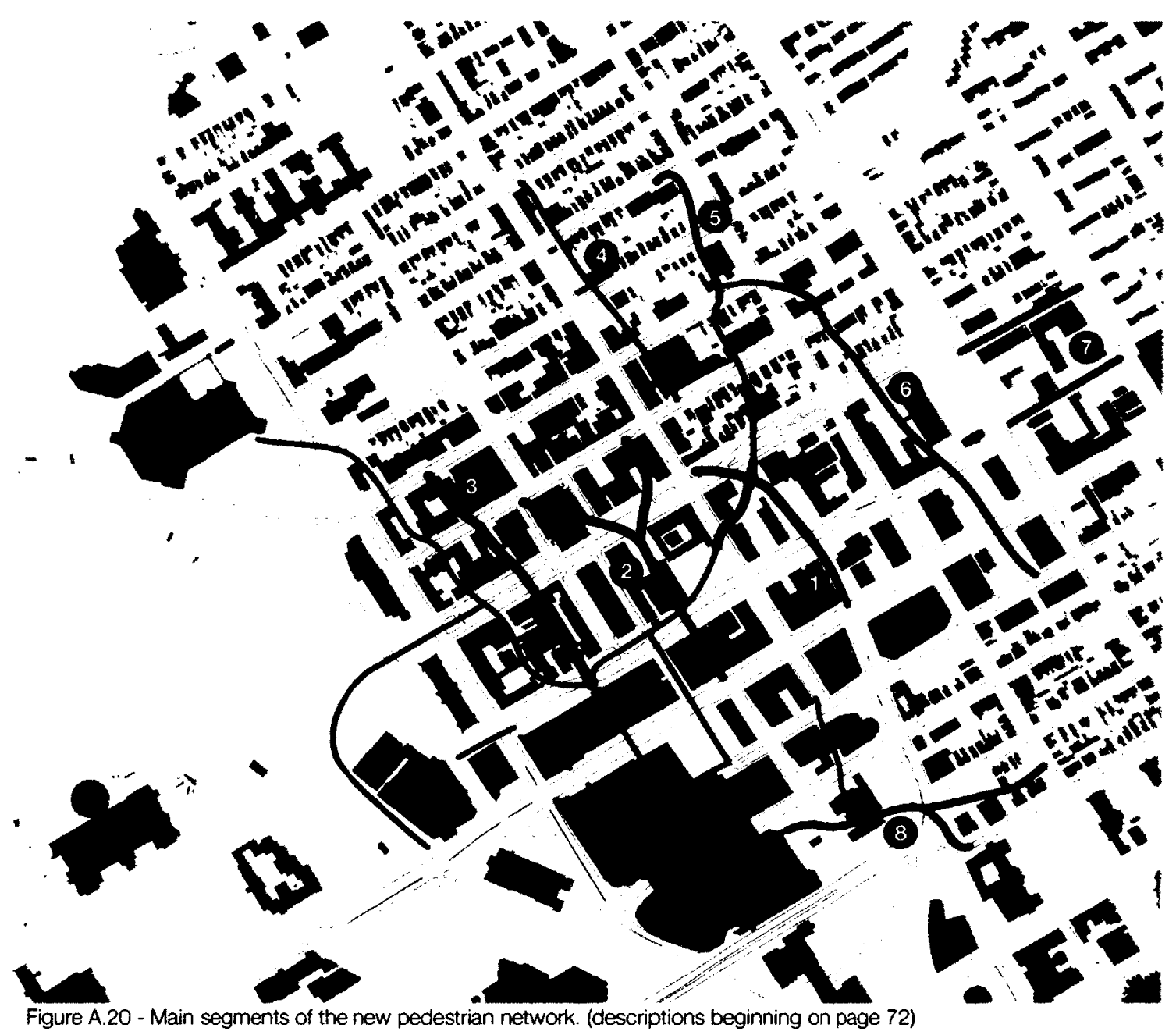




$$
\begin{aligned}
& \text { ILLUSTRATIONS } \\
& \text { Figure Image - source } \\
& \text { 1.1 La Sortie du Numero } 113 \text { Palais Royal - Arcaces, the listony ot zulining Tyno } \\
& \text { 1.2 Paris street map - Arcades the : fistory of a Zuliding Typo } \\
& \text { 1.3 Passage des Panoramas map - Arcaces the listory of } 3 \text {-3utling Tyine } \\
& 1.4 \text { Gallerie Vero-Dorat - rcaces the : ftory nt a Buiding Ty,o } \\
& 1.5 \text { Passage des panoramas - xcades the thstory ot a 3uilding Ty.oe } \\
& \text { 1.6 Burlington Arcade map - Arcados the : istory of a Bulding Typo } \\
& \text { 1.7 Burlington Arcade detail - rcades, the istony of a Building Typo } \\
& 1.8 \text { Galeria Vittorio Emanuelle II map - Arcaces the / istory of a Building Ty,pe } \\
& 1.9 \text { Wooden portico on San Vitale - Shannon I Martin } \\
& 1.10 \text { Porticoes in Bologna - Shannon Martin } \\
& 1.11 \text { Porticoes at Piazza Cavour - Shannon Vlartin } \\
& \text { 1.12 Atrium at Brookfield Place, Toronto - Shannon Mlartin } \\
& 1.13 \text { Seagram Plaza, New York - http/ umu fick com/photos/ } \\
& \text { doctorcasino/1794316999/ }
\end{aligned}
$$

1.14 One Worldwide Plaza, New York - - http: /openbuildings com/buildings/onoworldwide-plaza-profile-6705>

1.15 Stroget, Copenhagen - http//bikodonton. files wordpross.com/2010/08/strc3h8getaftor.jpg

1.16 Sparks Street Mall, Ottawa - thttp://uww flickr.com/photos/lenkins/2819340825/ sizos/zin/photostrcam/s

1.17 reNEWable Times Square intersection - http //molydiworth com/timossquaro.htmly

1.18 reNEWable Times Square - - http//molydiworth com/timessquare htmls

1.19 Green Light for Midtown - Columbus Circle - khttp:/ uww. fickr com/photos nycstrects/sots/72157622973444484/with/4174447672/>

1.20 Green Light for Midtown - Harold Square - http://umu flick com/photos/nycstroots/ sets/72157622973444484/with/4174447672/>

1.21 Andersonville Parklet by Moss Design - http//inhabitat com/andersonville-parket-is chicagos-tirst-permanent-parking-space-urban-oasis/>

1.22 Le Flâneur, Paul Gavarni, 1842 - http//en. wikipedia org/wikj/Fl\%C3\%A2noury

1.23 Union Street Aberdeen (satellite image) - -http://maps.gongle ca:, modifiod.

1.24 Union Street Aberdeen c. 1900 - - http// w wsw probertencychpaedia com/photolib/ scenery/Contemporary20 thoto\%200t\%20 Inion\%20 Street, \%20/herdeen,\%20circa\%20 $1900 \cdot h t m>$

2.1 The Ponte Vecchio, Florence - Shannon M Martir

3.1 Jane Jacobs, Movement through blocks - The _oath and Lito of Groat Amorican Cities. 
3.2 Eaton Centre (satellite image) - htth mans gnogle ca> modifien.

3.3 Commuter routes in the PATH network - htth: mmbartosik. com Commuter-TrackingHATH H.S.STOM:

3.4 Changing urban fabric in comparison to PATH system growth - htth: mmbartssik com'Commutor-Tracking-NAT 1-System:

3.5 Seating at 345 Park Avenue - Tho Social Lto of Small l man Spaces

3.6 Seagram Building plaza - Tho Sncial Lito of Small l jran Soacos

3.7 People watching in New York City - The Social Lito of Small I Irhan Spaces

3.8 Crystal Court, IDS Center - Tho Social Lito ot Small irhan Snacos.

4.1 Plaza at the Seagram Building, New York - Shannon M Martin

4.2 Rockefeller Center massing - To Scaie one hundrod urhan blans.

4.3 Rockefeller Center movement at street level-To Scalo ono huncroc urhan plans. modified by S. Martin.

4.4 Rockefeller Center movement at concourse - To Scalo onc hundred urhan plans . modified by S. Martin.

4.5 Midtown through-block passages - Nrivatoly Ownod rublic Spaco The N Now York City Experienco, modificd by S. Martin

4.6 Atrium space in the former IBM Building, New York thtp:/iwnw northjorsoy com/ arts_entertainmont/art/see_what_youvo_been_missing html:

5.1 ByWard Market Building - Shannon Martin

5.2 Clarendon Courtyard - Shannon Martin

5.3 ByWard Market building usage - Shannon Martin

5.4 Private-public ownership - Shannon Martin

5.5 Major destinations - Shannon Martin

5.6 Parking structures and lots - Shannon Martin

5.7 Existing pedestrian paths - Shannon Martin

5.8 Existing shortcuts - Shannon Martin

5.9 Potential pathways - Shannon Martin

5.10 Pedestrian network - Shannon Martin

5.11 Pedestrian network, numbered segments - Shannon Martin

5.12 Segment 1- Shannon Martin

5.13 Waller Mall - Shannon Martin

5.14 Path location, south of York St. - Shannon Martin

5.15 The A-channel Media Market Mall - Shannon IMartin

5.16 Segment 2 - Shannon Martin

5.17 View across hotel parking lot - Shannon Martin

5.18 Segment 2 - Shannon Martin

5.19 Parking structure from George Street - Shannon I Jartin

5.20 York St. looking east - maps gonglo com

5.21 Segments 4 and 5 - Shannon M Martin

5.22 Looking south from Guigues Ave. - mans gongle.com

5.23 Looking north from St. Patrick - maps google com 


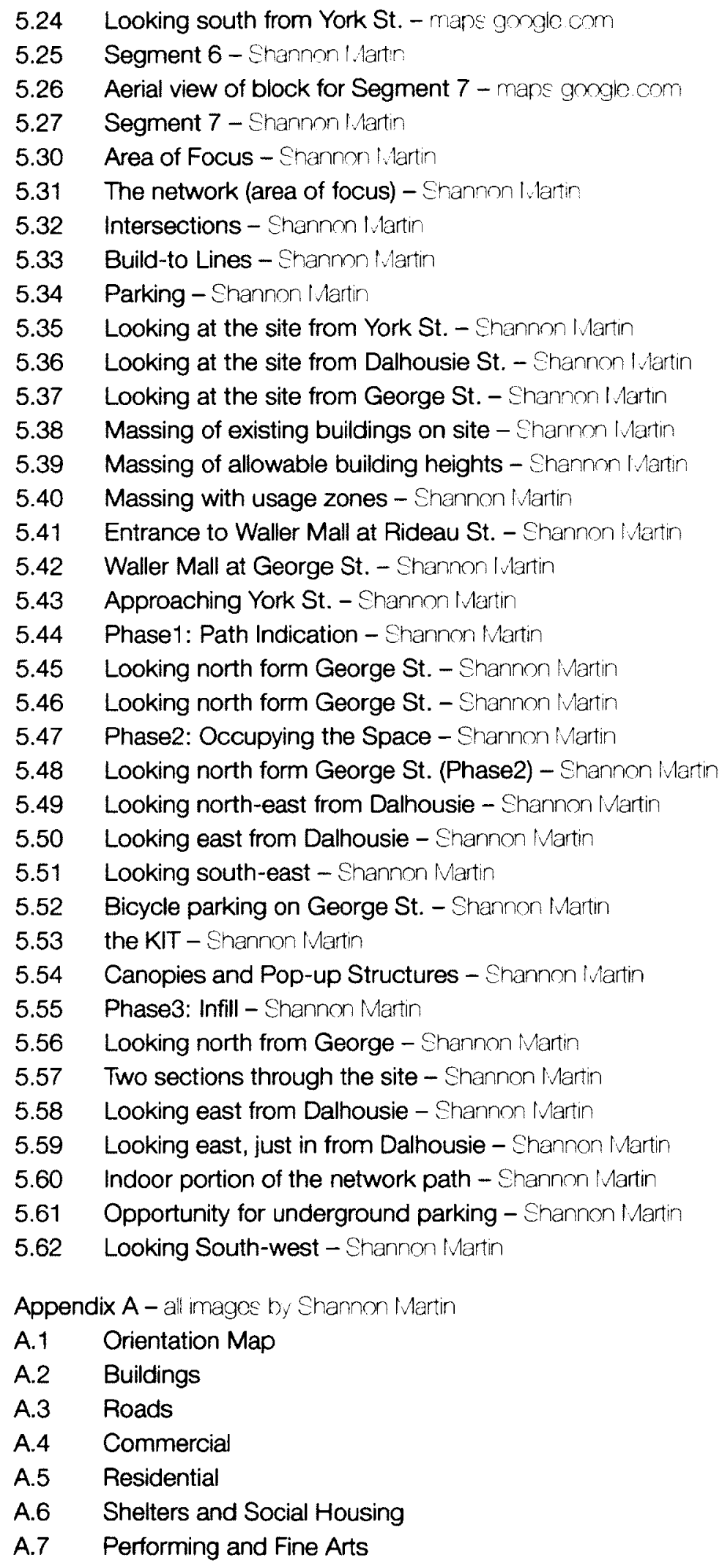


A.8 Hotels

A.9 Major Destinations

A.10 Main Routes into the Market Area

A.11 Public Parking: Indoor and Outdoor

A.12 Potential and Impending Redevelopment

A.13 Privately owned v.s. publicly owned land

A.14 Established Pedestrian Pathways

A.15 Existing Pedestrian Shortcuts

A.16 Potential Pedestrian Links

A.17 Pedestrian Network

A.18 Pedestrian Network with Roads

A.19 Pedestrian Network with Adjacent Open Space

A.20 Pedestrian Network Segments 


\section{BIBLIOGRAPHY}

Alsop, William. "Clarke Quay Redevelopment." Europaconcorsi. 13 Oct. 2006. Web. 27 Dec 2012. <http://europaconcorsi.com/projects/16777-Clarke-Quay-Redevelopment>

Benjamin, Walter. The Arcades Project. Ed. Rolf Tiedemann. Trans. Howard Eiland and Kevin McLaughlin. Cambridge, Mass: Belknap Press, 1999. Print.

ByWard Market. ByWard Market Business Improvement Area. 2010. Web. 3 June 2012. $<$ http://www.byward-market.com/>

City of Westminster. Dept. of Planning and City Development. Churchill Gardens Consenvation Area Audit. 15 Apr. 2005. Digital.

"Development Application" Service Ottawa. City of Ottawa. 31 Dec. 2012.

Web. 25 Jan. 2013. <http://app01.ottawa.ca/postingplans/appDetails.

jsf?lang=en\&appld $=$ _8E3BLV>

Geist, Johann Friedrich. Arcades, the History of a Building Type. Cambridge, Mass: MIT Press, 1983. Print.

Halprin, Lawrence. Cities. Cambridge: MIT Press, 1972. Print.

Hanssen, Beatrice, ed. Walter Benjamin and The arcades Project. London: Continuum International Publishing Group, 2006. Print.

Jacobs, Jane. The Death and Life of Great American Cities. New York: Random House, 1961. Print.

Jenkins, Eric J. To Scale: one hundred urban plans. New York: Routledge, 2008. Print.

Kayden, Jerold S., New York . Dept. of City Planning, and Municipal Art Society of New York. Privately Owned Public Space: The New York City Experience. New York: John Wiley, 2000. Print.

Kingwell, Mark, and Patrick Turmel. Rites of Way : The Politics and Poetics of Public Space. Waterloo, Ont: Wilfrid Laurier University Press, 2009. Print.

Loukaitou-Sideris, Anastasia, and Irena Ehrenfeucht. Sidewalks : Conflict and Negotiation Over Public Space. Cambridge, Mass: MIT Press, 2009. Print.

Madanipour, A. "Why are the design and development of public spaces significant for cities?" Environment and Planning B: Planning and Design, 26(1999): 879-891. Print.

New Oxford American Dictionary. 3rd edition. Oxford University Press, 2010. Digital. 
New York City Department of Transportation. The City of New York. 2012. Web. 10 Nov. 2011. <http://www.nyc.gov/html/dot/html/home/home.shtml >

"Official Plan" Ottawa. City of Ottawa. 2012. Web. 3 April 2012. < http://ottawa.ca/e/ CON015317>

Ochman, Joan, ed. Architecture Culture 1943-1968: A Documentary Anthology. New York: Rizzoli, 1993. Print.

"PATH facts" Toronto. City of Toronto. 2012. Web. 20 Feb. 2012. <http://www.toronto.ca/ path/>

Privately Owned Public Space. New York City Department of City Planning. 2012. Web. 10 Nov. 2011. <http://www.nyc.gov/html/dcp/html/priv/priv.shtml>

Rockefeller Center. Tishman Speyer. Web. 20 Oct. 2011. <http://www.rockefellercenter. $\mathrm{com} / \mathrm{>}$

Sheppard, F. H. W. (General Editor). "Shaftesbury Avenue." Survey of London: volumes 31 and 32: St James Westminster, Part 2 (1963): 68-84. British History Online. Web. 17 Mar. 2012. <http://www.british-history.ac.uk/report.aspx?compid=41455>

"The Porticoes of Bologna". World Heritage Convention. UNESCO. 1 June 2006. Web. 20 Nov 2011. <http://whc.unesco.org/en/tentativelists/5010/>

"The World's longest Pedestrian Street - Strøget". Copenhagen-Portal. Web. 3 Feb. 2012. $<\mathrm{http}: / /$ www.copenhagenet.dk/cph-map/CPH-Pedestrian.asp >

Topper, Josh. "Density Toronto: Could that condo's courtyard be a public park" Toronto Star. 23 Nov, 2012. Web. 24 Nov, 2012. <http://uww.thestar.com/ news/gta/ article/1292209--density-toronto-could-that-condo-s-courtyard-be-a-public-park>

"Underground City: La Ville Souterraine (RÉSO)" A view on cities. 2012. Web. 20 Feb. 2012. $<$ http://mww.aviewoncities.com/montreal/reso.htm>

Vergnust, Jo. "Rhythms of Walking: History and Presence in a City Street." Space and Culture 13 (2010): 376-388.

Whyte, William Hollingsworth. The Social Life of Small Urban Spaces. Washington, D.C: Conservation Foundation, 1980. Print.

Witold, Rybczynski. Makeshift Metropolis, Ideas About Cities. NY: Scribner, 2010. Print. 